321,15 Manual
UC-15

Reporting Date: December 1974 Issued: March 1975

\title{
A Guide to Gamma-Ray Assay for Nuclear Material Accountability
}

by

T. D. Reilly

J. L. Parker

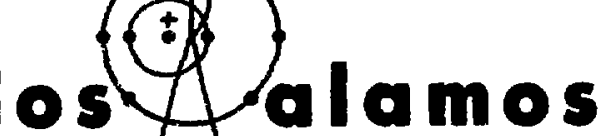

solontifto Iaboratory

of the University of California

IOS ALAMOS, NEW MEXICO 87544<smiles></smiles>

An Alfizmative Action/Equal Oppoitunity Employer 
In the interest of prompt distriburion, this manual was not edited by the Technical information staff.

Work supported by U. S. Energy Research and Development Administration, Division of Safeguards and Security.

Printed in the United States of Americe. Available from National Technical Information Service

U.S. Department of Commerce 5285 Port Royal Road Springfield, VA 2215!

Price: Printed Copy $\$ 5.45$ Microfiche $\$ 2.25$

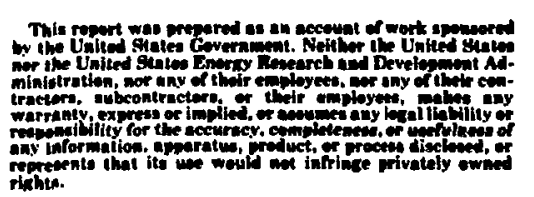

repreten. 


\section{A GUIDE TO GAMMA-RAY ASSAY FOR NUCLEAR MATERIAL ACCOUNTABII ITY}

\section{NOTICE}

This report was prepared as an account of work sponsored by the United States Government. Neither the United States nor the United Stater. Energy Research and Development Administration, nor any of their employees, nor any of their , nontactors, subcontractors, or their employees, makes any warranty, express or implied, or assumes any leat bability or responsibility for the accuracy, completeness or usefulnes of any information, apparatus, product or process disclosed, of represents that its use would not infringe privately owned rights.

by

T. D. Reiliy and J. L. Parker

\begin{abstract}
This report discusses the fundamental principles of gamma-ray assay for nuclear material accountability.
\end{abstract}

\title{
1. INTRODUCTION
}

\subsection{Scope of Report}

The subject of this report is the measurement of uranium- and plutonium-bearing materials using methods of gamma-ray spectroscopy. It is meant to be a guide for a knowledgeable person and assumes the reader has at least a basic understanding of such matters as half-life and decay rate, gamma-ray interactions with matter (attenuation), detectors and detection processes, and the use of gamena spectroscopy equipment (detectors, multichannel pulseheight analyzers and associated electronics). For background in these subfects consult the listed references. $1.1,1.2,1.3$ It cannot be too strongly emphasized that the most important Ingredient in implementing and supervising any gamma-ray assay system is a capable and well trained technical person. Gama-ray measurement.s can yield very accurate information for uranium and wlutonfum accountability but only if performed and taterpreted properly.

\subsection{General Principles of Gamme-Ray Assay}

The basis for gamma assay is that wany of the 1sotopes of uranium and plutonim emit gama rays whose energy and intensity are uniquely characterIstic of the decaying 1sotope. For example, one gram of ${ }^{235} U$ enits approximateiy $4.3 \times 10^{4}, 185.7-$
keV gamma rays per second. The general procedure for gamma-ray assay is outlined in Eq. (1.1).

$$
M=\frac{C R \cdot C F}{\mathrm{~K}} \text {, }
$$

where

$$
\begin{aligned}
M= & \text { mass of isotope of interest, } \\
C R= & \text { neasured count rate fron signature of } \\
& \text { isotope, } \\
C F= & \text { correction factor for sample attenuation, } \\
K= & \text { caltbration factor (corrected counts } \\
& \text { per gram). }
\end{aligned}
$$

The calibration factor (X) is determined by measuring a known standard. This can be represented by inverting Eq. (1.1).

$$
K=\frac{\mathrm{CR}_{s} \cdot \mathrm{CF}_{\mathrm{s}}}{\mathrm{K}_{\mathrm{s}}},
$$

where

$$
\begin{aligned}
\mathrm{M}_{s}= & \text { known was of enitting isotope in stand- } \\
& \text { ard, } \\
\mathrm{CR}_{8}= & \text { weasured count rate from standard, } \\
\mathrm{CF}_{s}= & \text { correction factor for attenuation in } \\
& \text { standard. }
\end{aligned}
$$

The standard essentially provides a measurement of the detector efficiency, the specific activity of the signature of interest, and the effecta of saple geonetry (size, shape, and saple-to-detector distance). These equations assure the standard is the 
same shape and $1 \mathrm{~s}$ measured in the same position as the unknowns. The basic idea may be stated simply, but the assaylst needs a good understanding of the many factors involved in order to apply them correctly:

(1) Gama-Ray Signatures: the energies and intensities of the releyant gama rays place fundamental restrictions on the sensitivity, precision, and accuracy of any assay.

(2) Detectors and Gamma-Ray Spectra: an understanding of detector properties and the general appearance of pulse-helght spectra la necessary to interpret the measured data.

(3) Peak Stripping and Background Subtraction: these are the basic procedures for extracting information frow the measured spectrum.

(4) Detector Efficiency and the Inverse Square Law

(5) Gama-Ray Attenuation and the Attenuation Correction Factor: the key to accurate gana assay.

(6) System Count Rate Limitations

(7) Sample Scan Procedures

(8) Types of Gamma-Assay Systerns

These subjects are all treated in some detail in this report.

\section{REFERENCES}

1.1 R. H. Augustson and T. D. Reilly, "Fundasentals of Pasaive Nondestructive Assay of Fissionable Material," Los Alamos Scientific Laboratory report LA-5651-M, 1974 .
1.2 F. Adams and R. Dams, Applied Gamma-Ray Spec trumetry, (Pergamon Press, Inc., NY, 1970). Th1s book contains a wealth of information on gama-ray spectrometry. The first three chapters cover gammaray emission and interaction, and the proper ties and characteristics of scintillation and semi conductor detectors. Chapter 5 deals with assoclated detector instrumentation. The appendices Include many useful tables, graphs, and spectra [e.g., x-ray absorption edges and emission energie (table); NaI gamma-ray spectra (over 250 actual pu1se-height spectra); Ge(Li) spectra (over 200); intringlc efficiencies of NaI detectors (tables); and tables of gamma-ray energies]. This is a useful reference for the gama assayist.

1.3 R. D. Evans, The Atomic Nucleus, (McGraw-Hil Book Company, Inc., 1955). Though old, this is on of the best texts on nuclear physics. Reconaended chapters include: Chapter 15--Radiaactive Decay, Chapters 23 through 25--Interaction of Electromagnetic Radiation with Matter, Chapter 26--Statistical Fluctuations in Nuclear Processes, and Chapter 28--Applications of Poisson Statistics to Sone Instrunents Used in Nuclear Physics. 


\section{GAMMA-RAY SIGNATURES, SPECTRA, AND DETECTORS}

\subsection{Signatures}

The major gamma-ray signatures for uranium and plutonium are 1isted in Table 2.1. References 2.12.4 at the end of this chapter contain more complete tabulations of gamma-ray data. Both major fissile isotopes have moderately intense, * interference-free signatures: ${ }^{235} \mathrm{U}-185.7 \mathrm{keV}$; $239 \mathrm{Pu} \sim 413.7 \mathrm{keV}$. Most of this report will deal with the measurement of uranium or plutonium using these gamma rays. Appendix 1 contains a brief discussion of the measurement of other plutonium isotopes. Figures 2.1 and 2.2 show complete $G(t, i)$ spectra of uranium and plutonium, respectively: Figure 2.3 is an expanded view of the $414-\mathrm{keV}$ region of plutonium.

\subsection{Detectors}

The major detectors for nuclear materials assay are $\mathrm{NaI}(\mathrm{T} 1)$ scintillation detectors and $\mathrm{Ge}(\mathrm{Li})$ semiconductor detectors. NaI has the advantage of

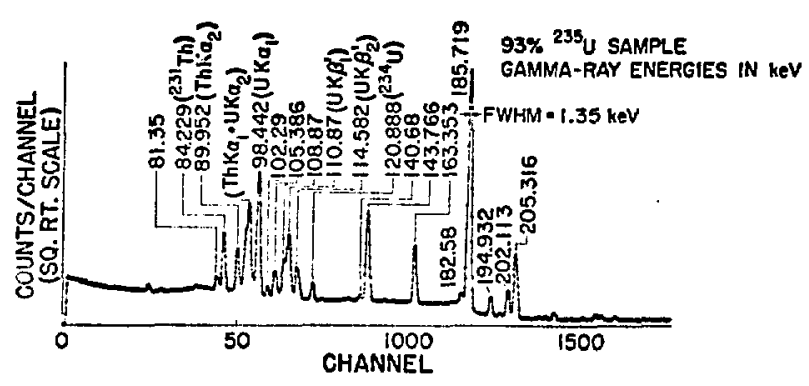

Fig. 2.1. Characteristic gamma rays of $235 \mathrm{~V}$. This spectrum was measured with a high resolution Ge(Li) cletector.

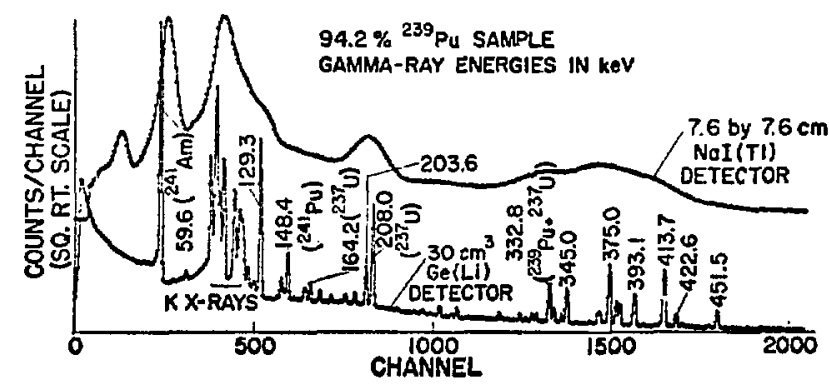

Fig. 2.2. Comparison of plutonium gamma-ray sisctra from $30-\mathrm{cm}^{3} \mathrm{Ge}(L i)$ detector and $7.6-$ by 7.6-cm NaI detector. Note the square root scale.

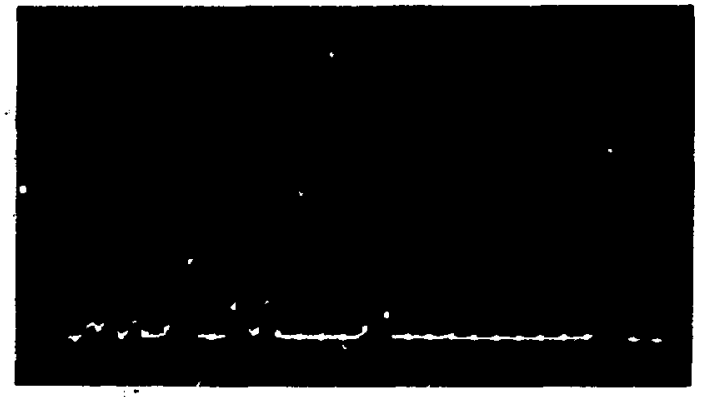

'Fig. 2.3. Ge(Li) spectrum showing 414-keV region of plutonium spectrun in detail. The three highest peaks are 375.0. 393.0. and $413.7 \mathrm{keV}$, all from $239_{6}^{\prime} \mathrm{u}$.

room temperature operation, economy and higher efficiency. Unfortunately, its resolution is clear1y marginal for many assay situations. The 186-:aV gamma from ${ }^{235} \mathrm{U}$ is usually resolved by NaJ (Fig. 2.4) if there are no other significant gamma emitters in the sample. A good $\mathrm{NaI}$ will have a resolution of about 12\% (22 keV) FWHM at $186 \mathrm{keV}$. Any intense gamma ray within about $70 \mathrm{keV}$ ( 3 FWHM) of $186 \mathrm{keV}$ can be expected to interfer directly with the ${ }^{235_{U}}$ photopeak. High'r energy gamma rav's will interfere by producing a large Compton continuum under the photopeak. If high energy gammus exist with intensity much over $10 \mathrm{HCi}$ per gram of ${ }^{235} \mathrm{U}$, serious signal-to-backgro:nd problems can be expected in the $186-\mathrm{keV}$ region. For low-enriched uranium $\left(<1 \%{ }^{235} \mathrm{U}\right)$ the daughter product activity of ${ }^{238} \mathrm{v}$ (765 and 1001 keV) interferes quite severely with the NaI measurement of the $186-\mathrm{keV}$ gamma ray. The NaI detector is not recommended for accurate measurenents of low enriched uranium.

Due to its low resolution the NaI photopeak includes a significant number of scattered gamma rays caused by small angle (hence, small energy loss) Compton scatters within the sample. This can be described by a "buildup factor" (see Ref. 1.3, p. 732) which is difficult tu compute and can greatly complicate the interpretation and measurement of sample attenuation. The magnitude of this effect can vary considerably depending on the sample density and composition. In contrast, the $\mathrm{Ge}(\mathrm{L} i)$ detector suffers much less from this effect. The Ge(Li) photopeak can be assumed to contain only 


\section{MASOR GAMMA-RAY SIGNATURES FOR THE FISSIONABLE ISOTOPES}

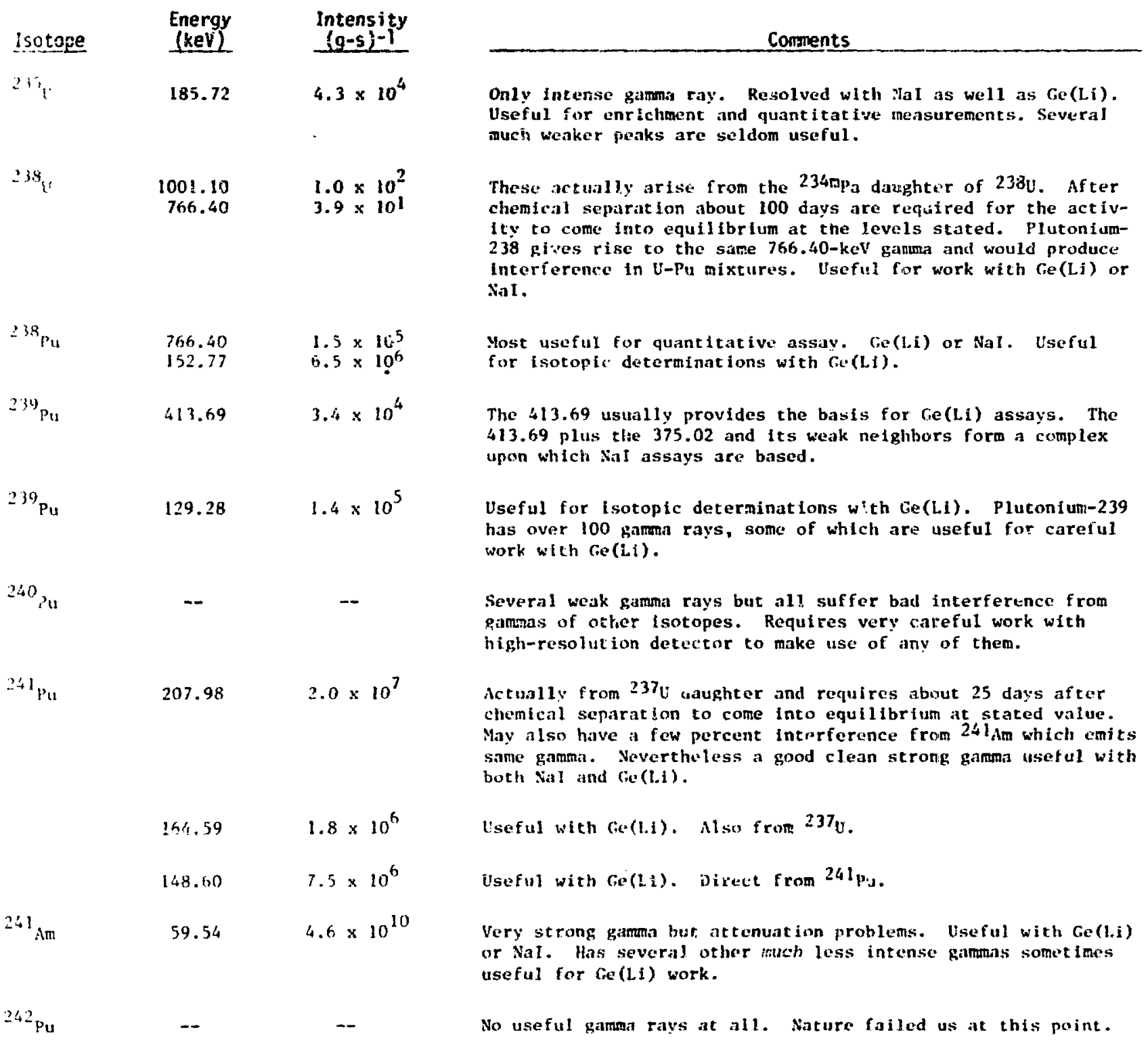



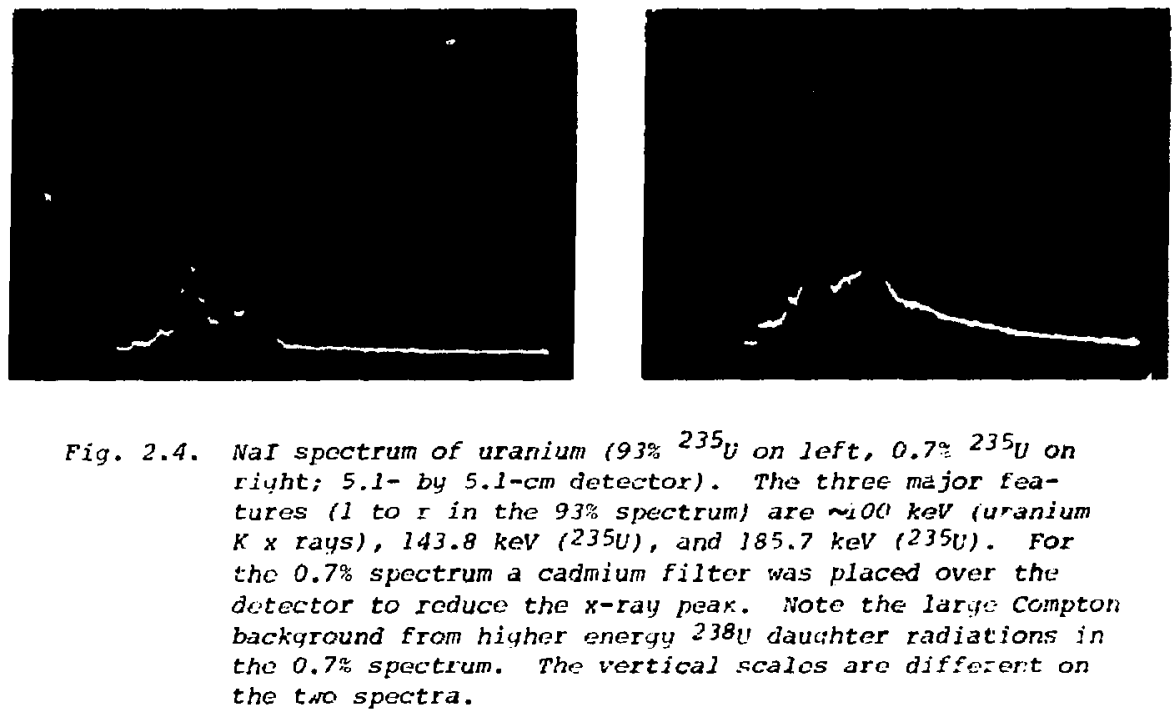

Some guidelines can be given for choosing the proper size NaI detector. For Tost measurements of the $186-\mathrm{keV}$ gamma ray of ${ }^{235} \mathrm{U}$, a $2.5-$ r.t-thick detector is recommended. This wil, atsorb ovcr $90 \%$ of the gamma rays of intercst. rhicker detectors wi.11 just add background. With a signal-tobackground mach less than one, it can be shown that the opt imum detertor thickness is about $1.2 \mathrm{~cm}$. The use of xal for such counting steuations is not recommended. For normal, lower background situatons the $2.5-\mathrm{cm}$ cryitil is a more practical choice. Ae 414 keV detectors up 6013 con thick may bs usud. but $y$ om is misulls adeçuate (this till absorb netarly 707 of the pamma rays af interest).
The Ge(Li) detector is preferred for nuclear material assay because of its superior resolucion (e.R., at $414 \mathrm{keV}$ a good Ge(1.i) will have a resolution of about $1.4 \mathrm{kel}$ FWH as compared to a good NaI with $40 \mathrm{keV}$ FinM? . The obvious advantage is the abilicy to separate the peaks of interest from other nelghboring gamma-ray [*aks. For example. the broad peak in the kal spectrum of fig. 2.5 is resulved by fie(Li) into many individual componeuts. The 4l4-kel hamma ray is well resolved by even a medium fuality re(i.i). A Jess obvious advantage is that the full energy park in a Ge(l.i) spectrum is more nearly composed oi unscatlered ganma zays (thero is litcle "bulldup" under the peak). Due t.J
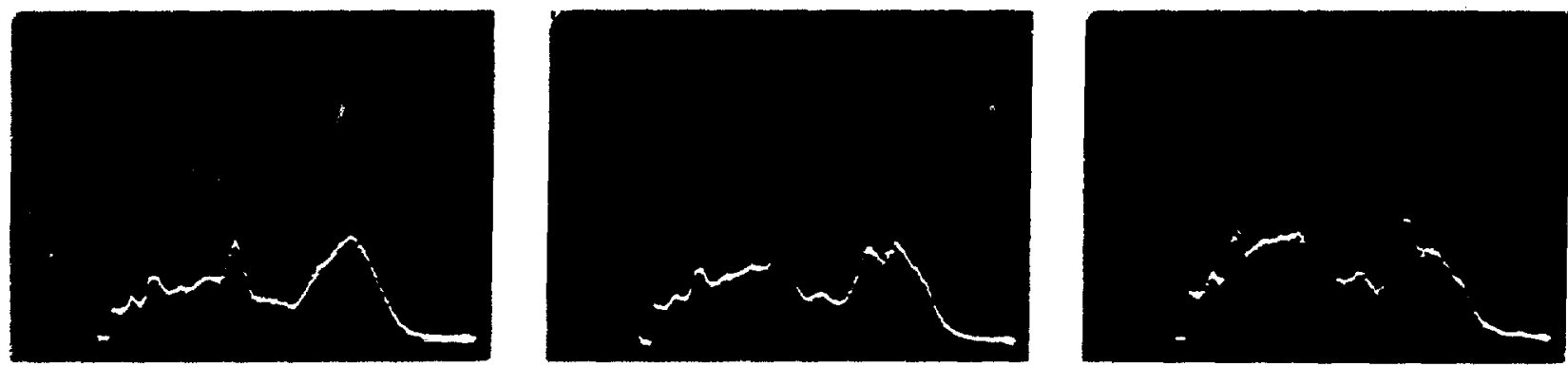

Fig. 2.5. NaI spectrum of plutonium (5.1-bu 5.1-cr, detector). Three different plutonium isotopics are shown: from 1 to $r, 239 p u, 945,87^{\circ}, 75^{\circ}$ : $24]$ iv, $0.3 \%, 2.5 \%, 5 \%$. The two major features of the spectrum are the 208-koV podi from 24lyu $(237 U)$ and the broad peak i33-414 kel from $239 \mathrm{pu}$ and $\mathrm{dI} \mathrm{Pu}$. The low-onergy side of this peat is rup mustio to $24 \mathrm{lu}$. A lcad and cadmium filtex is placed over the detector to reciuce the $241_{A m}$ and $x$-ray activity. Those picturos illustrate the

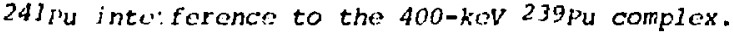


its high resolution even small angle Compton scitterings result in a secondary gamma which is outside the full energy peak. This is very important for bulk miterial assay since it simplifies the interpretation and evaluation of sample attenuation, tie kev factor in gamma-ray assay. In simplust termis the (ev(it) detector provides a nore unambiguous signal, and its use is preferred for nuclear material assay.

for most assay of hulk samples fe.f.. scrap and wates) a cie(ti) detector with the following performanec specif inat fons should be adequate:

$$
\text { FWHS at } 13 \mathrm{~g} \text { keV }=2.0-2.2 \mathrm{kel} \text {. }
$$$$
\text { Fons at } 122 \mathrm{kev}=1 . \mathrm{l}-1.2 \mathrm{ki} \cdot
$$

fiff at i il3? kel - ilo:

The r.solut ion at 122 ked $f^{57} \mathrm{Co}$ : should be specificd when ardering the detector since most panma ravs of inferest for nuclear material assay are in the ramge 100-500 kel, and this is at more rolevant speatication. harger detectors are avallable (off $25 \%$ ): however, the gain in affictency at $100-400 \mathrm{kel}$ is much smaller than rhat at $1332 \mathrm{kc} . \mathrm{y}$. and the added cost is ustally not fust iffed. The frontal area of zhese. large detectors is often wo preater than a well rinesen 10 detector. and the

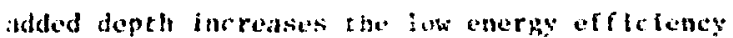
onle slightiv. This ruflects the same conslderafion discussed above for Sil: a detertor need be no more than 2-3 moan iree paths thick to the highe'st entergy fatumia ris of interest. The low enorgy resolution can be improved constederably through tise thes of a coolud PFT in the tirse stage of the decertor preamp (e.p.e large decectors are avaliable with a resolution in the range $500-700$ at at 122 kev). This would usually be warranted only for very high resolution spectroscopy; 4. .. plutonium isotopic measurement. It is not recommensled for assays based on the 186-keV o: 414-keV gamas alone. The detector mounting (cryostat and dewar) must be compatibls with the required shielding and collimation and should be considered carefully then ordering a detector. More information on specifying Ge(Li) spectroscopy systems is provided in Regulatory Guide 5.9. 2.5 Large high purity germanium detectors are not yet available commercially and are not discussed here. Their use and required performance specifications would not differ significantly from those discussed above for Ge(Li).

\section{REFERENCES}

2.1 C. M. Lederer, J. M. Hollander, L. Perlman. Table of Isotopes: Gth ed., (.Joln Wlley and 5:ms, Inc., 1967). This is a tabulation of gamma rays from all radloactlve isotopes. It Inciudes nuclear energy level diagrams, $x$-ray informacton. and much more. It is a very useful reference for gammaray moisuremines.

2.2 J. E. Clint, "Gamma hays Emited by the Fissionable duclides and Associated Isotopes." Idaho Suclear Corporation report IX-1648 (Jamury. 1971). and supplement. "Gama kats Eated by the flistonable Nuclides and Assoctiat ad tsotopes." Aerojet Nucloar Conpiny repor: Asch-1069 (fuly. 1972). Ihfs ISts all gamat rays from the flisionable isotognes and reliateri isotopess. It fncludes typical tie(t.i) spectra of the materials of intercit. Thate ase sono sianlficant discrepanclio between this and fer. 2.3 regatding 1 fac futerstefes.

2.3 9. Ciunninix and H. J. Murros. "Goitgat-Ray Enke-

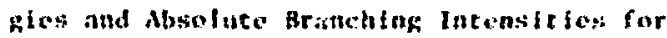

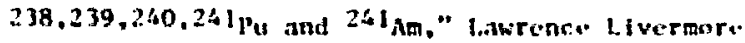
Laboratory reporc tert-51087 (JuIy, 1971). This lists gantil rays from the plutonfism isotoges and shows typtcal ce(t.i) spectra. It probably rontalis the bese avallable daca on plutoniua gamma-ray intensitles.

\subsection{R. Gunnink and J. F. Tinney, "Mnalys is of} Fuel Rods by liamo kay spectongrop:" lawrence Livermore Laboratory peport UCRL-51086 (August, 1971). Appendf $x \mathrm{C}$ contalins a listing of gamma rays rom the fissionable isotopes (simllar to Ref. 2.2).

\subsection{USAEC Regulatory Guide 5.9, Specification of} Ge(Li) Spectroscopy Systems for Material Protection Measurement:--Part I: Data Acquisition. 


\section{PEAK STRIPPING AND BACKGROUND SUBTRACTION}

\subsection{Introduction}

The information discussfd. In this section pertains to the basic procedures for extracting information from the measured gamma-ray spectrum. The basic data for the assay usually are the full energy peak areals of one or more gamma rays in the speretrum (e.g., from each isotope of interest, from an external transmission source used to measure sample attenuation, and from a reference source used to measure system livetime and pulse pileup). The Compton continuum which underlies these photopoaks must be subtractud to get the true source activitv. In situations where this background is much less chan the peak activity, only small errors are made by omfteing the background subtraction, but in general this procedure is not recommended. For most nuclear miaterial assay the peaks of interest are well resolved, and the background subtraction can he done by simple straight line subtraction prosedures without the use of computer peak flcting tochiques. This is certainly the case for assays based on the 186-keV and 414-keV peisks. Thu measurement of other plutonium isotopes, particularly $240 \mathrm{pu}$, is often difflcuit even with the best peak ftting techniques, due to the severe interfermens frivolved. Such techniques will not he discussed here.

\section{3.? Straightine Subtraction Techniques for Well Resolved Single Peaks}

A simple, yet fairly general, method of determining photopeak areas is described below The mothod is applicable tn Phi dita or to data obtained from scalers connected to single-channel inalyzers. Figure 3.1 shows a portion of a pulselictig spectrum containing a single photopeak. The area under the peak, $P$, may be obtained by stimming the contents of the channels as shown in the figure. The background under the peak can be approximated by a straight line, shown dashed in the figure. Groups of channels lyiug on each side of the peak may be averaged to estimate the background. If $n_{1}$ channels are used on the low side of the peak, $n_{2}$ channels are used on the high side, and $n$ channels used in the peak ( $n$ should be equal to about 3 FW(M), then the background is given by

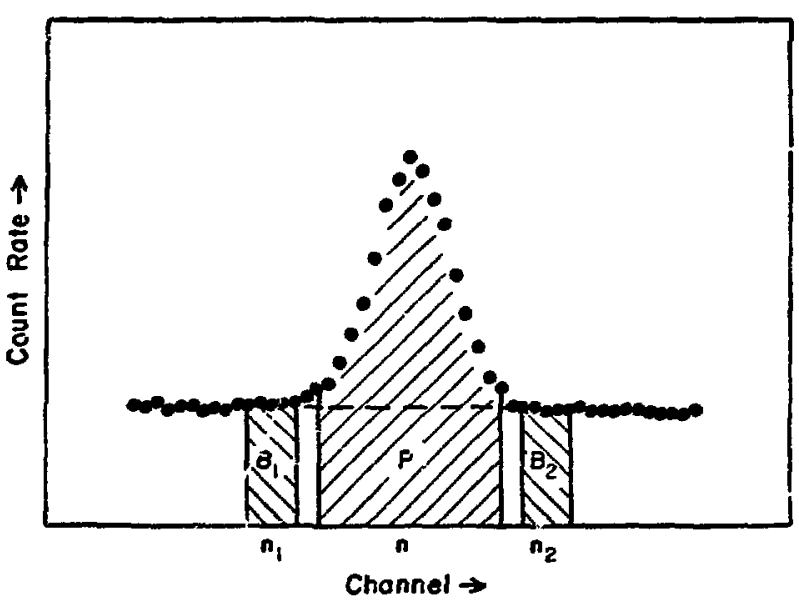

Fig. 3.1. Pulse-height spectrum of single photopeat iliustrating general proctiure for determininy photopeak area. The area of interest is above the dashed line which is determined from $B_{1}$ aric $B_{2}$.

$$
B=(n / 2) \cdot\left(B_{1} / n_{1}+B_{2}^{\prime \prime n_{2}}\right) .
$$

The peak area corrected for background is given by

$$
\begin{aligned}
& A=p-(n / 2) \cdot\left(B_{1} / n_{1}+B_{2} / n_{2}\right), \quad(3.2 a) \\
& A=p-\left(n / 2 n_{1}\right) \cdot\left(B_{1}+B_{2}\right), \text { if } i_{1}=n_{2},(2.2 b) \\
& A=P-\left(B_{1}+B_{2}\right), \text { if } n_{1}=n_{2}=n / 2 \quad \text { (3.2c) }
\end{aligned}
$$

If the slope of the straightline background is essentially constant for a particular set of tieasurements, then channels on one side of the peak only can be used for the background determination. The peak area would then be given by

$$
A=P-\left(n / n_{1}\right) \cdot(k \cdot B),
$$

where $k$ is a factor that corrects for the background slope (k = 1 for a "level" background) deternined from an appropriate calibration. This situation is 11 lustrated in Fig. 3.2. This "two-window" procedure is commonly used with NaI-SCA instrumentation. For this, one SCA window is set over the peak and the other set slighly higher in energy. Scaiers attached to the $S C A$ 's measure $P$ and $B$, respectively (if only one SCA-scaler combination is available, two separate counts can be made at different threshold settings). The net peak area then becomes

$$
\Lambda=P-(k \cdot B) \text {, }
$$

where $k$ is determined during the system calibration. 


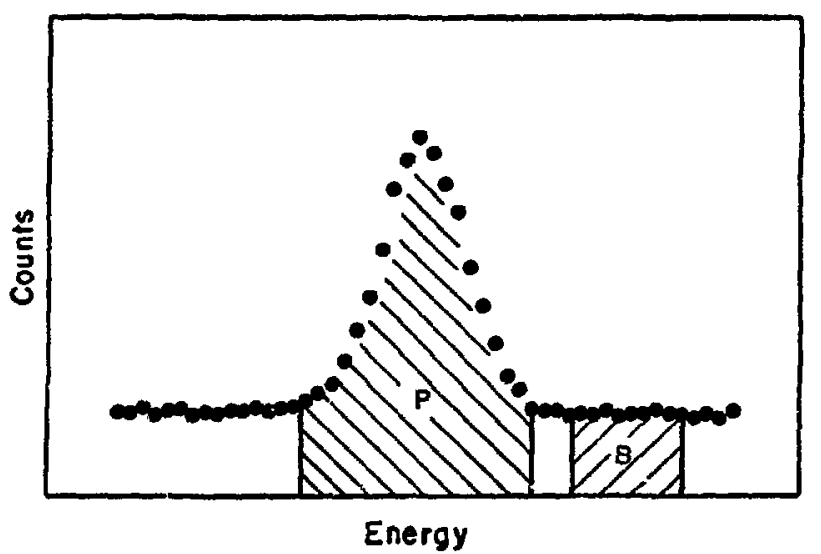

Fig. 3.2. Pulse-height spectrum of sinule photopeak illustrating two-window method for deternininy photopeik area. This is the most common procedure for NaI-SCA measurements.

It $c$ an be determined in several ways. The simplest is to choose $k$ such that $A=0$ when no sample is in front of the decector. A better procedure is to use several standards of different uranium or pluconium masses and $i$ it the measured responses to Eq. (3.3a). If the peak and background windows are of equal width, $k$ shivuld be about $1 .:$ for ${ }^{235} u$ (186 keV) and 1.0 for ${ }^{239} \mathrm{Pu}(414 \mathrm{keV})$.

The statistical uncertainty of the measured areas should also be determined since this gives an estimate of the precision of the peak measurement. The expressions below give an estimate of the standard deviation in the area determined by Eqs. $3.2 a-c$.

$$
\begin{aligned}
& \sigma(A)=\sqrt{P+(n / 2)^{2} \cdot\left[B_{1} /\left(n_{1}\right)^{2}+B_{2} /\left(n_{2}\right)^{2}\right]} \\
& J(A)=\sqrt{P+\left(n / 2 n_{1}\right)^{2}\left(B_{1}+B_{2}\right)}, \text { if } n_{1}=n_{2}, \\
& J(A)=\sqrt{P+B_{1}+B_{2}}, \text { if } n_{1}=n_{2}=n / 2
\end{aligned}
$$

These uncertainties should then be propagated through the full assay expression (including attenuation corrections, 1 ivetime and pileup corrections, etc.) to determine the total precision of the assay. An example of such a computation for a transmissioncorrected scan is given in Ref. 3.1.

Two other background subtraction procedures deserve mention. The first is similar to the procedure deseribed above but actually computes the equation of the background $l$ ine and makes a channe1by-channel subtraction of the peak region. Refer to Fig. 3.1; let $\left(\bar{x}_{1}, \bar{x}_{2}\right)$ be the average chammel number in the (lower, upper) backgroms region. Let $x_{1}$ to $x_{n}$ refer to the channel numbers in the peak region. The peak area is computed fran the following expressions:

$$
\Lambda=\mathrm{P}-\mathrm{B},
$$

where

$$
\begin{aligned}
& B=\sum_{i=1}^{h}\left(m x_{i}+b\right), \\
& m=\left(\frac{B_{2}}{n_{2}}-\frac{B_{1}}{n_{1}}\right) /\left(\overline{x_{2}}-\overline{x_{1}}\right) . \\
& b=\frac{B_{2}}{n_{2}}-\overline{\mathrm{x}_{2}} .
\end{aligned}
$$

For most single peaks this will give nearly tike same area as is given by the first procedure. Thers: are situations where several peaks are nearly sosolved but there is not room to assign a barkground region next to the prak of interest. In such cases the background regions may be assigned on either side of the multiplet and the peat region assigned to the peak of interest. This latter procedurs. should be used te analyze such a situation (actually computer peak fitting techniques will wsually be required to accurately analyze multiplets). An example of where this can be used is in the 160-keV rogion of the plutonium spectrum. With a good decector two peaks are niarly resolved, one at about $160.2 \mathrm{kel}$ ( from ${ }^{241} \mathrm{Pu}$ and ${ }^{240} \mathrm{pu}_{\mathrm{u}}$ ) and one at 161.5 keV (i rom ${ }^{239} \mathrm{Pu}$ with a small amerfeium contribut ton).

The other wiethod, developed by Gunnink, 3.2 uses a channel-by-channel background subtraction; however, the shape of the background is not linear. Consider the peak showt in Fig. 3.3. The background on the low energy side of a peak is usually higher than that on the high energy side fin most cases, the difference is not as large as illustrated here). This is due to small angle scaters in the sample and mu1tiple Compton scatters in the detector. In the above procedures it is assumed that the variation between the two points is a straight line. The shape indicated in this figure is more physically accurate. The following procedure subtracts a background of this general shape. The same three regions are selected as in the other procsiures. The total counts in these regions are $P, E_{1}$ and $B_{2}$ (as before), and the number of channels are $n_{,} n_{1}$, and $n_{2}$. 
The contents of the individual channels of the peak region are labeled $P_{1}$ through $P_{n}$. The area under the peak is given by the following expressions:

$$
A=P-B,
$$

where

$$
\begin{aligned}
& P=\sum_{i=1}^{n} P_{i}, \\
& B=\sum_{i=1}^{n}\left(l_{i}^{n}-1 \frac{i}{p}\right) \text {. } \\
& r_{i}=\sum_{i=1}^{i} i_{i} \\
& د=\frac{\vec{n}_{1}}{n_{1}}-\frac{n_{2}}{n_{2}} \text {. }
\end{aligned}
$$

This provedure will alsu work far nearle resolved mule inlets as disiussid shove. For a single. well

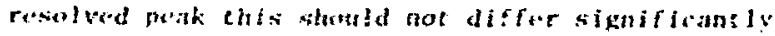
from the area dectrmined ot the first procedure. [n mertot. the first procedure will be adequate for well resolved singlo pouks. One of the other

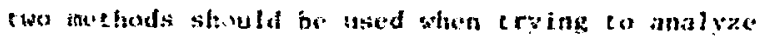

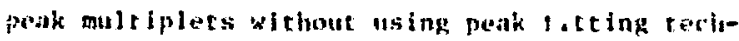
niquss.

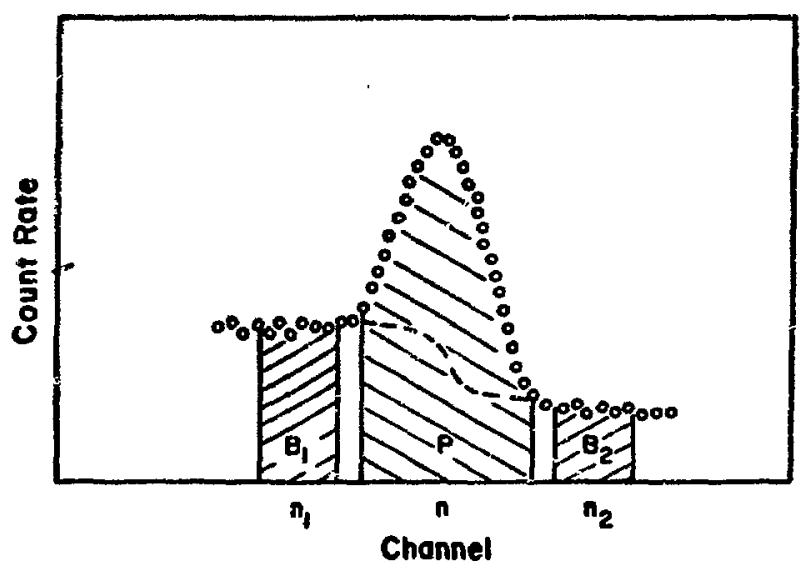

Fix. 3.3. Pulse-height spectrum of single photopeak illustrating Gunnink's procedure for determining photopeak area. The area of interest is above the dashed line. This is a more physical shape for the underlying compton backgruund than is used in Fig. 3.1.

\subsection{Multiple Peaks}

In sume instances, as explained above, nearly resolved multiples can be analyzed with simple. channel summation algorithms. Nith alequate sta:nards it is possible to get plutonium isotopic information from some peak multiplets using the procedures deseribed in the previous section and nearby we 11 resolved lines to evaluate the inresolved interferences (sue appendix $A$ ). For most sitlations, kowever, the accurate analysis of complicated peak multiplets requires the use of computer fitting tecimiques. Reforenies $3.3-3.5$ give examples of such techniques, The peak shaple algorithms uned in limusul have had the most saccess in cxt ract ing plutonitur isotopic information from the complex rlutonium speretrurio. 3.2 In closing, it should agatin ine noted that these fitting procedures are mor wavally reammended or required for routime 235 , 238,239 Pu, or 241 Pu assay.

\section{REFERENCES}

3.1 E. H. Martin, D. F. Jones, "Computer-oriented Gatman Scan Sistem," los alamos Scientific Laberacor: report $1 A-5379-4.4$ (1973).

\subsection{R. Gunnink, 1. B. Niday, P. D. Siemens, "A} Syotem for Analys is by Gama-Ray Spectrometrv: Part I: Description of the- Techniques for Analysis of Solut iors." Lawrence livermore Laboratory report LCR1-51577 PR. 1 (1974).

3.3 R. Gannink, J. B. Niday, "Computerized Quantitative Analysis by Gama-Ray Spectromecry (The GAMANAL Program)." Lawrence Livermore Laboratory report UCRI.-5106i, Vol. I-III (1971).

3.4 R. G. Helmer, M. H. Putnam. "Gauss V, A Computer Program for the Analysis of Gamma-Ray Spectra from Ge(Li) Spestrometers." Aeroset Nuclear Company report ANCR-1043 (1972).

\subsection{W. M. Sanders, D. M. Holm, "An Analytical} Method for Unfolding Gamma-Ray Spectra, Los Alamos Scientific Laboratory report LA-4030 (1969). 


\section{DETECTOR EFFICIENCY AND THE INVERSE SQUARE LAW}

The incrinsic photopeak efficiency of all detectors varies with energy. Typical examles of this variation are shown in Fig. 4.1 for MaI and Fig. 4.2 for Ge(Li). Knowledge of detector efficiency as a function of energy is required when accompting to make plutonium isotopic measurements by gamma spectrometry. Several lines at different energies are compared to extract isotopic ratios. As thw figures illustrate, detection efficiency call change considerably over just several keV. It is often useful to have a plot of detector efficiency vs anelgy for all detectors in use (relative efficiency is usually adequate; the absolute counting efficiency is more difficult to measure accurately). This can he measured quite easily with he standard calibration sources avaijable from NBS, IAEA, and others: or with the multi-isotopic point sources now available from NBS. It should be noted that absolute counting efficiency noed not be known since all gamma as say should be based on

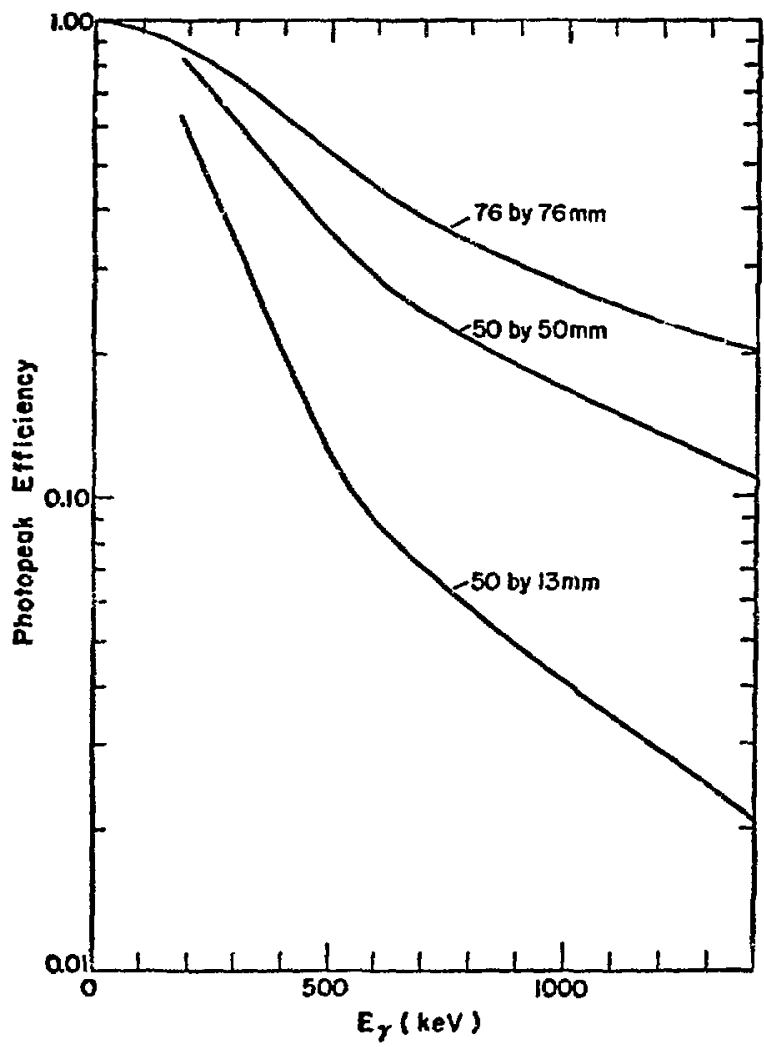

Fiq. 4.1. Photopeak efficiency vs energy for three different size NaJ detectors.

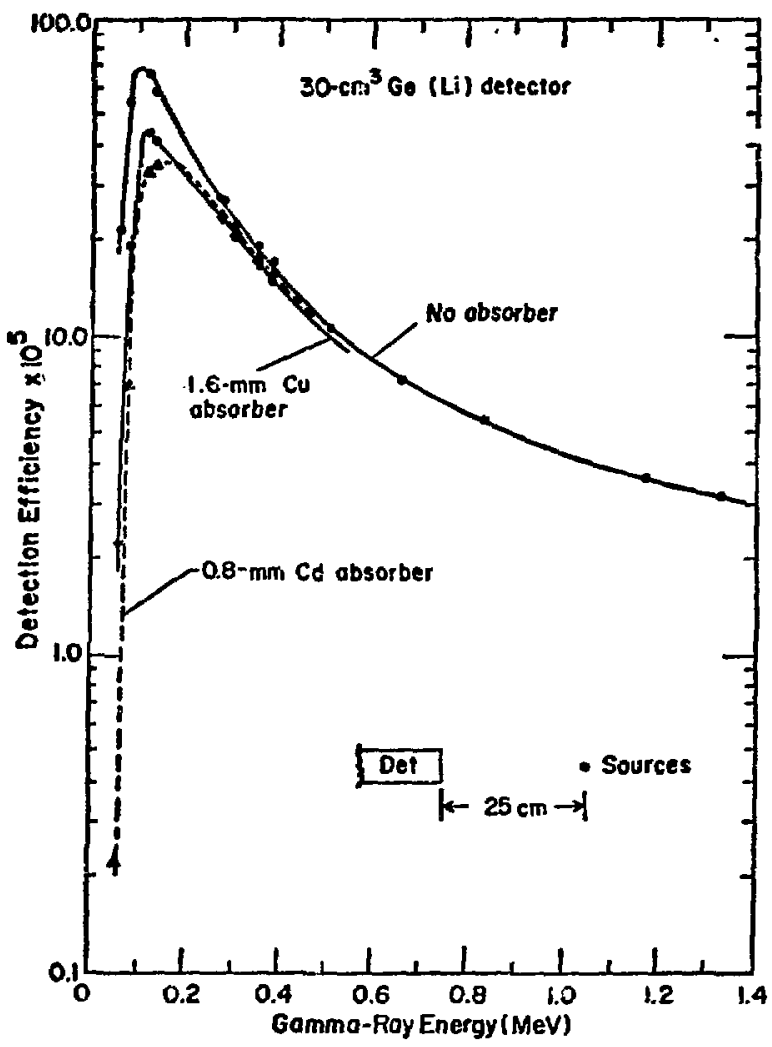

Fig. 4.2. Absolute efficiency vs energy for $30-\mathrm{cm}^{3}$ Ge(ii) detector.

measurements made relative to a known calibration standard. A measurement of absolute efficiency is implicit in the standard calibration.

The variation in efficiency with source-todetector distance affects gamma-ray assay in an otvious and important way. The basic formula for the absolute efficiency to detect gamma rays from a point source is given as

$$
\varepsilon_{T}=\frac{A \cdot \varepsilon_{p}}{4 \pi r^{2}},
$$

where

$$
\begin{aligned}
& A=\text { visible detector area, } \\
& \epsilon_{P}=\text { detector photopeak efficiency, } \\
& r=\text { source-to-detector distance. }
\end{aligned}
$$

Most samples for fissionable matertal assay are extended sources, so $r$ and $\epsilon_{T}$ vary from one point to another on the sample. This means a gram of uranium may yield different count rates depending on its location within the sample. Consider the cross section 
of a 55-gal dram (diam $=60 \mathrm{~cm}$ ) 11lustrated in

Fig. 4.3. One gram of material in position 2 counts four times as much as in position 4. If all samples were uniform, this variation of response (count rate) with position would be unimportant.

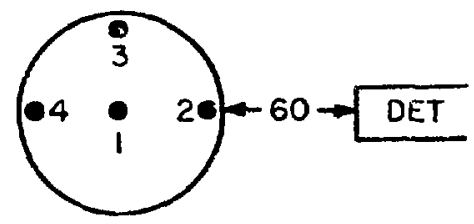

$$
\begin{array}{ll}
r_{1}=90 \mathrm{~cm} & C R_{1} / C R_{1}=(90 / 90)^{2}=1 \\
r_{2}=60 & C R_{2} / C R_{1}=(90 / 60)^{2}=2.25 \\
r_{3}=95 & C R_{3} / C R_{1}=(90 / 95)^{2}=0.90 \\
r_{4}=120 & C R_{4} / C R_{1}=(90 / 120)^{2}=0.56
\end{array}
$$

Fig. 4.3. Illustration of count rate variation with position in 55-gal drun.

Since many samples are not uniform (particularly the waste stored in 55-gal drums), this represents a potential source of error and should be minimized. This an be accomplished by increasing the sampleto-detector distance, but only at the expense of count rate. If the detector in Fig. 4.3 were $120 \mathrm{~cm}$. from the drum codge, the ratio of count rates between position 2 and position 1 would be $(150 / 120)^{2}=1.56$, but the overall count rate would have dropped to nearly one-third that at $60 \mathrm{~cm}$. A better procedure is to rotate the sample. Consider the following diagram.

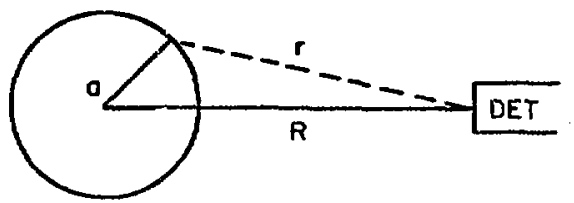

The ratio of the average response of a source rotating on the radius (a) to the response at the center is

$$
\frac{C R(a)}{C R(0)}=\frac{1}{1-(a / R)^{2}}
$$

Table 4.1 1ists this function for several values of $a / R$. By rotating the sample the maximutn count rate variation in Fig. 4.3 due to position is reduce? from 2.25 to 1.125 with no loss in overa11 count rate. Thus, whenever possible the sample should be
TABLE 4.1

\section{THE EFFECT OF SAMPLE ROTATION ON COUNT RATE VARIATION}

\begin{tabular}{lcc}
$\begin{array}{l}\text { a/R } \\
1 / 2\end{array}$ & $\begin{array}{c}\text { CR (a)/CR(0) } \\
\text { Rotating }\end{array}$ & $\begin{array}{c}\text { CR(R-a)/CR(R) } \\
\text { Not Rotating }\end{array}$ \\
\cline { 2 - 3 } $1 / 3^{a}$ & 1.33 & 4 \\
$1 / 4$ & 1.125 & 2.25 \\
$1 / 5$ & 1.067 & 1.78 \\
$1 / 6$ & 1.042 & 1.56 \\
$1 / 7$ & 1.021 & 1.44 \\
a This is the case i11ustrated in Fig. 4.3.
\end{tabular}

rotated to ainimize the potential error sue to nonuniform distributions of material within the sample. Rotation minimizes the effect of radial variations. If the sample is taller than it is wide, the vertical variation must be considered also. This is illustrated in Fig. 4.4, where $\mathrm{L}=\mathrm{I}_{2}$ height of container and $n \cdot L=$ distance from detector to center of container. The maximum variation is reduced to $10 \%$ with a sample-to-detector of $3 \mathrm{~L}$.

In gencral, the choice of sample-to-detector distance is a compromisa between minimizing the response variation and maintaining an adequate count rate. A general guideline can be given as follows: The maximum count rate variation with position is 1ess than $\pm 10 \%$, if the distance between the center of the sample and the detector is equal to or greater than three times the 1arger of the dimensions $a$ or $L$ (radius or $\frac{1}{2}$ height) and the sample is rotated. If the sample cannot be rotated, it should

$\frac{\triangle C R}{C R}=10 \%$, if $R=3 a$ or $3 \mathrm{~L}$, whichever

is larger, where a = radius of sample and $L=1,2$ height and the sample is rotated. This applies to $1 / \mathrm{r}^{2}$ variations only.

at least be counted in two orientations $180^{\circ}$ apart. Usually there will be little need to increase the sample-to-detector distance beyond this because of considerations of sample attenuation which wili usually be the largest source of count rate variation. 
$2.24 L$

$L$

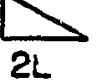

$3.16 L$

L $3 L$
4.12L

$L$

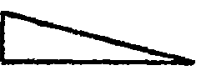

4L

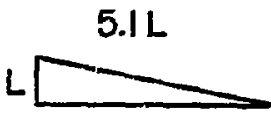

5L

$$
\frac{C R(2.24)}{C R(2)}=0.80 \quad \frac{C R(3.16)}{C R(3)}=0.90 \quad \frac{C R(4.12)}{C R(4)}=0.94 \quad \frac{C R(5.1)}{C R(5)}=0.96
$$

Fig. 4.4. Maximum vertical count rate variation as a function or sample-to-detector distance.

A source at the center of the sample will experience a larrer attenuation than will a similar source near the edge. This effect cannot be minimized by increasing the sample-to-detector distance. In most samples it will be the dominant effect, so sample-to-detector distances larger than indicated by the above discussion and $\mathrm{Eq} \cdot(4.5)$ are usually of little value. Consider a 55-gal drum of com- bustible waste $\left(a=30 \mathrm{~cm}\right.$, density $\approx 0.1 \mathrm{~g} / \mathrm{cm}^{3}$ or about $45 \mathrm{lb}$ net weight, $\left.\mu m(414) \approx 0.1 \mathrm{~cm}^{2} / g\right)$. Only $74 \%$ of the gamma rays emitted at the center would reach the surface of the drum $\left(e^{-(0.1)(0.1)(30)}\right.$

$=0.74$ ). This is a maximum count rate variation of $26 \%$, so a sample-to-detector distance larger than sperified by $\mathrm{Eq}_{\text {. }}(4.5)$ would not be justified. 


\section{ATTENUATION CORRECTION FACTORS}

\subsection{General Attenuation Considerations}

Figure 5.1 is a graph of mass attenuation coefficients vs energy for a selected range of elements. It also indicates the energies of the more useful gamma rays for the e.ssay of several important isotopes. In a qualitative way, the figure indicates many of the possibilities and constraints in performing gammi-ray assays. Several important features should be emphasized. Between 1 and $3 \mathrm{MeV}$, the mass attenuation coefficients of all elements (except hydrogen) are equal at a given energy within $\sim \pm 20 \%$. The maximum and minimum values within this range are $\sim .08 \mathrm{~cm}^{2} / \mathrm{g}$ and $\sim .035 \mathrm{~cm}^{2} / \mathrm{g}$ and the overall average value in the range is $\sim 0.05 \mathrm{~cm}^{2} / \mathrm{g}$. If nature had equipped all the isotopes of interest with an intense gamma ray in this range, gamma-ray assay would be much easier, but unfortunately only ${ }^{238} \mathrm{U}$ is so equipped. At lower energies, the coefficients

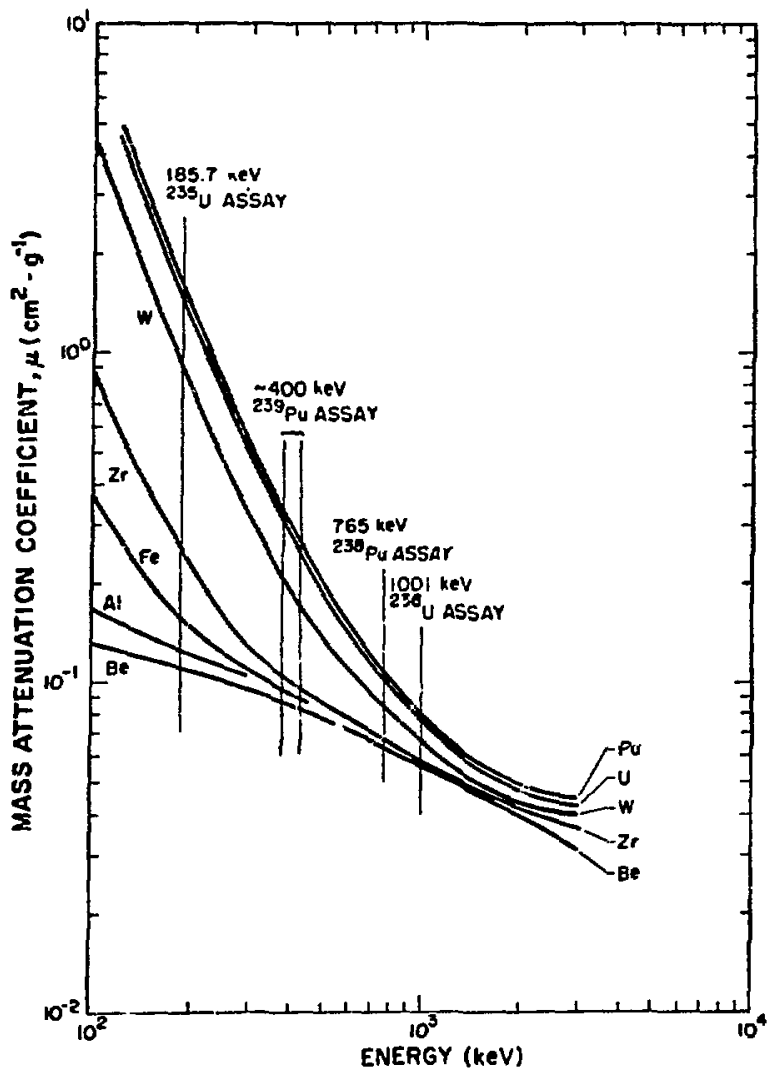

Fig. 5.1. Mass attenuation coefficient is energy for selected elements. The energies of several important assay lines are indicated on the graph. of the high-Z elements of interest become much larger than those of the lower- $Z$ materials, reaching values $\sim 20$ times higher near the $\mathrm{K}$-absorption edge of plutonium. These larg: differences make quantitative assay by low energy gamna rays difficult, or even impossible in many cases. The mass absorption coefficients of uranium and plutonium are nearly six times larger at $\mathbf{1 8 6} \mathrm{keV}$ than at $414 \mathrm{keV}$. This means the assay of ${ }^{235_{\mathrm{U}}}$ (using its $186-\mathrm{keV}$ gamma ray) is subject to a greater potential error than the assay of ${ }^{239} \mathrm{Pu}$ (using its 414keV gamma ray). The region between 80 and $120 \mathrm{keV}$ is usually not useful for assay measurements due to the $K \times$ rays of uranium and plutonium. Below 80 keV most attenuation coefficients increase rapidly, making attenuation unmanageably severe for most cases. An exception to this is the measurement of very low level $(\sim 10 \mathrm{nCi} / g$ ) waste materials where $L x$ rays $(\sim 20 \mathrm{keV})$ must be measured to achieve the desired sensitivity. Nearly all uranium and plutonium assay is done with gamma rays of energies between 100 and $1000 \mathrm{keV}$.

Figure 5.1 and the discussion above indicate the existence of limitations and constraints due to sample self-attenuation. The correction for sample attenuation will be discussed in some detail since it is the most imfortant factor in gamma-ray assay. The attenuation correction factor is defined here by the following expression:

$$
C F=\frac{C R(\mu=0, \text { no atteruation })}{C R(\text { actual observed rate })},
$$

where

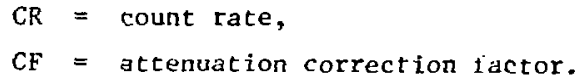

This expression is symbolic. CF cannot be computed from Eq. (5.1) because $C R(j=0)$ cannot be measured directly. The product $\mathrm{CR} \cdot \mathrm{CF}$ is sometimes cailed the "corrected count," i.e., the count which would be measured in the absence of attenuation. As defined, the correction factor has a minimum value of one. Experience has shown that the maximum value that can be determined with reasonable accuracy ( $\pm 5 \%$ ) is about five. It should be emphasized that $\mathrm{CF}=5$ is a large correction implying that only $20 \%$ of the gamma rays of interest escape from the sample. 
Large values of CF imply high potential for error. Sample nonuniformities become more troublesome as $C F$ increases.

The basic necessai 3 assumption for all quantitative yamma assay is that the mixture of uranium or plutonium and matrix material (everything other than uranium or plutonium in the sample) is reasonably unifurm, and the uranium or plutonium particles are small enough to ignore self-attenuation within tho emitting particles. It is difficul: to define "reasonably uniform," but some rough guidelines can be discussed. If the individual particles of uranium or plutonium have significant self-attenuation, the assay results will be low. For some cases special procedures may be used to correct for the error caused by individual particle attenuation. The self-attenuation of the individual particles can be estimated from the following formula.

$$
\begin{aligned}
& C F=\frac{\mu x}{1-e^{-\mu x}}, \\
& C F \approx 1+\mu x / 2, \text { if } \mu x \leq 1, \\
& C F \approx \mu x, \text { if } \mu x \geq 3,
\end{aligned}
$$

where

$$
\begin{aligned}
\mu= & \text { linear attenuation coefficient of emit- } \\
& \text { ting material, } \\
x= & \text { mean linear dimension of particle. }
\end{aligned}
$$
(The approximations are good to $5 \%$ ) The actual particles are irregular shapes and their size is not usually well knom, so it is difficult to compute the self-attenuation exactly. This formula should only be used to estimate the order of magnitude of the particle self-attenuation. Figure 5.2 illustrates the variation of self-attenuation with size for uranium and plutonium oxide particles. As indicated in the figure, small particles can heve significant self-attenuation, particularly uranium. A 130- $\mu$ particle of uranium oxide will absorb $10 \%$ of the $186-\mathrm{keV}$ ganma rays emitted within the particle. Larger particles, such as fuel pellets, are even worse. A $1-\mathrm{cm}$ pellet of $\mathrm{UO}_{2}$ requires a correction factor of about $15\left[\mathrm{\mu x} \approx\left(1.5 \mathrm{~cm}^{2} / \mathrm{g}\right)\right.$ $\left.\mathrm{x}\left(10 \mathrm{~g} / \mathrm{cm}^{3}\right)(1 \mathrm{~cm})=15\right]$ for the $186-\mathrm{keV}$ gamma ray. A similar"plutorium recycle pellet would require a correciton factor of about 2.5 for the 414-keV gamna ray. If such pellets were in a container of low density combustible waste (rags, gloves, Kim-

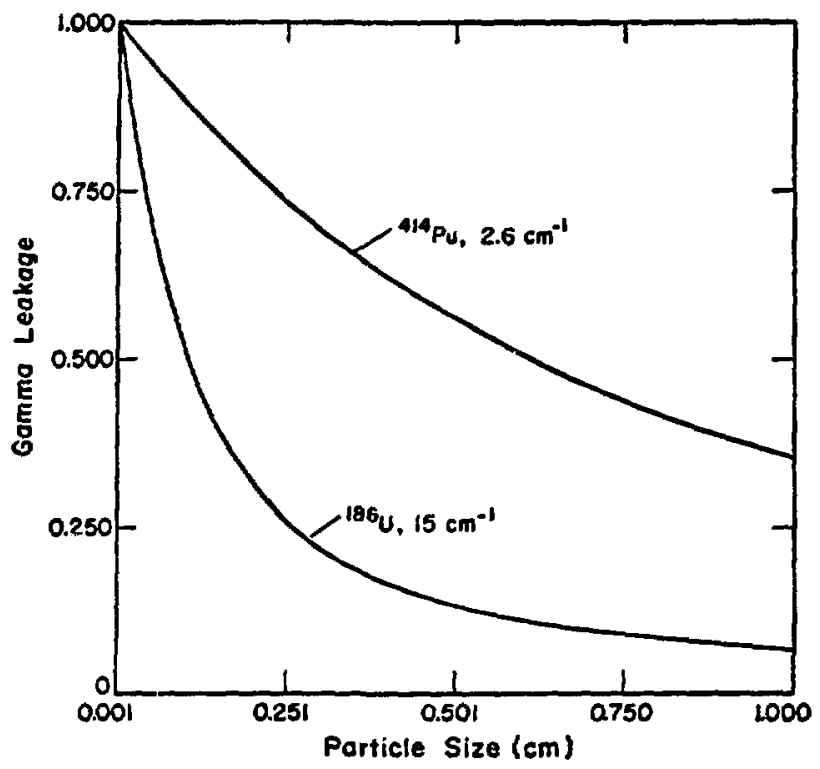

Fig. 5.2. Self-attenuation vs particle size.

wipes, etc.), the package would clearly not meet the requirement of reasonable uniformity. HTGR-coated particles come close to meeting the requirement, but assay results will still be $5-10 \%$ low if corrections are not made for particle size. Pure powders $\left(\mathrm{PuO}_{2}\right.$, $\mathrm{UO}_{2}, \mathrm{U}_{3} \mathrm{o}_{8}$, etc.) clearly meet the requirement as do certain well mixed powder scrap materials, such as most incinerator ash. Small quantities of powder mixed with combustibles may meet the requirement if the powder is distributed uniformly in the matrix and not in lumps.

The above discussion illustrates some of the basic problems of gamma-ray assi, . There are some techniques which allow less stringent uniformity conditions, which will be mentioned below. Nevertheless, it is generally true that in order to perform gamma-ray assay with any assurance of accuracy. the assayist must know that the samples meet the basic assumption of unfformity. In favorable casesi. accuractes of $\pm 5 \%$ (10) are readily obtainable; however, for samples which grossly depart from uniformity, measurements can be low by a factor of two or more. Several comon ways of computing the atcenuation cortection factur wiil "1wn be dis̄eissed.

\subsection{Attenuation Correction Factor Expressions}

Equat tons (5.3) list several comon and wheful expressions for the correction factor. 


$$
\begin{array}{ll}
C F=\frac{\mu D}{1-e^{-\mu D}} & \text { slab, } \\
C F=\frac{\pi / 4 \mu D}{1-e^{-\pi / 4 \mu D}} & \text { cylinder, } \\
C F=e^{+\mu L} & \text { absorber. }
\end{array}
$$

In these expressions $D$ is the cylinder diameter or or slab ttickness, and $L$ is the thickness of any pure absorbers between the sample and the detector. The slab formula, Eq. (5.3a), is an exact expression for the case where the sample-to-detector distance is very large compared with the dimensions of the source and the detector (this is sometimes calied the far-field approximation). It is used for rectangular samiies (plates, boxes, air filters, etc.) viewed parallel to a side (usually through the thin dimension). The expression works well even for fairly small sample-to-detector distances (one or two tilles the sample thickness). Equation (5.3b) is an ap.roximate expression for cylindrical samples. It has the same form as Eq. (5.3a), with $\mu D$ replaced by $(\pi / 4) \mu D(\pi / 4=0.785)$. This expression works quite well even when the detector is only one diameter from the edge of the sample. Both Eqs. (5.3a) and (5.3b) are plotted in Fig. 5.3. Equation (5.3c) is merely the fundamental law of gamma attenuation and is used for absorbers placed between the sample and the datector. This expression would be applied to the walis of the sample container. For this case, the total correction factor would be the product of Eq. (5.3a) or (5.3b) times Eq. $(5,3 c)$.

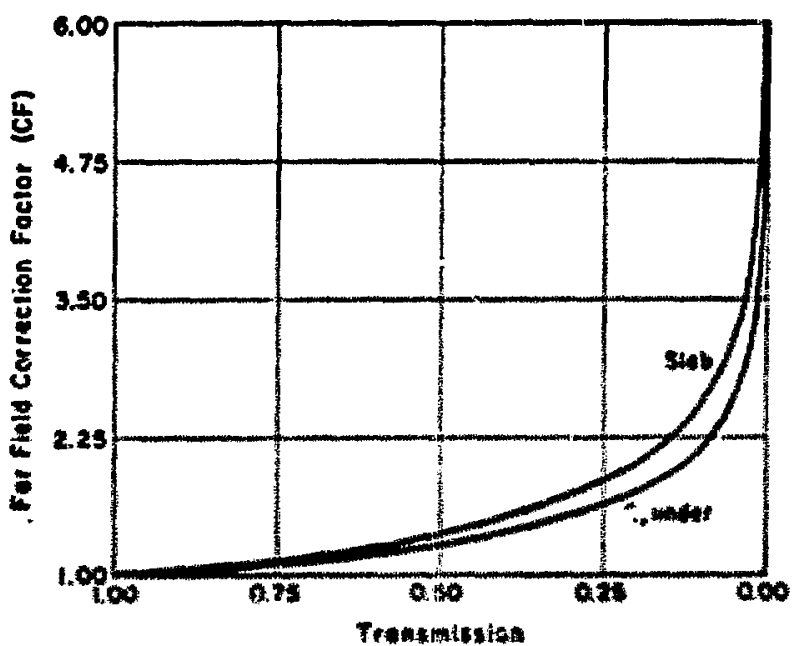

In general, these expressions are approximate but quite accurate, particularly for use with high zesolution detectors. For NaI they usually overestimate CF due to the effects of small angle scatters in the sample. In many cases, $\omega 0$ can be determined by an external source transrission measurement as described below. Other times (e.g., equipment holdup and large waste centainers) $\mu D$ is estimated from knowledge of the sample and CF computed directly from the appropriate expression above.

\subsection{Transmission-Corrected Gamma-Ray Assay}

Consider the situation pictured in Fig. 5.4 . The sample is placed between the detector and an external gamma-ray source. $I_{0}$ is the measured intensity of the source with no sample, and $I$ is the intensity with the sample in place. The transmission, $\mathrm{T}$, is defined as

$$
T=I / I_{0},
$$

i.e., the fraction of gama rays from the source which pass through the sample with no change in

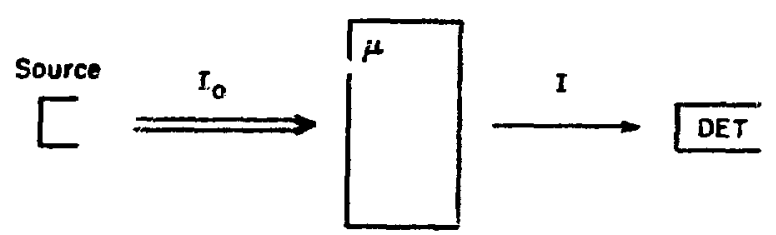

Fi. 5.4. Diatram of a transmission measurement.

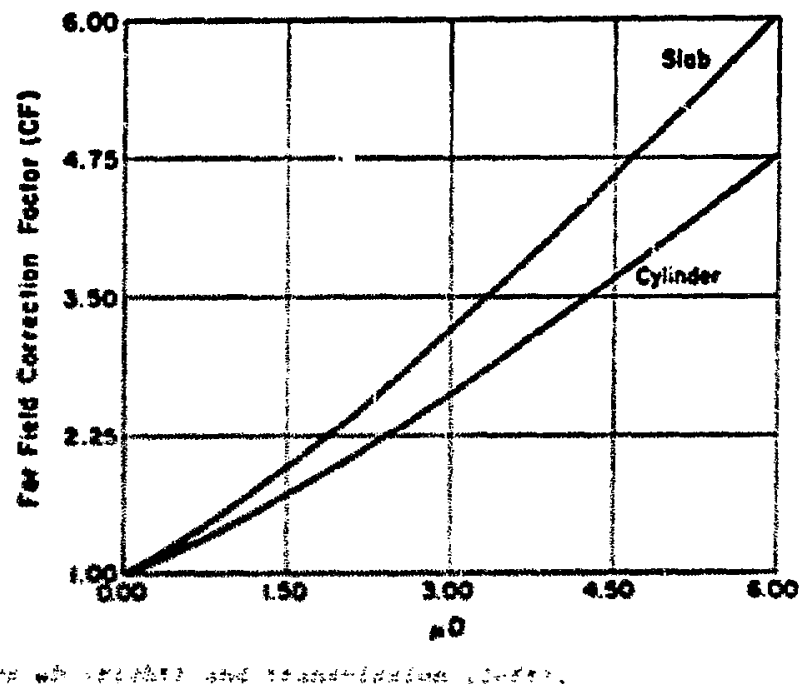

7. 
energy or direction. From the fundamental attenuation relationship,

$$
T=e^{-\mu \Gamma}
$$

The correction factor Eqs. (5.3) can be rewritcen in terms of $T$.

$$
\begin{array}{ll}
C F=\frac{-\ln T}{1-T} & \text { slab, } \\
C F=\frac{-\pi / 4 \ln T}{1-T^{\pi / 4}} & \text { cylinder. }
\end{array}
$$

Figure 5.3 also shows a plot of CF vs $T$. For $T$ greater than $0.2, C F$ is less than 2.0 and does not change rapidly. This is a favorable range for assay work. For $T$ less than 0.2 , CF rises rapidly and the possibility of error increases. Measured transmissions become less accurate when $T$ is less than $10 \%$. For careful work with high resolution detectors, transmissions as low as $\sim 0.5 \%$ (CF 5.3) can be measured with confidence. Caution is advised when measuring transmissions below $10 \%$ with NaI. The effects of small angle (small energy change) Compton scattering or "buildup" are more troublesome for NaI measurements.

Table 5.1 lists some of the common transmission sources. Equations (5.5a) and (5.5b) assume the transmission is measured at the same energy as the assay gamma ray. As indicated in Table 5.1, transmission and assay energles may be quite different. In this case a correction must be applied for the difference in attenuation between the two

TABLE 5.1

\section{COMMON TRANSMISSION SOURCES}

\begin{tabular}{cccc}
$\begin{array}{c}\text { Assay } \\
\text { Isotope }\end{array}$ & $\begin{array}{c}\text { Assay } \\
\text { Energy (keV) }\end{array}$ & $\begin{array}{c}\text { Transmission } \\
\text { Source }\end{array}$ & $\begin{array}{c}\text { Transmission } \\
\text { Energy (keV) }\end{array}$ \\
\cline { 2 - 4 } $235 \mathrm{v}$ & 186 & ${ }^{169} \mathrm{Yb}$ & 177,198 \\
& & $235_{\mathrm{v}}$ & 186 \\
$238 \mathrm{v}$ & 1001 & ${ }^{137} \mathrm{Cs}$ & 662 \\
& & ${ }^{54} \mathrm{Yn}$ & 834 \\
& & ${ }^{22} \mathrm{Na}$ & 1275 \\
$239 \mathrm{Pu}$ & 414 & ${ }^{75} \mathrm{Se}$ & 401 \\
& & $22 \mathrm{Na}$ & 511 \\
& & $137 \mathrm{Cs}$ & 662 \\
& & $239 \mathrm{Pu}$ & 414
\end{tabular}

energies. This correction usually involves some knowledge of the composition of the sample. The relation between the transmissions at the two energies is given by

$$
T_{\mathbf{a}}=\mathrm{T}_{\mathbf{t}}^{\alpha},
$$

where

$$
\begin{aligned}
& \text { a refers to the assay energy, } \\
& t \text { refers to the transmission energy, } \\
& \alpha=\mu_{a} / \mu_{t} .
\end{aligned}
$$

The measured transmission is raised to the $\mu_{a} / \mu_{t}$ power before substitution into Eqs. (5.5). As an example of how reasonable values of $\alpha$ may be obtained, consider the assay of ${ }^{239} \mathrm{Pu}(414 \mathrm{kev})$ contaminated incinerator ash using ${ }^{137} \mathrm{Cs}(662 \mathrm{keV})$ as a transmission source. This mixture can be treated as two components, one having the attenuation properties of oxygen and the other those of plutonium, in calculating the composite attenuation. Table 5.2 illustrates the change in $\alpha\left(\mu_{a} / \mu_{t}\right)$ with the plutonium weight fraction. Most incinerator ash will be less than $10 \%$ plutonium by weight, so $\alpha=1.27$ might be picked as an average value for the measurements. If a wider range of weight fractions is encountered, it may be necessary to perform an iteration (i.e., pick a trial $\mathrm{F}_{\mathrm{pu}}$, calculate the mass of plutonium, calculate $F_{p u}$ from this value and the sample net weight, recompute the mass of plutonium, etc.).

The choice of a transmission source is frequently limited by the equipment and sources

\section{TABLE 5.2}

\section{THE VARIATION IN $\boldsymbol{\mu}(414) ; \boldsymbol{\mu}(662)$ WITH PLUTONIUM WEIGHT FRACTION}

Fu

0

0.1

0.3

0.5

0.7

0.9

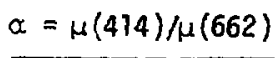

1.21

\begin{tabular}{|c|c|c|}
\hline & 474 & 662 \\
\hline$\mu_{\text {pu }}$ & $0.26 \mathrm{~cm}^{2} / \mathrm{g}$ & $0.13 \mathrm{~cm}^{2} / \mathrm{g}$ \\
\hline$\mu_{0}$ & 0.093 & 0.077 \\
\hline
\end{tabular}

1.33

1.54

1.71

1.84

1.95

Mass Attenuation Coefficients 
available. Uranium or plutonium is usuall $y^{*}$ eval1able, and neither of them requixes any energy correction as above. There are, however, three bad aspects of their use: they require a double measurement (with and without the source) to compensate for the uranium or plutonium activity in the sample; at low transmissior s this requires the subtraction of two large and nearly equal numbers, the result of which usually has a low statistical precision; and, finally, the high self-attenuations of uranium and plutonium make it difficult to get high intensity sources. Sources such as ${ }^{169} \mathrm{Yb}$ and ${ }^{75} \mathrm{Se}$ are usually chosen for use with high resolution detectors. With ${ }^{169} \mathrm{Yb}$ the transmission is measured at both 177 and $198 \mathrm{keV}$. The 186-keV transmission is determined by interpolation. With ${ }^{75} \mathrm{Se}$ the transmission energy ( $401 \mathrm{keV})$ is close enough to the assay energy ( $414 \mathrm{keV}$ ) to consider $\alpha=1$. NaI requires the use of uranium or plutonium or sources such as ${ }^{22} \mathrm{Na}$ and ${ }^{137} \mathrm{Cs}$ which are of sufficiently different energy as to reduce the interference with the plutonium gamma rays.

If the sample is uniform, one transmission. measurement will adequately define $\mu \mathrm{D}$. In more advanced procedures the sample is scanned to measure $T$ as a function of position.

\subsection{Differential Absorption Corraction}

This is another measured attenuation correction of use for some types of nuclear material assay. It is lased on two facts. First, some isotopes emit several gamma rays with significantly different energy. Thus, the ratio of the intensities of two different energy gamma rays from the same isotope will vary with the sample attenuation. In certain. circumstances this ratio can define the sample attenuation correction factor.

To apply this method the same assumptions are required as discussed above for transmission corrected assay. Several additional requirements must be met:

(a) The average or effective atomic number (2) musc be known; i.e., some knowledge of sample composition is required.

(b) The uranium or plutonium must be a small part of the total sample attenuation. (c) The required homogeneity and lack of selfabsorbing uranium or plutonium concentrations is wore severe than for transmission corrected assays.

(d) The i.ntope must have appropriate ganma rays. (It should be noted that the correction lines need not come from the isotope under assay; e.g., intense lines from ${ }^{241} \mathrm{Pu}$ can be used for ${ }^{239} \mathrm{Pu}$ assay.)

A major advantage of this technique is its simpiicity. It requires only a detector and a sample. It is most applicable to plutonium assay; and, since individual plutonium gamma rays must be measured, a $\mathrm{Ge}(\mathrm{Li})$ detector is required. A multichannel analyzer and computer will usually be required for data acquisition and analysis.

Cline describes a procedure for thr measurement of plutonium contaminated waste based on the differential absorption method. $5.1,5.2$ The absorption correction is based on the ratio of the intensities of the 129- and 414-keV gamma rays of ${ }^{239} \mathrm{pu}$. The expression derived for the attenuation correction factor is

$$
\mathrm{CCF}=\left[\frac{\left(\mathrm{I}_{129} / \mathrm{I}_{414}\right)}{\left(\mathrm{I}_{129} / \mathrm{I}_{414}\right)}\right]^{\frac{\mu_{\text {i } 14}}{\mu_{129}-\mu_{414}}} .
$$

where

$$
\begin{aligned}
\text { CCF }= & \text { differential absorption attenua- } \\
& \text { tion correction factor, } \\
= & \text { mass atcenuation coefficients for } \\
& \text { the appropriate atomic number, } \\
\left(\mathrm{I}_{129}, \mathrm{I}_{414}\right)= & \text { ratio of gama ray incensities } \\
& \text { for the measured sample, } \\
\left(\mathrm{I}_{129} / \mathrm{I}_{414}\right)= & \text { ratio of gamma iay intensities } \\
& \text { for a sample with negígible at- } \\
& \text { renuation. A thin foil is recom- } \\
& \text { mended to measure this. }
\end{aligned}
$$

The average atomic number of the waste matrix must be known to apply this procedure. For much combustible waste this is approximately $7=8$, and the exponent in Eq. $(5,7)$ las a value of $\sim 1.92$.

Figure 5.5 shows a graph of this exponent with respect to atomic number. Several assumetions are made in the derivation of this expresston, so to only holds over a limited actenuat ion range. The combustible waste situation is lllustrated in Table 5.3. The table cospars. Fin. (5.7) (CCF) with 


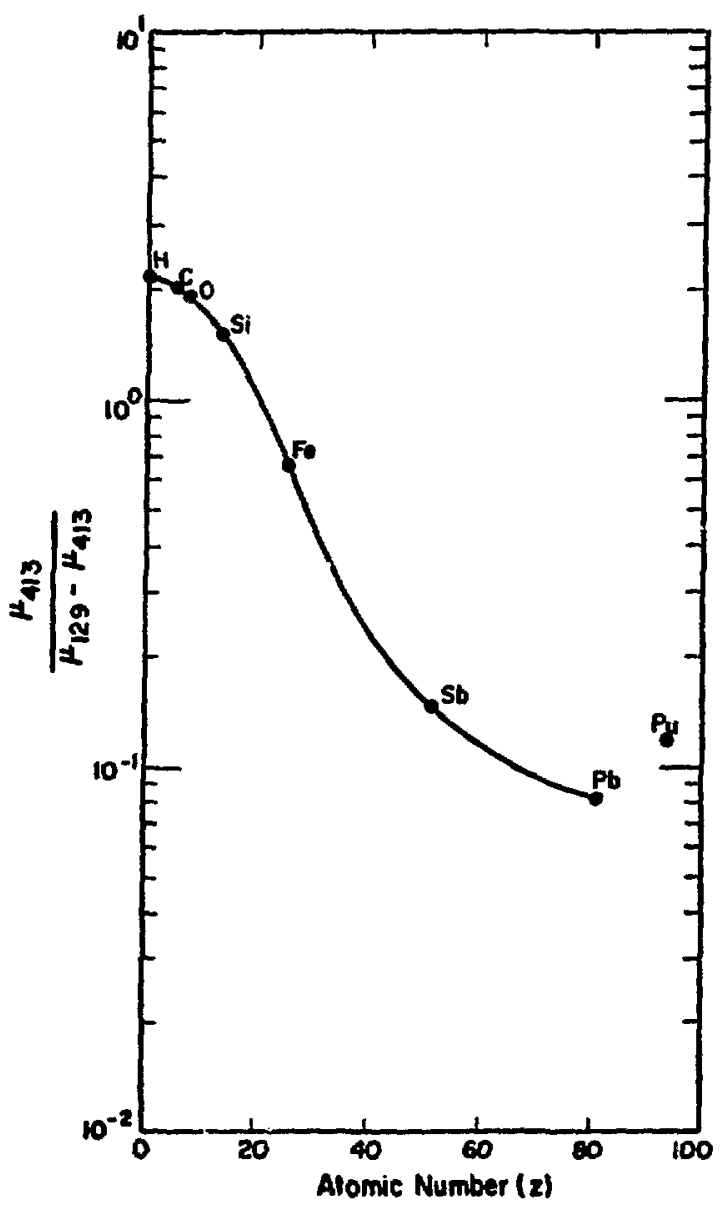

Fi:;. 5.5. Exponent in Equation (5.7), $\frac{\mu_{414}}{129-414}$, as a function of atomic number. raken trom Ref. 5.1 .
Eq. (5.3b) $\left(\mathrm{CF}_{414}\right)$ as a function of waste density. This shows that Eq. (5.7) should not be used if the $129 / 414$ ratio drops below $75-80 \%$ of the unattenuated value. It should be noted that most combustible waste wIll have a density of $\leqslant 0.3 \mathrm{~g} / \mathrm{cm}^{3}$; therefore, the expression should be adequate if the 75-80\% init is observed.

A more correct procedure can be given to compute the differential absorption correction factor. Consider two gamra rays labeled 1 and 2 ( 2 is the higher energy and is the line used for assay; e.g., 1-129 kev, $2-414 \mathrm{keV}$ ). The average atomic number (or some assumption of matrix composition) gives the two mass attenuation coefficients, $\mu_{1}$ and $\mu_{2}$. The measured intensity ratio $I_{1} / I_{2}$ is given by

$$
\frac{I_{1}}{I_{2}}=\left(\frac{I_{1}}{I_{2}}\right)_{\mathrm{en}} \frac{C F_{2}}{C F_{1}},
$$

where

$$
\begin{aligned}
& \frac{C F_{2}}{C F_{1}}=\frac{\mu_{2}}{\mu_{1}} \frac{1-e^{-\mu_{1} X}}{1-e^{-\mu_{2} X}} \quad \text { slab, } \\
& \frac{C F_{2}}{C F_{1}}=\frac{\mu_{2}}{\mu_{1}} \frac{1-e^{-(\pi / 4) \mu_{1} X}}{1-e^{-(\pi / 4) \mu_{2} X}} \text { cylinder, } \\
& X=\text { density - thickness (dlameter). }
\end{aligned}
$$

The correction factor is determined as follows:

(1) Values for $r_{1}$ and $\mu_{2}$ are determined for the assumed matrix composition.

TABLE 5.3

\begin{tabular}{|c|c|c|c|c|c|}
\hline $\begin{array}{l}\text { Density } \\
\left(\mathrm{u} / \mathrm{cm}^{3}\right)\end{array}$ & $\frac{I_{129} / I_{414}}{T_{129} T_{414]_{6 m}}}$ & $T_{414}$ & CCF & $\mathrm{CF}_{414}$ & $\begin{array}{l}\text { Diff. } \\
\end{array}$ \\
\hline 0.1 & 0.89 & 0.54 & 1.24 & 1.26 & -1 \\
\hline $0 . *$ & 0.82 & 0.29 & 1.47 & 1.56 & -6 \\
\hline 0.5 & 0.76 & 0.16 & 1.56 & 1.89 & -12 \\
\hline a. & 0.73 & 0.09 & 1.94 & 2,25 & -19 \\
\hline 47.4 & 0.69 & 0.01 & 2.05 & 3.06 & -33 \\
\hline 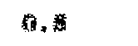 & 0.67 & 0,01 & 2.16 & 3.94 & -45 \\
\hline 1.6 & e.4k & 0,00 & 2.20 & 6.85 & -55 \\
\hline
\end{tabular}

COMPARISON IF DIFFERENTIAL ABSORPTION AND TRANSMISSION-BASED ABSORPTION CORRECTIONS

FOR COMBUSTIBLE WASTE 
(2) Iterate Eq. (5.8) to find the value $X$ wilich produces the measured line rat $10 I_{1} / I_{2}$.

(3) Compute $\mathrm{CF}_{2}$ (the desired attenuation correction) from:

$$
\begin{aligned}
& \mathrm{CF}_{2}=\frac{\mu_{2} \mathrm{X}}{1-\mathrm{e}^{-\mu_{2} X}} \quad \text { slab }, \\
& \mathrm{CF}_{2}=\frac{(\pi / 4) \mu_{2} X}{1-\mathrm{e}^{-(\pi / 4) \mu_{2} X}} \quad \text { cylinder } .
\end{aligned}
$$

The maximum possible change in the ratios is given by:

$$
\left.\frac{\mathrm{I}_{1} / \mathrm{I}_{2}}{\left(\mathrm{I}_{1} / \mathrm{I}_{2}\right)_{\text {em }}}\right)_{\text {minimum }} \approx \frac{\mu_{2}}{\mu_{1}} .
$$

As the attenuation of the low energy line reaches saturation, the method loses sensitivity to changing attenuation. This correction procedure should not be applied when the ratio gets below

$$
\left.\frac{\mathrm{I}_{1} / I_{2}}{\left(\mathrm{I}_{1} / \mathrm{I}_{2}\right)_{\text {em }}}\right) \approx 1 / 3+2 / 3 \frac{\mu_{2}}{\mu_{1}} \text {. }
$$

By itself the differential absorption method is best suited to low level plutonium contaminated combustible waste. It may also be applicable to some small containers of solid residue such as incinerator ash. There is relatively little experience with this latter category. If the matrix is too dense $\left(1.0 \mathrm{~g} / \mathrm{cm}^{3}\right.$ should st 111 be measurable in a $12-\mathrm{cm}$ or less diameter can) the $129-\mathrm{keV}$ gamma ray is saturated and the attenuation correction cannot be evaluated. When the sample does meet the necessary requirements, this method can be recommended due to the ease of operation. It also has the necessary feature that it includes an indication of when the sample is not measurable by differential absorption, namely, when the intensity ratio drops below the value given by Eq. (5.11).

There are several potential gama-ray pairs which may be used in plutonium assay. There is really only one that might be used for uranium, and this only for certain special situations. Information is given on several line pairs in Table 5.4. The 143, 186 or 345,414 combinations will generally not be useful for combustible waste assay since there is not enough difference between $\mu_{1}$ and $\mu_{2}$. These lines may provide information on uranium or plutonium lumps as indicated below. The value, $\left.\mathrm{I}_{1} / \mathrm{I}_{2}\right) \mathrm{em}$, is just the ratio of the relative intensities of the two gammas. The actual measured ratio will be affected by the different detection efficiencies at the two energies.

Another important use of the differential absorption method is to indicate the presence of source self-absorption (uranium or plutonium lumps) in samples undergoing transmission-corrected gamma assay. If the observed ratio (e.g., 129/414) is significantly lower than is indicated by the standards, the presence of luinps should be suspected. For this purpose the $143 / 186$ ratio can provide some limited information for uranium assay. The 345/414 ratio may be better for plutonium since the 129-keV line is too highly absorbed by plutonium (1t will saturate and indicate trouble when the 414-keV transmission-corrected assay is still ckay). For plutonium assay it is recommended that efther or both of the above ratios be monitored to check for anomalous source absorption. In principle it may

\begin{tabular}{|c|c|c|c|c|c|c|}
\hline 1sotope & $\begin{array}{l}\text { Energy } \\
\text { (keV) }\end{array}$ & $\left.{ }^{1}{ }_{1} / I_{2}\right)_{e m}$ & $\begin{array}{c}\text { Mass Absorp } \\
\text { Combustible } \\
\text { Waste } \\
\left(\mathrm{cm}^{2} / \mathrm{g}\right) \\
\end{array}$ & $\begin{array}{l}\text { Coefficient } \\
U \text { or } \mathrm{Pu} \\
\left(\mathrm{cm}^{2} / \mathrm{g}\right)\end{array}$ & $\begin{array}{r}T_{1} \\
\pi_{1} \\
\text { Comb. }\end{array}$ & $\begin{array}{l}\mathrm{em} / \min \\
\text { Uar } P_{\mathrm{u}}\end{array}$ \\
\hline $235 v$ & 143,186 & 0.10 & $.154, .141$ & $2.9,1.5$ & 0.42 & 0.52 \\
\hline${ }^{239} \mathrm{Pu}$ & 129,414 & 3.7 & $.156, .104$ & $3.8,0.28$ & 0.67 & 0.074 \\
\hline${ }^{239} \mathrm{Pu}$ & $345, \$ 14$ & 0.33 & $.111, .104$ & $0.4,0.28$ & 0.94 & 0.70 \\
\hline
\end{tabular}
even be possible to make some compensation for the

TABLE 5.4

GAMMA-RAY PAIRS FOR DIFFERENTIAL ABSORPTION METHOD 
self-absorbing lumps. For example, multienergy transmission measurements [e.8., for 143/186: 131-, $177-, 198-\mathrm{keV}$ lines from ${ }^{109} \mathrm{Yb}$; for $129 / 414,122-$ keV $\left({ }^{57} \mathrm{Co}\right)$ and $\left.401-\mathrm{keV}\left({ }^{75} \mathrm{Se}\right)\right]$ can be used to predict the intensity ratio which should be measured if there are no lumps and the transmission source is accurately measuring the total absorption. If the measured ratio is significantly below this, the difference can be ascribed to uranium or plutonium lumps and an appropriate correction made. This would never be a routine procedure, but it might be of use in certain assay situations.

To summarize, the differential absorption technique is nore restricted than transmissioncorrected assaybut, where applicable, is easier to use. It does provide a warning when it cannot be used. It complements transmission-correction techniques and can provide additional infornation in some assay situations. Appendix B contains a description of some recent work on the differential absorption technique and should be read carefully by anyone contemplating the use of this procedure.

\subsection{Other Attenuation Corrections}

Equations (5.12) give an approximate expression for a transmission-based correction factor which may be used for transmissions over $\sim 0.2$.

$$
\begin{array}{ll}
\mathrm{CF} \approx 1 / \sqrt{\mathrm{T}} & \text { slab },(5.12 \mathrm{a}) \\
\mathrm{CF} \approx 1 / \sqrt{\mathrm{T} \pi / 4} & \text { cylinder } \cdot(5.12 \mathrm{~b})
\end{array}
$$

This assumes that the average path length within the sample is one-half the slab thickness or one $\pi / 8$ th of the cylinder dlameter. Table 5.5 gives a comparison of Eqs. (5.12) with the exact expressions, Eqs. (5.5). For $T$ greater than 0.2 the approximate slab expression is less than $12 \%$ and the cylinder expression is less than $7 \%$ high.

In some cases, useful estimates of $C F$ can be made from knowledge of the sample weight and composition. If the sample is full and its weight and compostition known, the attenuation may of ten be calculated with suificient accuracy that no experimental measurement is required. Consider the example of a 55-gal drum of plutonium-contaminated combust bble wiste. The wate material must be weli sexregated (1,e.. no lathe beds, balls mills, etc., mixed with the combust tbles) and the pluranium con-
TABLE 5.5

COMPARISON OF APPROXIMATE AND EXACT EXPRESSIONS FOR CF

$\begin{array}{llllll}I & 1 / \sqrt{T} & \frac{-\ln T}{I-T} & & 1 / \sqrt{\mathrm{T} / 4} & \frac{-\pi / 41 \mathrm{~T}}{1-T \pi / 4} \\ 1.0 & 1.0 & 1.0 & 1.0 & 1.0 \\ 0.8 & 1.118 & 1.116 & 1.092 & 1.090 \\ 0.6 & 1.291 & 1.277 & 1.222 & 1.214 \\ 0.4 & 1.581 & 1.527 & 1.433 & 1.402 \\ 0.2 & 2.236 & 2.012 & 1.881 & 1.761 \\ 0.1 & 3.162 & 2.558 & 2.469 & 2.162\end{array}$

centration low so that it is a minor part of the total attenuation. Combustible waste will have attenuation properties similar to water.

Assume net weight $=32 \mathrm{~kg} ;$ size $=56 \mathrm{~cm}$ diam by $89 \mathrm{~cm} \mathrm{high;} \mathrm{walls}=0.1 \mathrm{~cm}$; volume $=0.22 \mathrm{~m}^{3}$. Straightforward computation using Eq. (5.3b) gives for the matrix $\mathrm{CF}=1.37$, and using Eq. (5.3c) for the wall attenuation one gets $C F=1.07$; this gives a combined correction factor for matrix and container of $1.37 \times 1.07=1,47$. Again using Eq. (5.3b) and assuming $100 \mathrm{~g}$ of plutonium distributed uniformly throughout the drum, one gets $C F=1.003$. This says that $100 \mathrm{~g}$ of plutonium will have a negIigible effect on the total gamma-ray attenuation in the drum if it is distributed so that there are no self-attenuating lumps.

The important factor in applying this attenuation correction is that the containers uust be filled or the fill volume known. The attenuation correction is based on the density of the sample. Consider a group of samples filled to different heights with materlal of approximately constant density. Since the density is constant, the correction factor should be constant. However, if only the weight is known and the samples are assumed to be full, different correction factors will be applied to each sample.

The final procedure to be discussed involves the use of standarcs to sover the range of materlal to be measured. In this case no explicit computation or measurement is made to correct for attenuation: the unknowns are assumed to have the same attenustion properties as the standards. This procedure is acceptable where there is a class of 
samples which are very nearly identical in size, shape, and composition, varying only in concentration of uranium or plutonium. In such cases, the attenuation of the matrix will be nearly constant from one sample to another and the observed count rate will be uniquely related to the fissionable material concentration. This relationship can be determined by preparing a series of standards covering the expected concentration range and counting them in the same geometry as the unknowns. The resulting calibration curve may be somewhat nonlinear if the uranium or plutonium concentration is high enough that it begins to contribute to the attenuation in the standard. This procedure is the simplest to use, and where applicable, can yield acceptable results (at present, it is probably the most widely used gamma assay procedure). For example, this would be used for product control or quality assurance where deviations from a mean (the standard) are to be measured. However, it is the most susceptible to error and must be applied with caution. It should only be used on very well controlled material since there is no check that the unknowns actually do resemble the standards. The standards must have the same ma$\operatorname{tr} \mathfrak{i x}$ at tenuation as the unknowns, or else there will be a constant bias on all measurements. This procedure is generally not recommended. Its undesirable features are discussed in detail in Section 9 (Standards).

\section{REFERENCES}

5.1 J. E. Cline, "A Relatively Simple and Precise Technique for the Assay of Plutonium Waste," Aerojet Nuclear Compan'r report ANCR-1055 (February, 1972). This report describes the use of differential attenuation of different energy plutonium gamma rays to correct for sample attenuation. It also ircludes a good discussion of the operation of $\mathrm{Ge}(\mathrm{Li})$ desectors and their associated electronics. This should be read in conjunction with the next reference, which describes some of the assumptions and limitations of the "contrast method" and reports sorre experimental results on plutonium waste standards.

5.2 T. D. Reilly and J. L. Parker, Los Alamos Scientific Laboratory report LA-5197-PR (1972), pp. 15-18. This report contains some discussion of Ref. 5.1 and some measurement results on mixed oxide (uranium-plutonium) waste standards. 


\section{RATE-RELATED COUNTING LOSSES}

\subsection{Nature of the Problems: Methods of Minimi- zation}

Failure to record (or to correctly record) gamma-ray interactions in the detector because of the rate-dependent effects of instrumental deadtime and/or prise pileup is a significant potential source of error in gamma-ray assays. Such counting losses have been dealt with in various books and papers. $6.1-6.4$ However, for the sake of completeness, a brief discussion will be given here along with suggestions for a few specific procedures for correcting such losses.

The term "deadtime," of course, generally refers to the fact that some components of common data acquisition systems (usually single or multichannel analyzers) have a finite "deadtime" or analysis time during which they cannot accept another event. This deadtime per evert ranges from a few microseconds for single-channel analyzers to several tens of microseconds for most multichannel analyzers. In the latter case the total fraction of deadtime may often be several tens of percent. Most multichannel analyzers have a good internal correction for their own deadtime if the spectral shape remains constant during the count interval. It should be noted that if the spectral shape is not constant, the deadtime correction for different spectral components will differ. In many NDA measurements for uranium and/or plutonium, the spectral shape and rates will be constant during a count interval. In segmented scans both rate and spectral shape will vary but the variation within a single segment will almost never produce a significant error in total result. What must be emphasized is that running a multichannel analyzer in a livetime mode does not correct for losses due to pulse pileup which may be just as significant.

The term "pulse pileup" refers in general to the fact that gamma-ray interactions which are separated (temporally) by less than the output pulse width of the main amplifier will produce a piled up or summed amplifier output. Roughly speaking, if the time between interactions is less than half the pulse width, the maximum pulse height w111 not correspond to either event, and neither event w1.11 be recorded in the proper place in the MCA spectrum. A single event will be recorded at a spot in the spectrum corresponding to some fraction of the sum of the two independenc events. The effects can be appreciable with germanium detectors where the full energy spectral peaks are narrow and the amplifier output pulse is of ten 10- to 20- $\mu$ s wide. Consider a system using an amplifier with unipolar shaping and 3- or 4- $\mu$ s time constants; this produces an output pulse whose width is $\sim 15 \mu \mathrm{s}$. At a gross rate of $\sim 10^{4} \mathrm{~s}^{-1}$ the fraction of events thrown out of a full energy peak is $\sim 0.15\left[\sim\left(15 \times 10^{-6}\right.\right.$ s) $\left.\left(10^{4} s^{-1}\right)\right]$. Thus $\sim 15 \%$ of the full energy peak events would be lost over and above any loss due to deadtime. In general, even at gross rates of only a few thousand per second such losses will be a few percent.

The most direct way to minimize pileup losses is to use the shorkest possible amplifier time constants consistent with the resolution required. If, for example, $1-\mu$ s shaping is adequate, the pileup effects will be a factor of four less than with 4- $\mu$ s shaping.

The use of absorbers to selectively attenuate low energy gamma radiation while preserving most of the usable higher energy flux also helps reduce pileup and deadtime by reducing the the gross rate in the detector. For most NDA measurements of plutonium and/or uranium no use is made of the ropious $x$-ray emissions or, for plutonium, of the $60-\mathrm{keV}$ gamma rays from $241 \mathrm{Am}$. When assaying ${ }^{239} \mathrm{Pu}$ by means of its $413.7-\mathrm{keV}$ gamma ray, 1 to $2 \mathrm{~mm}$ of lead backed with $1 \mathrm{~mm}$ of cadmium greatly reduces the radiations below $\sim 150 \mathrm{keV}$. Such selective filters will usually include a thin layer of high-z (e.g., $\mathrm{Pb}$ or $\mathrm{W})$ materials because they offer the best selective discrimination against low energy gamma rays.

\subsection{Constant Rate Pulser Corrections}

After doing what can be done to minimize the effects of pileup and deadtime, corrections should usually be made for residual effects which are still nontrivial. A common and effective method for making deadtime and pileup corrections is to insert a pulser peak into the spectrum through a 
preamplifier input. If the pulser rate is reasonably low (typically 60 Hertz from a very stable mercury switch pulser), the losses from the pulser peak will be nearly the same as from other spectral peaks. Knowledge of the count time and pulser rate determines the expected pulser count in the absence of losses. Standard procedures give the actual area and the ratio of actual-topredicted gives the fractional counting loss. Since the pulser is periodic and the gamma-ray events are random, the gamma-ray peaks will suffer slightly higher losses than the pulser peak. The factor by which the gamma-ray peak deadtime losses exceed the pulser peak deadtime losses is $\sim(1+$ $R T$ ), where $R$ is the pulser rate and $T$ is the deadtime per pulse. Thus, for a 60-Hertz pulser and a combined system deadtime of $30 \mu \mathrm{s}$ per pulse, the factor is $\sim 1.002$, which may be ignored for most NDA work. The factor by which the gamma-ray peak pileup losses exceed the pulser.peak pileup Losses is $\sim(1+R T)$, where $R$ is the pulser rate and $T$ is the amplifier pulse width. This factor is genera1ly smaller than the factor for deadtime because the amplifier pulse width is usually less than the MCA deadtime. The two correction factors'just mentioned are usually small enough to be negligible in most practical cases, but it is good to be aware of the possibilities if it is casually de- cided to uge a high pulser rate or a long (2 100 ws) MCA deadtime.

A note of caution is appropriate on the use of pulsers. It is often difficult to eliminate the undershoot from the amplified pulser pulses. If the amplified pulses have a long undershoot, even of small amplitude, it will cause excessive pileup losses and/or peak distortion. Effort should be taken to make the amplified pulser pulses nearly identical in shape to the amplified detector pulses. It is possible to add a pole-zero cancellation network to the preamplifier pulser input. Such a circuit is shown in Fig. 6.1. $R_{L}$ is chosen to match the pulser output impedance, usually $93 \Omega$ or $50 \Omega$. $\mathrm{RC}$ is chosen to match the fulser pulse decay time. $R$ is chosen as large as practical ( $) M \Omega$ ) to limit the degradation in system resolution. From a noise standpoint, $R$ appears in parallel with the feedback resistor in the first stage of the preamplifier. It increases the resistance noise contribution and lowers the resolution. For example, if the pulse decay time is $10^{-3} \mathrm{~s}$ and $\mathrm{R}$ is chosen to be $10^{9} \Omega$, $\mathrm{C}$ should be chosen as $1 \mathrm{pF}$. This should eliminate the pulser pulse undershoot with minimal resolution degradation.

\subsection{Gamma-Ray Source Normalization}

In some cases a better correction method is to use a gamma-ray source for deadtime and pileup

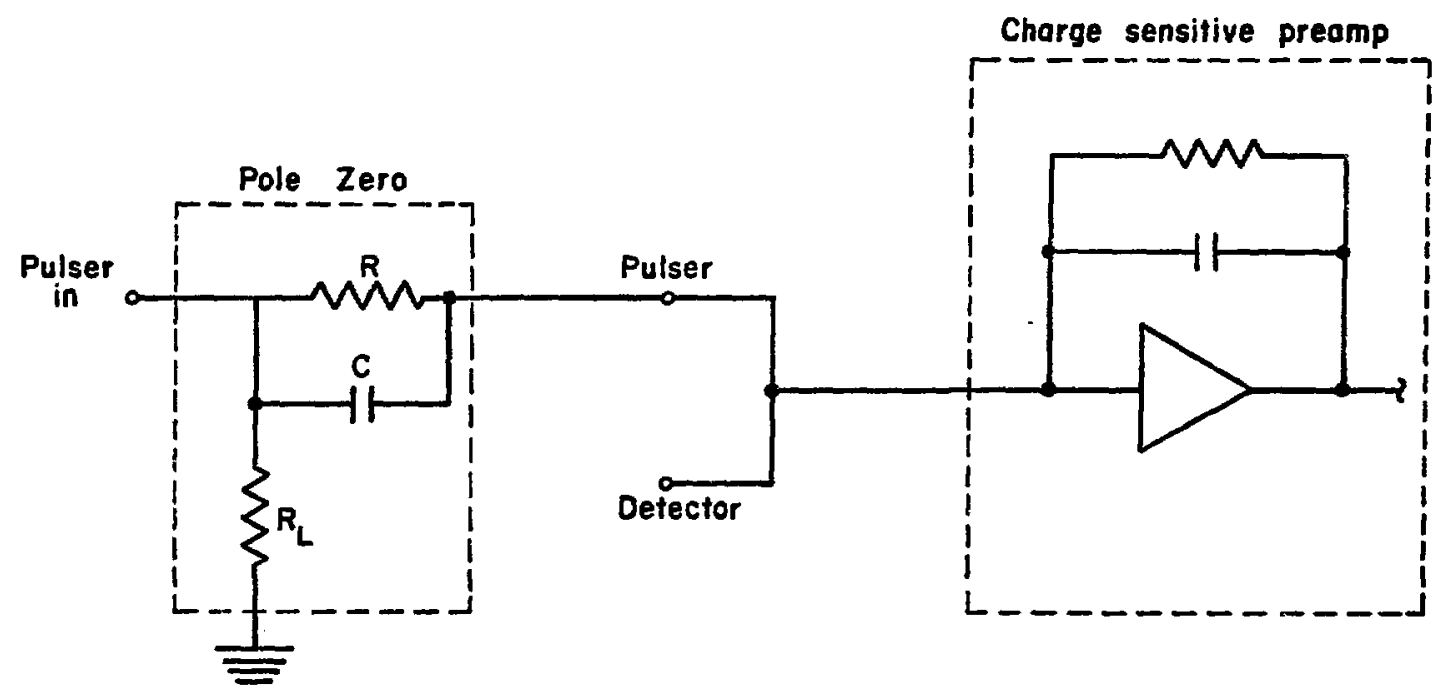

Fig. 6.1. A pole-zero cancellation circuit which can be added to the preamplifier pluser input to cancel the undershoot produced when using an external pulser to correct for system deadtime and pileup. 
normalization. A suitable source is positioned so that the detector always sees a constant flux from the source. Before making measurements, the normalization rate $R_{0}$ (counts in chosen full energy peak per unit time) is determined with no sample in the assay position. For actual measurements, the full energy peak rate $R$ of the normalization gamma ray is determined and all full energy peak areas of interest ara multiplied by the ratio $R_{0} / R$. This procedure assumes tiat all spectral peaks will suffer the same fractional loss from pileup and deadtime. With respect to pileup, the assumption is not strictly true. If none of the peaks involved is a significant fraction of the total rate (perhars $\leq 5 \%$ ), the errors involved will be small. The following expression relates the fractional pileup losses of two full energy peaks:

$$
\frac{\mathrm{L}\left(\mathrm{r}_{1}\right)}{\overline{\mathrm{L}}\left(\mathrm{r}_{2}\right)}=\frac{1+\mathrm{r}_{1} / \mathrm{R}}{1+\mathrm{r}_{2} / \mathrm{R}},
$$

where $L\left(r_{1} ;, L\left(r_{2}\right)\right.$ are fractional losses for peaks of rates $r_{1}$ and $r_{2}$, and $R$ is the total rate. Note that $r / R$ is the fraction of the total rate due to a given peak. As an example, if $r_{1} / R=.05$ and $r_{2} / R=.01, L\left(r_{1}\right) / L\left(r_{2}\right) \sim 1.04$. This says that if peak $\left(r_{1}\right)$ suffers a $10 \%$ loss due to pileup, peak $\left(r_{2}\right)$ will suffer a loss of $\sim 9.6 \%$. For most cases such a difference can be ignored, but the possibilities should be kept in mind.

The advantages in ustng a gamma-ray source are tiat there is no possibiiity of gain shifts for the correction peak relative to the rest of the spectrum, that the rate is easily varied, that no corrections need be matie for the nonrandomness of a pulser, and that, in general, a source is simpler than a pulser. The disadvantages are the difficulty in finding a source of just the desired energy with a ufficiently long half-life and the general increase in rate due to Compton events and "extra" gamma rays.

\subsection{Detector Generated Pulser}

A third correction procedure is to use a fast discriminator on the preamplifier output, scale the discriminator pulses by a fixed factor, and use this to generate a pulse whose rate is proportional to the gross rate of the system. This pulse is then fed back into the preamplifier. 6.4 The fed-back pulse is again subject to both pileup and deadtime. Comparing the number of pulses generated with the number appearing in the correspondfng peak gives the desired correction. This procedure has an advantage over a fixed-rate pulser in that it gives correct results even if the rates. vary during a count interval, as long as the spectral shape remains constant. The disadvantage is a more complex system. The considerations with respect to corrections for the nonrandomness of pulsers apply here, as do those on the variation of pileup between peaks of different rates.

The emphasis of this section is that both deadtime and pileup may easily be significant in MDA measurements and due care snould be exercised to first minimize and then correct fö both effects.

\section{REFERENCES}

6.1 R. D. Evans, The Atomic Nucleus (McGraw-Hil1 Book Co., Inc., New York, 1955), Chapter 28, pp. $785-827$.

6.2 I. Harms, "Automatic Dead-Time Correction for Multichannel Pulse-Height Analyzers at Variable Counting Rates," Nucl. Instrum. and Meth. 53, 192 (1967).

6.3 P. Quittner, Gamma Ray Spectroscopy (Adam Hilger Ltd., London, 1972), Chapter 10, Pp. 96-104.

6.4 H. H. Bolotin, M. G. Strauss, and D. A. McClure, "Simple Technique for Precise Determination of Counting Losses in Nuclear Pulse Processing Systems," Nucl. Instrum. and Meth. 83, 1-12 (1970). 


\section{ASSAY PROCEDIJRES}

The procejures and equipment corfiguration adopted for a particular assay problem will depend on many factors. Ameng those factors" will be the isotopes to be measured, the size and shape of the container, type and aegree of homogeneity, required throughput, desired accuracy, and the available equipment. No attempt will be made to prescribe optimum procedures for every situation; rather a few general procedures applicable to a large fraction of probable assay problems will be discussed.

\subsection{Transmission-Corrected Segmented Scanning}

It is observed that in the process of filling scrap and waste containers vertical variations frequently occur in the volume denstties of source and matrix materials. Radial inhomogeneities are less pronounced, and their effects can be substantially reduced by sample rotation. In such cases the container may be scanned as a vertical sequence of independent thin segments, each of which is assumed to be reasonably homogeneous. ${ }^{7.2}$ The differential measurements of uranium and/or plutonium activity and gamma-ray transmissions are obtained by scanning the rotating container and using detector collimation to define the segments. Combining transmission-determined correction factors on a segment-by-segment basis with the resolution of the Ge(Li) detector gives probably the best current method of doing gamma-ray assays of packages containing $\approx 10 \mathrm{~g}$ of ${ }^{235} \mathrm{v}$ or ${ }^{239} \mathrm{Pu}$. It must be recognized that the advantages of the segmentation procedure are gained at the loss of some degree of sensitivity; hence a system employing segmentation would probably not be used on samples containing $\leq 1 \mathrm{~g}$ of ${ }^{239} \mathrm{Pu}$ or ${ }^{235} \mathrm{U}$.

For a segmented, transmission-corrected gammaray assay the general spatial relationships of detector, collimator, assay sample, transmission so'rce, and the pileup and deadtime normalization source are shown in Fig. 7.1. The spucific arrangement shown is tailored to the assay of ${ }^{239} \mathrm{Pu}$ in cylindrical containers $\leq 20 \mathrm{~cm}$ in diameter. A rather detailed discussion of this assay problem, with comments concerning assay of other isotopes and package sizes, will suffice to illustrate the ideas and constraints involved.
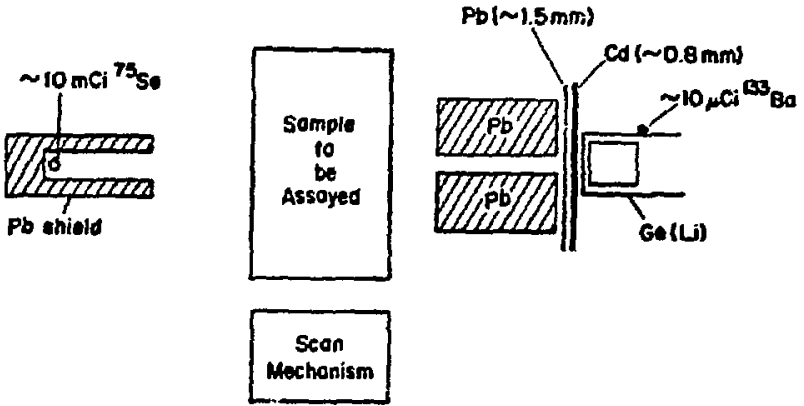

Fig. 7.1. General arrangements for segmented, transmission-corrected gamma-ray assay. The specific situation shown is tailored to the assay of ${ }^{239} \mathrm{Pu}$ in cylindrical containers $520 \mathrm{~cm}$ in diameter.

The sample container is positioned as close as possible to the collimator (the constraints are often bagging and/or container handles) to maximize count rates and give the best segment resolution. The "segments" overlap somewhat as determined by the sample size, collimator dimensions and their relative positions. For the case illustrated in Fig. 7.1 a collimator $\sim 1.25 \mathrm{~cm} \mathrm{high}$ and $\sim 10 \mathrm{~cm}$ deep (often composed of two standard lead bricks properly spaced) provides a reasonable trade-off in sensitivity and spatial resolution. For $30-$ and 55-gal drums a collimator $\sim 5 \mathrm{~cm}$ high and $\sim 20 \mathrm{~cm}$ deep has been $:$ reasonable choice. The spatial resolution of the segments cannot be as sharp in the latter case but it is still sufficient to provide useful information on the degree of uniformity of material distribution. The ofvious cholce of collimator material will usually be lead. If space is a consideration, a tungsten alloy may be used.

Tr maximize count rates the detector will be as close as possible to the collimator. For the plutonium measurement a filter of lead $\left(\sim 1.5 \mathrm{~mm}^{\prime}\right.$ and cadmium ( $0.8 \mathrm{~mm}$ ) serves to reduce the rate of low energy events from ${ }^{241} \mathrm{Am}$ and the $x$ rays of both plutonium and lead. As discussed in chapter 6, such filters are useful in reducing the effects of pileup and deadtime. The exact filter configuration will depend on the sample. For ${ }^{235} \mathrm{U}$ assay the cadmium alone should suffice, because there will not be the $60-\mathrm{keV}^{241} \mathrm{Am}$ flux found in plutonium materials. 
In this case of ${ }^{239} \mathrm{Pu}$ assay ${ }^{75} \mathrm{Se}$ is used as the transmission source because it gives the most accurate correction. Its $400-\mathrm{keV}$ gamma ray is clcse in energy to the $414-\mathrm{keV}$ gamma ray of ${ }^{239} \mathrm{Pu}$. Since it is lower in energy, its Compton continuum dons not significantly decrease the ${ }^{239} \mathrm{Pu}$ sensitivity as would the continuum from ${ }^{137} \mathrm{Cs}$ or ${ }^{22} \mathrm{Na}$. A source strength of $\sim 10 \mathrm{mCi}$ should provide usable intensity for at least cne year in spite of the short 120-day half-1ife of ${ }^{75}$ Se. Position adjustment and judicious lead filtering are used to adjust the ${ }^{75}$ Se count rate to the desired level.

The transmission source itself should be encased in a collimacor-shield to avoid undue personnel expcsure.

The $356-\mathrm{keV}$ gamma ray from the ${ }^{133} \mathrm{Ba}$ source is used for deadtitne and pileup correction as well as for spectral stabilization. It has no gamma rays which incerfere with either the $414-\mathrm{keV}$ gamma ray of ${ }^{239}$ Pus or the 400-keV gamma ray of ${ }^{75} \mathrm{Se}$. The 10.4-y half-life is also convenient. A source of $\sim 10 \mu \mathrm{Ci}$ is generally adequate and may be positioned right on the detector housing to give a proper rate. Fu: i.e assay of different isotopes, other combinations of transmission source, correction source, and assay gamma ray will be necessary. Table 7.1 gives several useful combinations. It is possible (see Chapter 6) to use a pulser instead of the source, if one is available with adequate rate and stability.

Segmented scans may be accomplished in several ways, which may be divided under the general headings of discrete and continuous scans. In a discrete scan the sample is positioned, counted while fixed vertically, repositioned, counted again, etc. In a continuous scan the rotating sample moves with a constant speed past the collimator. The count dwell time is often chosen as the time required for the container to move the height of the coiliuator, Both methods would give acceptable results, and the decision of which to use might be based on hardware availability. The continuous scan scheme probably gives a better average transmission within segments. For the ${ }^{239} \mathrm{Pu}$ assay system shown in Fig. 7.1 the continuous mode is used with a vertical speed of $\sim 0.127 \mathrm{~cm} / \mathrm{s}(0.05 \mathrm{in.} / \mathrm{s})$ and a count dwell time of $10 \mathrm{~s}$. The scan of a container $25 \mathrm{~cm}$ high takes $\sim 200$ seconds. All analysis and sample changing
TABLE 7.1

USEFUL COMB!NATIGIY OF SOURCES

\begin{tabular}{ccc}
$\begin{array}{c}\text { Isotope } \\
\text { Assayed }\end{array}$ & $\begin{array}{c}\text { Transmission } \\
\text { Source }\end{array}$ & $\begin{array}{c}\text { Correction } \\
\text { Source }\end{array}$ \\
\cline { 2 - 3 } $238_{\mathrm{Pu}}$ & ${ }^{137 \mathrm{Cs}}$ & $133_{\mathrm{Ba}}$ \\
$766.4 \mathrm{keV}$ & $661.6 \mathrm{keV}$ & $356.3 \mathrm{keV}$ \\
$239 \mathrm{Pu}$ & ${ }^{75} \mathrm{Se}$ & $133_{\mathrm{Ba}}$ \\
$413.7 \mathrm{keV}$ & $400.1 \mathrm{keV}$ & $356.3 \mathrm{keV}$ \\
$235_{\mathrm{U}}$ & $169 \mathrm{Yb}$ & $57 \mathrm{Co}$ \\
$185.7 \mathrm{keV}$ & $177.2,198.0 \mathrm{keV}$ & $122.0 \mathrm{keV}$ \\
$238_{\mathrm{U}}$ & $534.8 \mathrm{keV}$ & $137 \mathrm{Cs}$ \\
$1001.1 \mathrm{keV}$ & $203 \mathrm{Hg}$ & $661.6 \mathrm{keV}$ \\
$237 \mathrm{~Np}$ & $279.2 \mathrm{keV}$ & $185.7 \mathrm{keV}$ \\
$311.9 \mathrm{keV}$ & & $235 \mathrm{H}$
\end{tabular}

might take another $100 \mathrm{~s}$, so assays of $25-\mathrm{cm}-\mathrm{tali}$ containers might take $5 \mathrm{~min}$ each. The ${ }^{133} \mathrm{Ba}$ and ${ }^{75}$ Se sources are genc.rally adjusted to give $\sim 10^{4}$ counts/segment in the full-energy peaks of interest. For better precision or greater sensitivity the scan speed may be decreased if the longer assay time is acceptable. A compromise must be reached between precision and throughput.

In all segmented scans the computations are performed on a segment-by-senment basis using the appropriate correction factors and corrections for deadtime and pileup discussed previously. Appendix $C$ lists the relevant assay equations and the appropriate counting precision equations for this situation. 7.2

\subsection{Variations of Transmission-Correction Procedures}

Numerous variations are possible to the procedures described above. Two such situations are commonly encountered and will be discussed.

If a category 0 : scrap or waste exists which is a reasonably uniform mixture of matrix and material, and if the containers are filled to a known and constant depth, the segmentation may be eliminated. The detector can then be backed up far enough to reduce $1 / \mathrm{r}^{2}$ effects to an acceptable 
level, and the transmission measured at a single location near the middle of the container. If the content- .. uniformly distributed, the correction factor so uetermined will apply to the whole container. Such a system will generally have a better sensitivity than one using vertical collimation. The sample may also be scanned up and do'n over a fraction of its height and thus average the measured transmission over a larger fraction of the sample.

If the transmission gamma ray is higher in energy than the assay gamma ray, its Compton continuum will decrease both the precision and sensitivity of the assay peak measurement. Even if the assay gamma ray is of higher energy, pileup from low energy events can produce background under the assay peak. If the utmost sensitivity and precision is desired and i decrease in throughput is acceptable, an assay may be done in two scans. The container is first scanned with the transmission source to obtain applicable correction factors. Then the transmission source is shielded or removed find a scan is made of the assay gamma ray. - using ${ }^{169} \mathrm{Yb}(177 \mathrm{keV}$ and $198 \mathrm{keV})$ as a transmission source for the assay of ${ }^{23 j} \mathrm{U}$ (186 keV) this two-scan scheme is particularly useful.

\subsection{Differential Absorptinn Methods}

The data acquisition procedures for differential absorption methods are quitc simple. The possibilities and Iimitations of the method have been outlined above in Section 5.4 and in Appendix $B$. If the sample meets the necessary assumptions, the assity consists of acqutring a high resolution spe trum with sufficient activity in the required peaks to sive the desired assay preciston. As in other procedurcs. sample-to-detector distance will be a compromise between minimizing $1 / \mathrm{r}^{2}$ ef fects and maximizing count rate. Usual cautions must be observed with respect to minimization of and correction for deadtime and pul- -ileup. The sample w111 probably be rotated but not scanned. Because of the simplicity of the data acquisition procedures, the method is attractive where there is a sufficient number of samples to which it clearly applies.

\subsection{Nal Detector Procedures}

The advantages and limitations of NaI detectors relative to $\mathrm{Ge}(\mathrm{Li})$ or intrinsic Ge detectors have been discussed previously. That discussion indicates that $\mathrm{Ge}(\mathrm{Li})$ or intrinsic $\mathrm{Ge}$ is preferred (ignoring factors of cost) except in cases where the potentially greacer efficiency of NaI is required. The assay of laxge containers (e.g., 30and 55-gal drums) of low-leve! waste is such a situation. Rapid screening wherein a fraction of items may he flugged for a more careful assay by other methods is also a common application.

Many of the ideas and principles in doing assays with high resolution detectors directl: appl: to the use of NaI. A few comments should tri made on significant differences. Pulse pileup is not the prublem with NaI that it is with Ge(LI). Such snorter ampliffer time constants may be used with resulting output pulses as narrow as 1 ph full width. This reduces the problem of pileup and allows higher count rates. The wide windows used for peak area determinations also tend to reduce pileup effects. It must be noted, however, that, although the effect can be much smaller $(5-10 \%)$ than in Ge(Li) detectors, it is more difficult to make corrections. The system is usually so set up to 1 imit the count rates such that pileup may be ignored.

A last cautionary item concerns backgrounds and background subtractions. In an; gamma ray assay, whether $\mathrm{Ge}$ (Li) or NaI, the detector should De carefully shielded. It should be possible to eliminate all contributions to the full-energy peaks of interest save from th: sample being assayed. The only "background" remaining is the continuum under the full-energy peaks, and these are subtracted out by one of the usual methods. Background runs are not required if the detectors are properly shielded and if the assay is based on fullenergy peak areas only. An occasional count to assure that the background peak areas are indeed zero is all that is necessary. Occasionally procedures are employed in which continuum subtraction is not used. In such cases backgrounds must be more carefully considered, as the continuums under fullenergy peaks may be more easily changed than the actual peaks. 


\section{REFEREHCES}

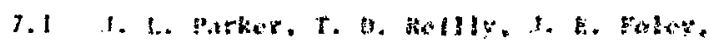

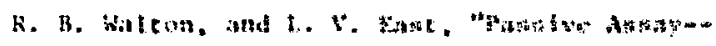

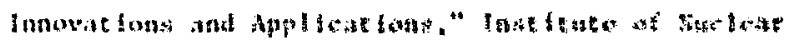

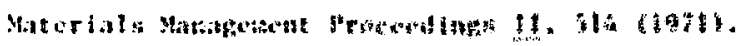

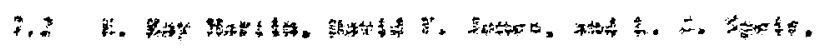

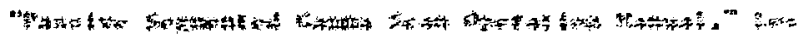
A 


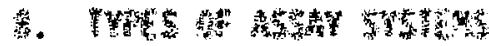

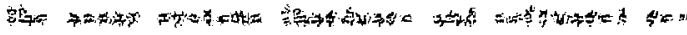

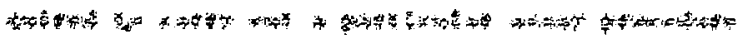

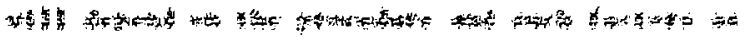

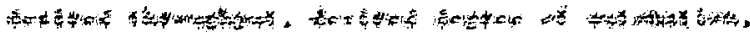

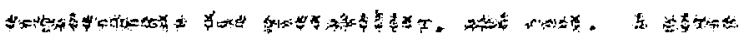

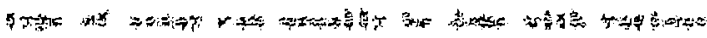

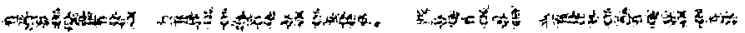

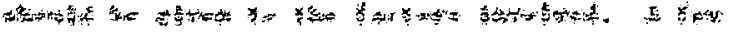

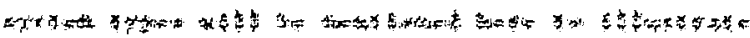

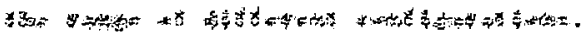

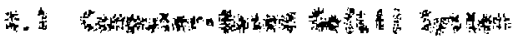

\section{2}

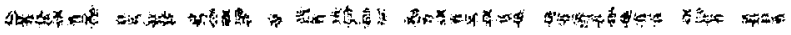
然

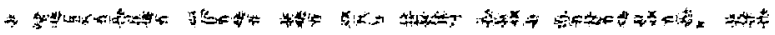

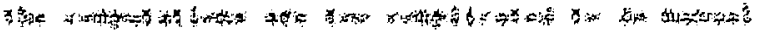

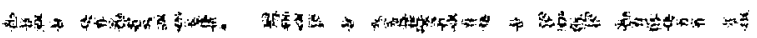

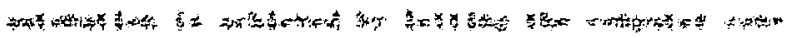

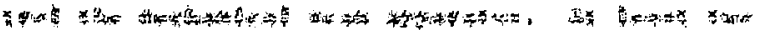

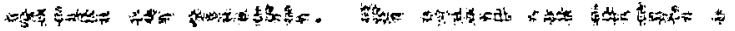

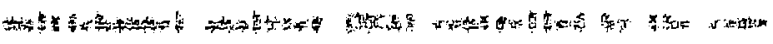

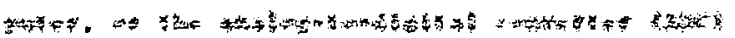

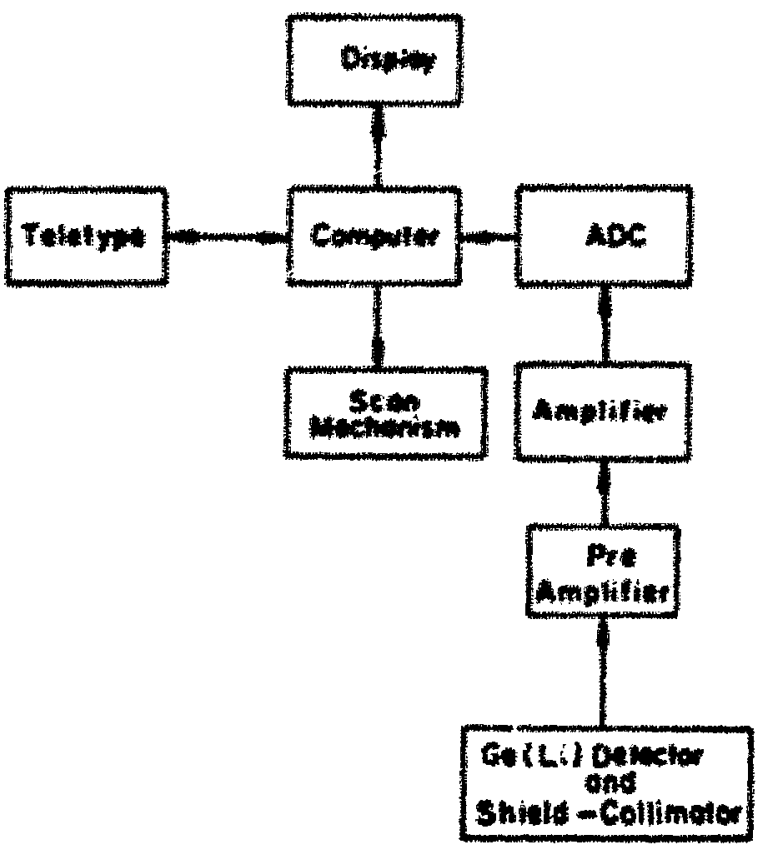

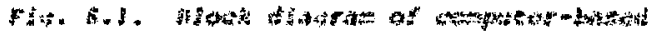
(2)

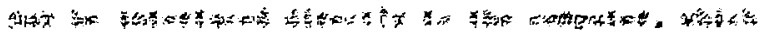

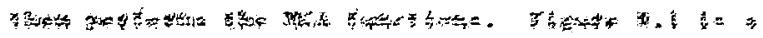

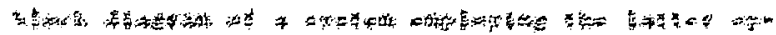

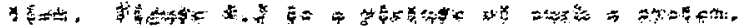

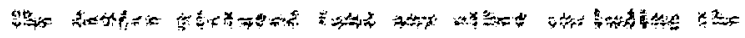

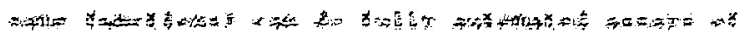

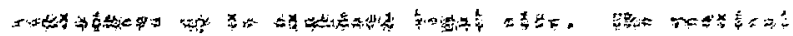

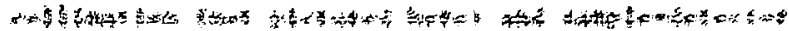

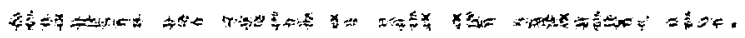

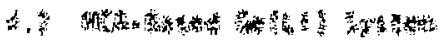

Ty

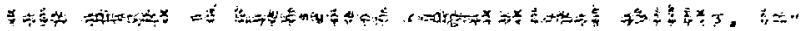

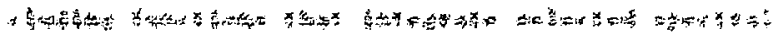
\$

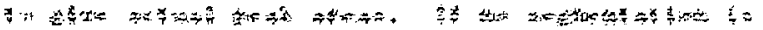

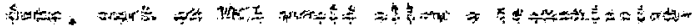

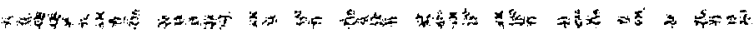

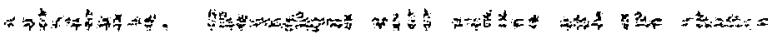

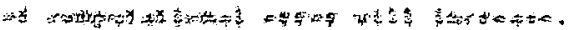

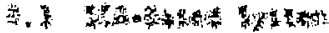

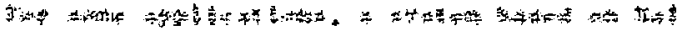

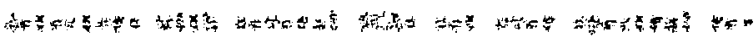

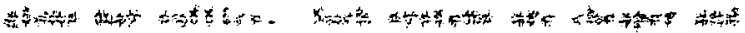

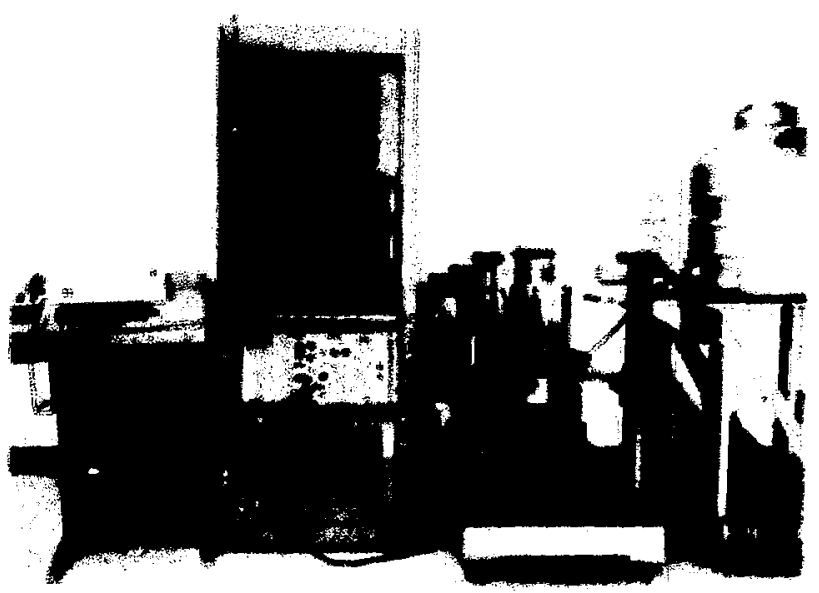

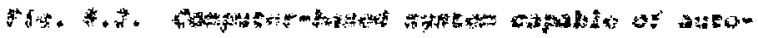

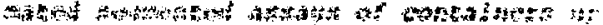

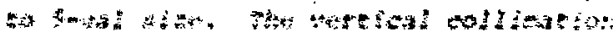

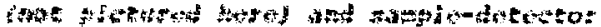

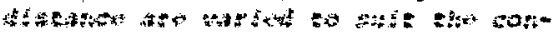

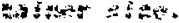




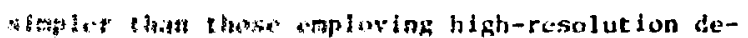

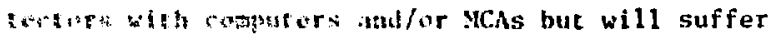

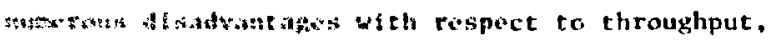

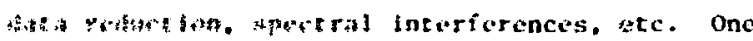

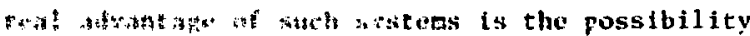

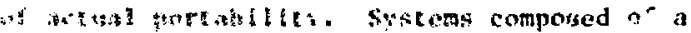

shielded NaI probe and bactery-powered electronics exist and can be easily carried by one man. Data reduction can often be done with a pocket calcu1ator. Such systens offer qualitative and even reasonably quantitative assay capability. 


\section{STANDARDS}

All gamma-ray assays should be misio relative to a standard which is representative of the material being measured. Consequently adequate standards are a very vital part of any assay system. A good general guide to NDA standards and calibration procedures is given in a recent American National Standard, ANSI N.15.20.9.1 This guide is recommended to potential users of gamma assay equipment. The standards essentially provide a measurement of the detector efficiency, the specific activity of the signature of interest, and the effects of sample geometry (size, shape, and sample-to-detector distance). in systems where a measured attenuition correction is not used, the standard is also expected to have the same attenuation as the unknown samples This latter procedure is not recommended. In general terms the purpose of the standards is to define the callbration factor, K, in Eq. (1,1). Formally

$$
K=\frac{\mathrm{CR}_{s} \cdot \mathrm{CF}_{\mathrm{s}}}{\mathrm{M}_{\mathrm{s}}},
$$

where

$$
\begin{aligned}
K= & \text { calibration factor (counts/g of iso- } \\
& \text { tope of interest), } \\
M_{S}= & \text { known mass of emitting isotope, } \\
C R_{S}= & \text { measured count rate from the standard, } \\
C F= & \text { attenuation correction factor for the } \\
& \text { standard. }
\end{aligned}
$$

The following is a general discussion of the fabrication and use of gamma-assay standards.

Ideally the standard should be nearly identical to the unknown, but this is usually a fiction, particularly for the measurement of waste and scrap. A more reasonable criterion is that the standards have the same size and shape as the unknowns. In principle, it is possible to use different size standards and compute the effect of the different size on the standard response. Such coinputations are complicated if done correctly, and subject to large errors if not. In general, this approach is not recommended; nevertheless, it may be the only practical one for certain types of samples, particularly large and/or irregular shapes. Since standards are generally required for each different size sample, this should be a great incentive to minimize the number of different size conealnert used in a gizen facllity and in the lndustery as a whole (more on thls in the next section).

The main effect o: differenc matix material: is to vary the sample at:cnuation. Uranius and plistonfum are found in combination with a side range of $\mathrm{mo}^{\text {: }}$ ix materials (particularly in the scrap and waste categorles). This is the crux of the problem with assay procedures which do not usi a measured atteriation correction (external sourcs transmission or differential absorption). For such procedures it is necessary to assume that the unknowns have the same matrix attunuation as the standards. There is no way to verify this assumption. There may be some categories of material where the at:enuation does vary very little from sample to sample. Product materials such as fucl pins or plates are a good example. Here the assay is mainly to show a deviation from a mean (defined by the standard), and a medsured at tenuation correction is unnecessary in many cases. Such is obviously not the case for scrap and waste materials. The bulk density of most powders can be changed over a considerable range by agitation and vibration. The attenuation (and hence the measured sample gamma activity) of a container of incinerator ash can be changed significantly just by glving it a vigorous shaking, thus decreasing the bulk density of the contents. The matrix material (and its attenuation) will vary from sample to sample even within a single material category. Even if standards of different attenuation properties are aval1able, there is no way to choose which attenuation to apply. Large measurement biases are almost always introcuced when using procedures which do not have a measured attenuation correction. No matter how "representative" the standards are claimed to be, it is usually impossible to guarantee that the unknowns really have the same attenuation as the standards. Thus the use of a measured attenuation correction is strongly recommended.

The purpose of the attenuation correction (transmission or differential absorption) is to measure the degree to which the attenuation of the unknown differs from that of the standard. In principle, a single standard of each container size will 
ristof It

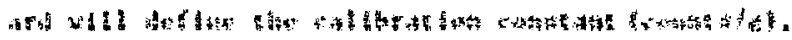

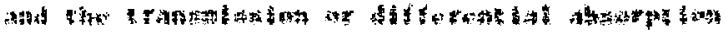

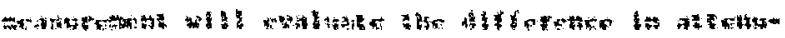

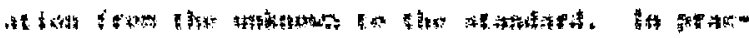

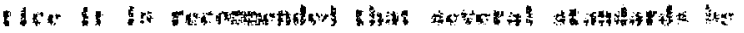

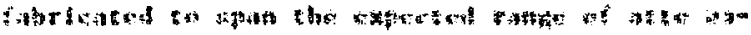

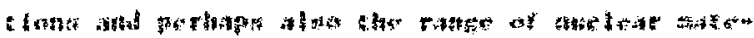

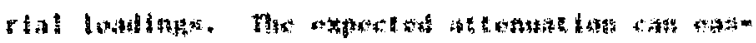

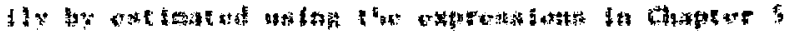

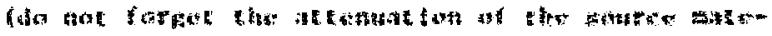

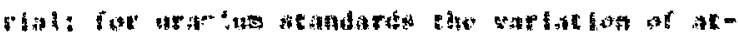

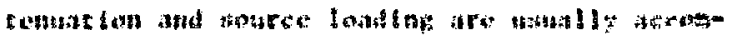

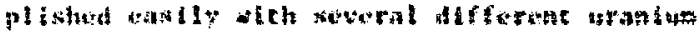

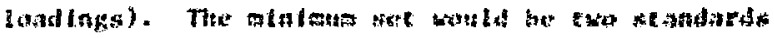

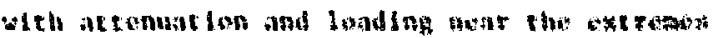

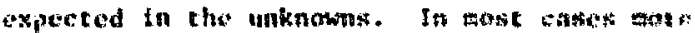

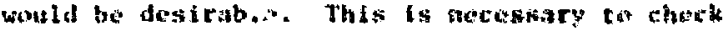

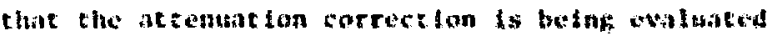

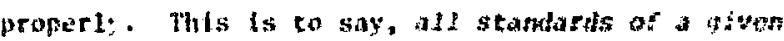
size container should yiold the satie collingtion factor (counte/g). The standiards med not cover every expected matrix, anly the different she containers. One way of coverting the expected actenuat Ions, however, may be to construct one standard In each of the expected matr $\mathrm{x}$ categortes.

If transmission measurements are used, the assay is quite insensteive to the chemical comm posttion of the matrix. The important parameter is the absorption coefilclent of the material. and this is obtained from the transmissio: measurement. Thus it is not necessary to duplicate the actual matrix material in the standards (though this may sometimes be desirable when attempting to track down measurement biases). Consider, for example, the range of atcenuations found in small containers (< $15 \mathrm{~cm}$ diam) of incinerator ash and other solid scrap residues (e.g., leached solids, sand-slag-crucible). There is a wide range of attenuations involved due to different materials and processes (Incinerator ash from one plant may be quite different frum that of other plants). This attenuation range $\left(\mathrm{CF}_{414} \approx 1.2-3.0\right)$ can be quite well covered by using matrices of diatomaceous earth, graphite powder, and fine-grained quartz or MgO sand [the MgO sand should be avoided if the standards are to be used for neutron coincidence counting also, due to the large $(\alpha, n)$ b.gckground

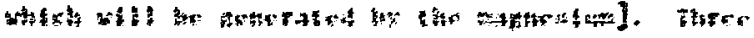

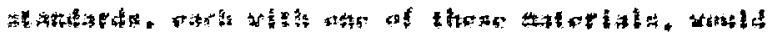

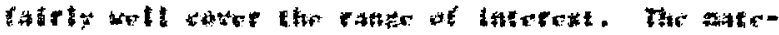

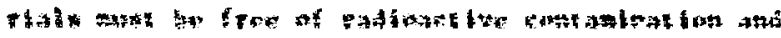

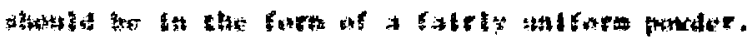

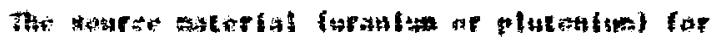
athe

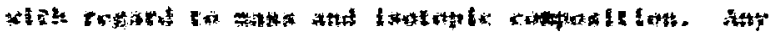

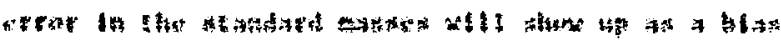

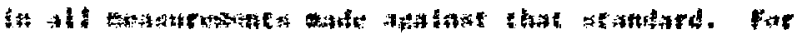
教 ack

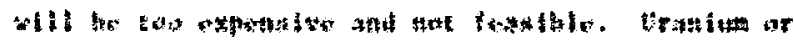

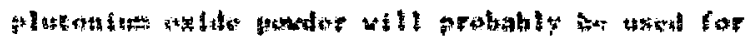

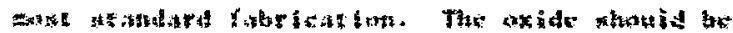

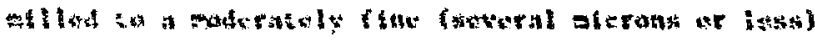

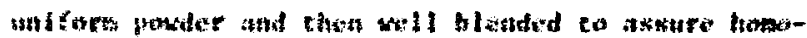

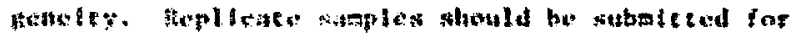

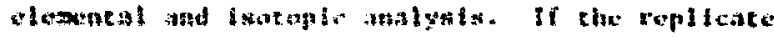

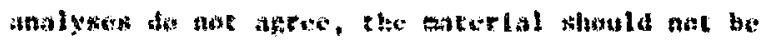

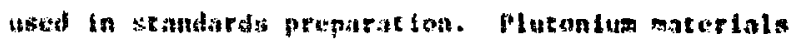

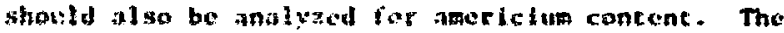
freparation and analysis of the sonted antertal should be carefully documenced and saved as part of the certiflcation of the scandards in wich it is used.

The sourze and ratefx material mugt now be combined. The uianiur. or plutonium oxtde should be carefully weighed into the destred quantities for the standards. The weigiting should be done to a relative accuracy of at least $0.1 \%$. The matrix material should be weighed also; this need not be as sccurate ( $1 \%$ is more than adequace). The source and matrix materials must be carefully blended and homogenized to assur. a uniform distribution in the calibration standards. This point is very important and should be considered as the cruclal goal throughout the design and fabrication of the standards. As has been explained in previous sections, nonuniform distribution introduces errors in gammaray measurements. Steps are always taken to mininize these effects (rotation, segmented scans, etc.). These will usually not eliminate such effects. Nonuniform calibration standards will usually lead to biases in the measurement system. Consider a large number of unknown samples. The distribution of material in any single container will usually show some degree of nonuniformicy. This may be reflected 


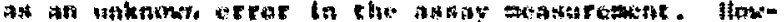

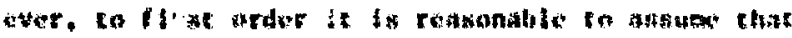

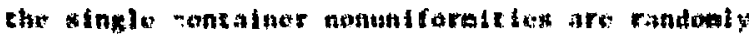

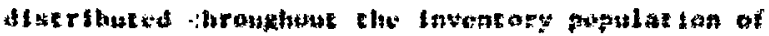

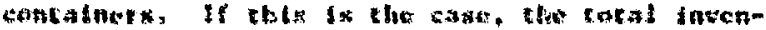

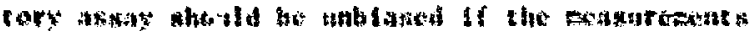

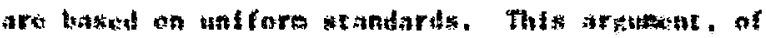

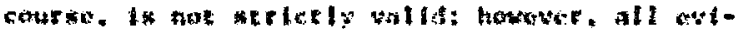

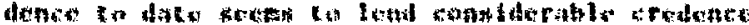

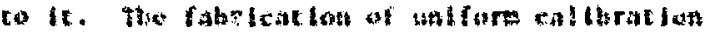

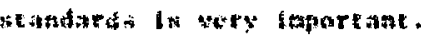

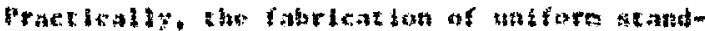

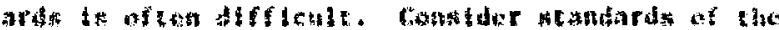

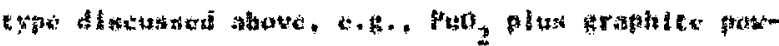

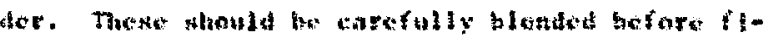

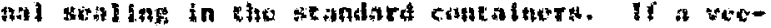

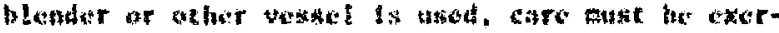

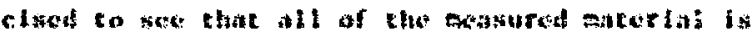

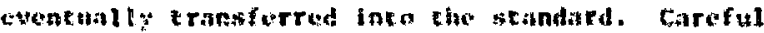

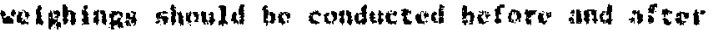
blending to afuck for thy loss of waterlal. Shen

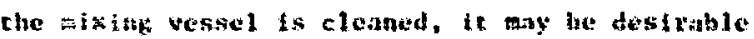
to assay the cleantng artertals iustng high senstcivity counting tetholques) to verify that ho thacerial his bech lost. The use of agliators or vibrntors for mixing is not rwcomended as this seems to segregato racher than blend some mixtures of matertal. Powder mixtures may be expected to setcle with time; the source macerial should be suspected of setting out of the mixture and altering the initial uniform distribution. Working standards should be scanned routinely leven if this is not the normal measurement procedure) to verify that this is not accurring. Tt is usually desirable to leave the standard containers not quite full so that they may be shaken from time to time to help maintian the uniform distribution of material. Most experience to date with the powder mixtures discussed above indicates that the settling and segregation is not a severe problem.

other techniques for achieving uniform standards bave been suggested and tried. Some of these involve putting the source material in solution, soaking the matrix in the solution, and then drying the combination. Several standards have been made at Los Alamos by drying plutontum nitrate solution on $\mathrm{MgO}$ sand. The process would seem to have merit but has not been completely satisfactory

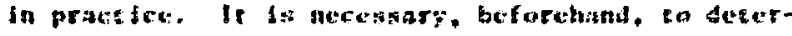

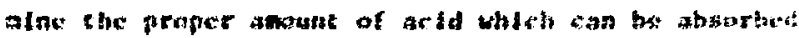

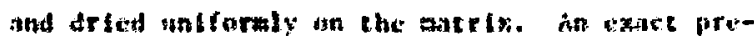

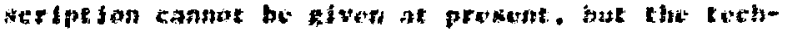

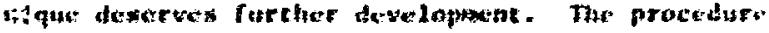

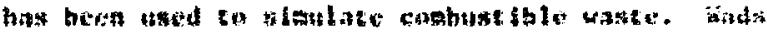

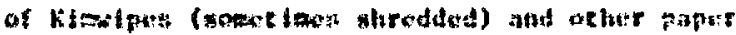

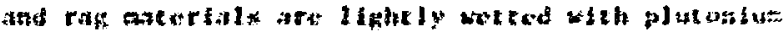

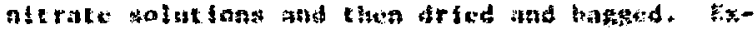

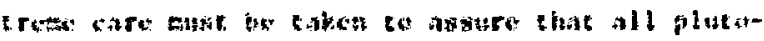

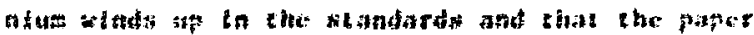

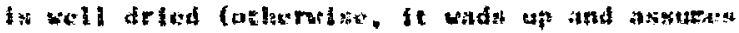

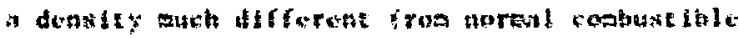

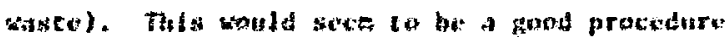

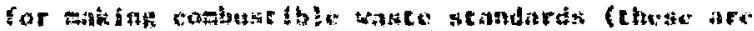

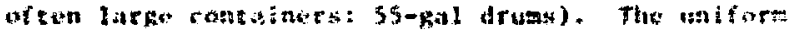

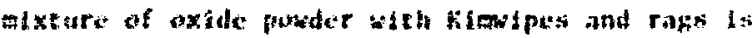

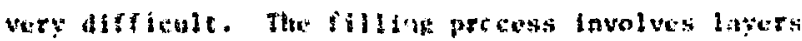
of shreddud anerix very ifght ly spristited bith

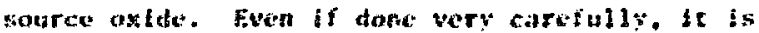

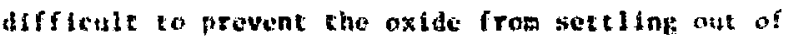

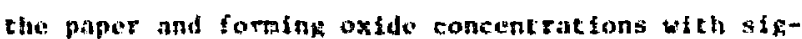
niflcant sulf-absorption. For plutontus assias based on the 4la-kel gaman (with its higher penet bility), this procedure can be used. General filectric has sucessifully fabricated mixed oxide waste standards ustag the oxide powder. $9.2,9.3$ The procedure is strongly not recommended for uranium waste standards (fo: 186-keV assay). To illustrace this, an experience ar. Los Mlamas should be cited. Natural and highly enriched uranium waste standards were fabrlcated as 1 -gal bags to be loaded into a 30- or 55-gal drum. The procedure was to place a strong plastic bag in a 1-gal hospital dressing can. The desired quantity of $\mathrm{U}_{3} \mathrm{O}_{8}$ (individual bags had 1,2 , or 5 grams) was divided into 10 or more roughly equal portions. A thin layer of shredded Kimwipes was placed in the bottom of the bag and one of the oxide portions sprinkled cn it. This was repeated until the oxide was $a 11$ in and the bag full. As each new layer was added, it was compressed to hold the oxide in place, In spite of this, when the standards were carefully scanned and assayed for certification, it was found that they were unusable due to significant self-absorption in the oxide concentrations (lumps) which formed. Even one gram dispersed in the gallon bag showed nearly $20 \%$ microabsorption which would not be corrected by 


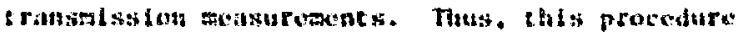

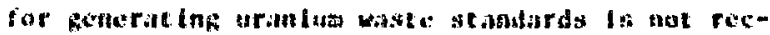

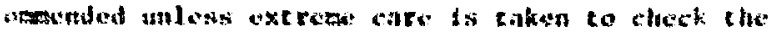

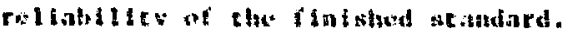

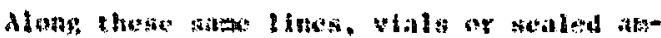

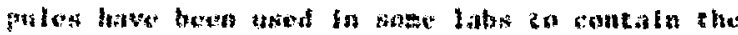

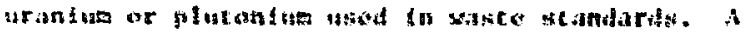

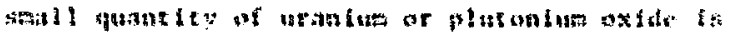

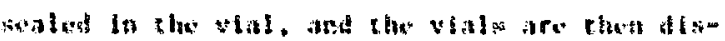

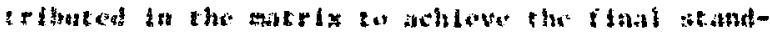

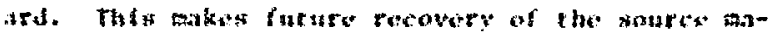

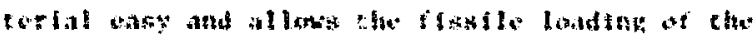

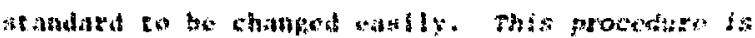

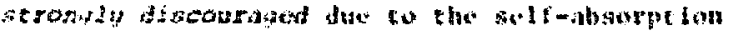
whin the sompere sapsule.

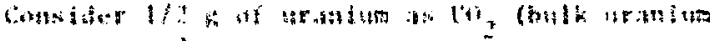

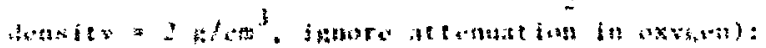

It concalned in a cube, the dimensiton of that cube is

$$
\begin{aligned}
& \left(0.5 \mathrm{~g} / 2 \mathrm{~g} / \mathrm{cm}^{3}\right)^{\frac{1}{3}}=0.63 \mathrm{~cm} \\
& U: \mu(186)-1.5 \mathrm{~cm}^{2} / \mathrm{g} .
\end{aligned}
$$

Using Eq. (5.2a).

$$
\begin{aligned}
\text { pix } & =\left(1.5 \mathrm{~cm}^{2} / \mathrm{g}\right)\left(2 \mathrm{~g} / \mathrm{cm}^{3}\right)(0.63 \mathrm{~cm})=1.9 . \\
C F & =\frac{1.9}{1-e^{-1.9}}=2.2 .
\end{aligned}
$$

That is, less than half of the 186-kev gamma rays will get out of this volume unat tenuated. For $\mathrm{PuO}_{2}, \mu(414)=0.26 \mathrm{~cm}^{2} / \mathrm{g}$, so this becomes

$$
\begin{aligned}
& \mu x=(0.26)(2)(0.63)=0.3, \\
& C F=1.17 .
\end{aligned}
$$

Though the self-attenuation is smaller, it still represents a nonnegligible error which will show up as a bias (assay will be high) on all measurements. Eurthermore, the self-attenuation of the vial will change as the source material shifts around in the vial. Distributed vials of fissionable material should definitely not be used.

After the standards are fabricated, they should be carefully measured to verify their contents. Uniformity of loading can be checked by careful segmented gamma scans and by radiography. The fissile contents should be measured to check for consistency with other similar gamma standards. If other assay techniques are available (neutron coincidence counting, active delayed neutron assay,

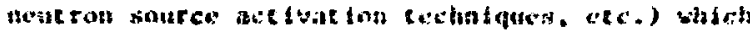

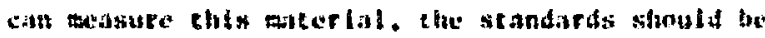

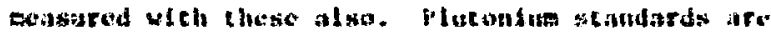

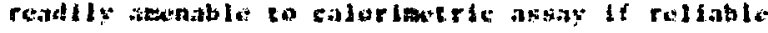

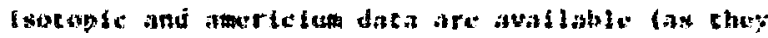
should bo (ar the standardal). It aly also be salua-

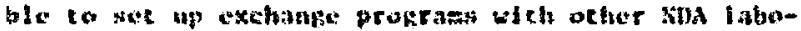

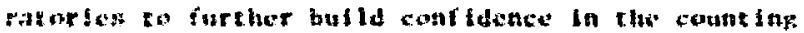

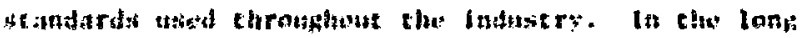

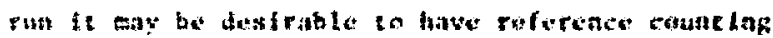

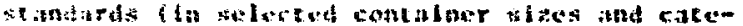

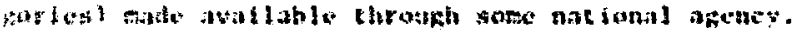

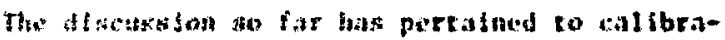
toth stindards used for tecteratning cite rosponse

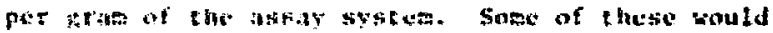

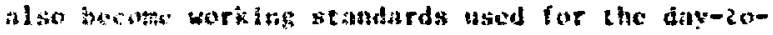
day colltration and disect of system operation. Ratche procedures are neved to assure that the aysem calibrat bof rematns constant. In outline of sttch adastrenent quiltey astarince programs is piven in the Aast standard refurred to earbler. ${ }^{\dagger} \mid$ In additon to these it may be necessary to fabricate additional standarts to document the $1 \mathrm{tm}$ t of escor of the system. The mafor errozs in a gamana assay system arise from nonuniform distributions of materlal. This may Include source material, matrix material, varfation with respect to density alone, or variactons of elemental and even isotopic concentration. Estimates of the degree of this variation can be rade computationally by analyzing the effect of loading variations on attenuation and counting efficiency. It may also be desirable to fabricate some nonuniform standards and measure the effect of such distributions on the system. For this a useful approach is to bufld a modular system of standards with small indfuidual standards which may be arranged in different configurations in the larger standard container. The Individual modules are usually made as uniform standards but with a variety of matrices and source loadings. They can then be loaded in the main container and counted to test the effect of various nonuniform distributions on the system performance. The Rocky Flats plant of the Dow Chemical Company has used such a nodular set of standards for many years. ${ }^{9.4}$. Such studies are probably not feasible for every plant, but rather some criteria should be developed at the larger facilities and the national laboratories (this would be 


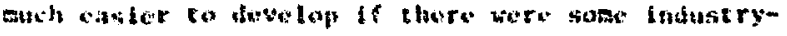

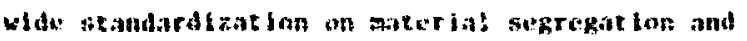

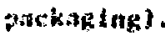

\section{REFERENCES}

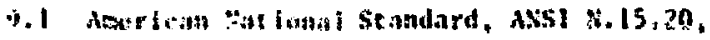

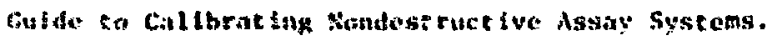
sertiong of parefcular incerest include 5.4-nources of Wh error (pp. 5.7-5.15), 6-- physical

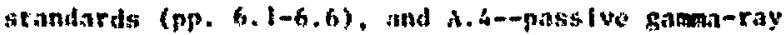
thouts (p. A.8-A.12).

9.2 Handbook of Mixed Plitonium-l'ranlum nxide Nondestructive Assay Reference Standards, General
Fiectic company internal report, to be published; coples should be avallable from D. M. Bishop. GF. Villerteos Nuclear Center.

9.3 S. L. Parker and T. D. Reilly, Los Alamos Sclent Iflc Laboratory report LA-5197-PR (1972), pi. 14-15. This article describes measurements made on the waste standards of Ref. 9.2.

9.4 L. W. Doher and J. D. McBride, "A Control Design for Plutonium Counting Systems," Proceedings of the Fleventh Annual Meeting of the Isxy, May, 1970, PP. 71-84. 


\section{PACKAGING}

Gamma-ray assny systems are more iffected by varlations in sample size and packaging procedures than are other NDA techniques. Calibration factors (K) change with size as do some other system parameters, such as collination and source-to-detector distance. The accuracy and reliability of gammaray assay is much improved if all materials are measured in the same size container (or a very limited number of different size containers). This minimizes the number of standards required (each different size requires different standards).

Material for gamma-ray assay should be packaged in small containers to minimize gamma attenuation. The important dimension is the container diameter as this determines the magnitude of the absorption. In general, a higher measurement accuracy is obtainable on smaller diameter containers. The effect of container diameter is illustrated in Table 10.1. The numbers in this table assume the following parameters:

(1) Matrix attenuation coefficient (low $Z$, (20):

$$
\begin{aligned}
& \mu_{186}=0.13 \mathrm{~cm}^{2} / \mathrm{g} \\
& \mu_{414}=0.095 \mathrm{~cm}^{2} / \mathrm{g} .
\end{aligned}
$$

(2) Matrix density: $1.0 \mathrm{~g} / \mathrm{cm}^{2}$ (many powder scrap residues such as ash, sand-slag-crucible, leached solids, etc., have a bulk density in the range $0.5-1.5 \mathrm{~g}\left(\mathrm{~cm}^{2}\right)$.

(3) Source (uranium or plutonium) attenuation coefficient :

$$
\begin{aligned}
& \mu_{186}=1.5 \mathrm{~cm}^{2} / \mathrm{g} \\
& \mu_{414}=0.25 \mathrm{~cm}^{2} / \mathrm{g} .
\end{aligned}
$$

(4) The maximum total attenuation correction factor (CF) consistent with reliable routine assay is about 4.0. This corresponds to a transmission actoss the can diameter of 1ess than $1.0 \%$. Gamma assays can be made with correction factors of $\mathbf{5 . 0}$ (transmission about $0.2 \%$ ) or higher; but these are difficult, require great care, and should not be made as a part of a routine assay procedure.

(5) The colunus $C F_{186}$ and $C F_{414}$ give the cor-

\begin{tabular}{|c|c|c|c|c|}
\hline \multirow[b]{2}{*}{ Diameter $(\mathrm{cm})$} & \multicolumn{2}{|c|}{ Matrix Only } & \multirow{2}{*}{$\frac{p_{U}{ }^{a}}{g / \mathrm{cm}^{3}-U}$} & \multirow{2}{*}{$\frac{\rho_{p_{u}}{ }^{b}}{\mathrm{~g} / \mathrm{cm}^{3}-P_{u}}$} \\
\hline & $\mathrm{CF}_{186}$ & $\mathrm{CF}_{414}$ & & \\
\hline $\begin{array}{lr}2-1 i t e r & \text { poly } \\
\text { bott1e } & 10\end{array}$ & 1.61 & 1.43 & $0.18(360 \mathrm{~g})$ & $1.3(2600 \mathrm{~g})$ \\
\hline 15 & 1.98 & 1.68 & & \\
\hline
\end{tabular}
rection factor for the matrix alone (no uranium or

\section{TABLE 10.1}

EFFECT OF PACKAGE SIZE ON GAMMA-RAY ATTENUATION

1-ga1 hospltal

$\begin{array}{lccccc}\text { can } & 20 & 2.38 & 1.95 & 0.05(190 \mathrm{~g}) & 0.4(1500 \mathrm{~g}) \\ & 25 & 2.81 & 2.23 & & \end{array}$

5-gal bucket

55-gal drum

This is the maximum uranium content consistent with the criterion $\mathrm{CF} \leq 4.0$. The first number is the uranium density in $\mathrm{g} / \mathrm{cm}^{3}$. The second is the uranium content in $\mathrm{g}$, assuming a full container. The assay energy is $186 \mathrm{keV}$.

b This is the maximum plutonium content consistent with the CF $\leq 4.0$ 1imit. The assay energy is $414 \mathrm{keV}$. 
plutonium). The last two columns give the maximum uranium or plutonium concentration that could be uniformly distributed in the matrix without exceeding the 4.0 limit on the correction factor. The numbers in parentheses are the approximate gram weights of uranium or plutonium that these densities would give in the listed container volume. Table 10.1 shows the obvious advantage of smaller containers for gamma-ray assay. Remember the possibility of measurement error increases with increasing CF. For combustible waste, the bulk matrix density is usually in the range $0.1-0.2 \mathrm{~g} / \mathrm{cm}^{3}$ so the matrix attenuation is lower. In principle, $1000 \mathrm{~g}$ of uranium or plutonium if uniformly distributed in a 55-gal drum of $0.2 \mathrm{~g} / \mathrm{cm}^{3}$ waste would not exceed the $C F \leq 4.01$ imit. However, at this level a uniform distribution is most unlikely and large systematic errors should be expected.

It is desirable to standardize packaging throughout the industry to facilitate the verification of shipments and receipts. The goal is to have a minimum number of container types in use throughout the nuclear industry. The following are suggested package types:

- 2-1iter plastic bottle (uranium or plutonium scrap),

- 1-gal can (plutonium scrap, not recommended for uranium gamma assay if $>150 \mathrm{~g}$ uranium),

- 5-gal bucket (uranium or plutonium waste), - 30- or 55-gal drum (uranium or plutonium combustible waste).
Any one plant should require on15 two container sizes, one for recoverable scrap and the other for lower-level waste. Regulatory Guide $5.11^{10.1}$ gives guidelines for scrap and waste containers (diameters less than $13 \mathrm{~cm}$, waste to be placed in sma11 cans before loading into drums). The guidelines stated there will certainly satisfy requirements for gamma assay. If drums are loaded with smaller packages, it is more accurate to measure the individual packages.

Strict segregation practices are necessary to maximize the accuracy of gamma-assay systems. Certain categories of waste and scrap should be defined on the basis of the material's amenability to gamma assay. The categories should be carefully observed. This applies particularly to large waste containers. A few rusty nails, nuts, or bolts in a small can of incinerator ash do not greatly affect the assay accuracy. is lathe bed in a drum of combustible waste will undoubtedly lead to an incorrect assay. When large containers are used for waste storage, strict administrative control is required to specify what may be put in the containers.

\section{REFERENCE}

10.1 USAEC Regulatory Guide 5.11, Nondestructive Assay of Special Nuclear Material Contained in Scrap and Waste. 


\section{MATERIAL CATEGORIES--PRECISION AND ACCURACY}

It would not be possible or useful to discuss all the spectfic types of material which are encountered in the nuclear industry. They do how'ver, fall in some general categories, and this section gives a brief discussion of the accuracy which can be ohtained on types which are amenable to gamna-ray accuracy. This informacion is presented in lable 11.1 . The sensitivity estimate given in the table is based on a 1000-s count of the sample with an uncollimated fe( $\left.L_{i} i\right)$ detector in fairly close coupled geometry. This is not meant to indicate the sensitivity that can be achieved with special low-level counting systems optimized for sensitivity. The assay systems discussed in this reporc are not designed for measuring very low-level waste. Most segmented scan systems have an effective sensitivity of about one gram of uranium or plutonium.

Th. precision of gamma-ray measurements needs litele discussion. Typically it will approach the limit set by counting statistics. A valuable test for the operation of a ganma-assay system is to check that the measurement precision as determined by repeated measurements is consistent with that which is predicted by the propagation of Poisson counting statistics through the assay equations. For most situacions considered here, the count rates are sufficiently hikh that the resulting presision should be 5\% or hetter. All mensurement resulcs should include an est imate of the precision.
Table 11.1 illustrates a good point: combustible waste is best measured after it has been incinerated (changed to ash) and counted in small containers. In general, it is difficult to determine the accuracy of any scrap and waste measurement system since there is no reliable method of determining the actual contents of a real sample. Several procedures are used to investigate this, but the amount of experience to date is still rather small. . Some of these approaches are listed below.

(1) A range of standards is fabricated to attempt to test the performance extremes of the assay system. (This was discussed in Chapter 9,)

(2) Plutonium samples can be calorimetered. If accurate isotopic and americium data can be obtained, this can give a good measurement of plutonium in small samples.

(3) Large combustible waste samples are incinerated, and the resulting ash can be measured quite accurately (by gamma techniques) and compared with the large container assay.

(4) The contents of a sample container can be split up and put in a number of smaller containers which can then be assayed more accurately for comparison with the initial assay.

(5) Chemical recovery is attempted of entire samples to determine the contained source material. This is often a very difficult process and should be followed very closely. All residues should be checked by gamma assay for possible uranium or plutonium.

\section{TABLE 11.1 \\ TYPICAL ACCURACIES FOR GAMMA ASSAY OF CERTAIN MATERIAL TYPES}

Category
Combustible Waste (55-gal)
Powder icrap Residue, e.g., ash
(2-1iter)
Solution Sample (2-1iter)
Product or Rich Scrap (2-1iter)

\begin{tabular}{cr}
$\begin{array}{r}\text { Relative Accuracy } \\
(20)\end{array}$ & $\begin{array}{r}\text { Sensitivity } \\
(\mathrm{gPu} \text { or U) }\end{array}$ \\
\hline $20 \%$ & $100 \mathrm{mg}$ \\
$5 \%$ & $1 \mathrm{mg}$ \\
$1 \%$ & $1 \mathrm{mg}$ \\
$5 \%$ & --
\end{tabular}


The data in Table 11.1 summarize experience gained

from experiments with most of the 1 isted procedures.

These experiments are really just beginning, and many more data are required to define NDA measure- ment accuracy. Some experiments may need to be done by every NDA laboratory, but eventually it should be possible for new facilities to just cite the accuracy experiments conducted at other related plants. 


\section{PLUTONIUM ISOTOPIC DISTRIBUTIONS BY}

\section{GAMMA-RAY SPECTROSCOPY}

\section{Background}

In the body of this paper the emphasis with respect to piutonium assay has been on the determination of ${ }^{239} \mathrm{pu}$. The reason is twofold. First, most plutonium currently in use is $\geq 75 \%{ }^{239} \mathrm{Pu}$, and it is usually preferable to assay the most abundant isotope. Second, the relatively high energy $413.7-\mathrm{keV}$ gamma ray from ${ }^{239} \mathrm{Fu}$ is emitted at a rate of $\sim 3.5 \times 10^{4} \mathrm{~s}^{-1} \cdot \mathrm{g}^{-1}$, allowing quite sensitive and accurate assays of the ${ }^{239} \mathrm{Pu}$ in many cases. Obviously difficulty arises when comparing a gama-ray assay for ${ }^{239} \mathrm{Pu}$ with a chemical assay for tatal plutonium, in that the isotopic fraction of ${ }^{239} \mathrm{Pu}$ tust be known in order to make the comparison. Sometimes the assayed samples are from a source with known or constant isotopic values but often no such knowledge is available, and experience has shown that assumptions of 1sotopic are all too frequently incorrect. It is true, of course, that any NDA measurement which is specific to a single isotope (or in some cases a small group of isotopes) suffers from the same difficulty of interpretation. A mass spectrometer isotoplc analysis solves the problem but is often not feasible or desirable on the basis of tinje and cost.

For the present problem of interpreting quantitative gama-ray assays of ${ }^{239} \mathrm{Pu}$, it would be desirable to be able to determine the isotopic fractfon of ${ }^{239} \mathrm{Pu}$ by gamma-ray spectroscopy. For other purposes, notably the interpretation of calorimetric measurements of the thermal power produced by a plutonium sample, it would be very useful to be able to determine the whole isotopic distribution including the ${ }^{241}$ Am content by a gamma-ray measurement. With varying degrees of precision and accuracy it is currently possible to obtain a good deal of isotopic information from gamma-ray spectroscopy. Only in a few special cases does the accuracy of such NDA determinations approach that of destructive analysis based on mass and alpha-ray spectrometry. However, the NDA measurement may ofien be adequate and preferred on a cost basis, and therefore it seems worthwhile to include here some discussion of the current status of measurement of plutonium isotopic fractions by gamma-ray spectroscopy. The gamma measurement may be used as a verification of the plutonium isotopic analysis.

\section{Current Status}

Whin the general problem area of determining plutonium 1sotopic distributions by passive gammaray spectroscopy there are perhaps ten different cases and situations each requiring a somewhat different approach. As of this writing (December, 1974) only a few of the cases have really been solved in the sense of having been thoroughly investigated and equipment and procedures set up to operate reliably on a routine basis. The two best worked-out cases are those of low concentration solutions (few grams plutonium per liter) and the "enrichment meter" cases in solfds. A.1, A.2 Work on almost all of the cases of Interest is now being pushed at several laboratories and within a year a considerably better plcture of capabilities and limitations of the technique to the varlous cases should be avallable.

Probably the most difficult prohlem is that of the arbitrary package of plutonfum waste or scrap, uncontrolled and/or unknown with respect to size, shape, matrix, mass of plutonium and packaging material. This problem is, of course, precisely the one usually faced in interpreting NDA assays of plutonium scrap and waste based on the quantitative measurement of the ${ }^{239} \mathrm{Pu}$. Some encouraging but preliminary results have been obtained in the problem of the "arbitrary package" and further work is in progress. The balance of this appendix will be devoted to procedures being investigated at LASL.

\section{Generalized Method Applicable to Scrap and Waste}

\subsection{Assumptions and Signatures}

3.1.1 Necessary Assumptions. The problem is attacked here in its most general form. Only two 
assumptions nead be made. The first aesumption that will be made is that the isotoptc distribution is constant throughout the volume of the sample. This assumprion is necessary because in many samples the effective volume "sampled" by the escaping gamma rays will vary stromgly with tae energy of the gamma ray. The second is that a measurable flux of gantma rays is emirted at energies $\geq 120$ $k e V$. for the scheme described wi:l depend only on gamma rays whose energy is $2120 \mathrm{kev}$. Subject to the tho requirements just given the samplo may be of any size or shape and of any chemical composithen. The discussion is confined to samples containing only plutonium and its daughters, although with some adjustments the scheme would work on plutonium-uranlum mixtures. A certain amount of extraneour activities from fission products could be tolerated but with ilicreased difficulty.

3.1.2 Useful Gamma Rays. The total number of gamma rays emicted by the $238,239,240,241 \mathrm{Pu}$ and

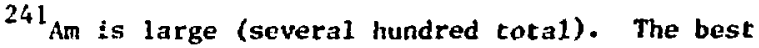
current complete compilation of energies and incensities is that of $R$. Gunnink (see Ref. 2.3). The short list in Table A.l is excerpted from Gunnink's report and Includes most of those gamma rays with energies $z 120 \mathrm{keV}$ useful in determining isotopic ratios and/or relative counting efficlences. All the energies are accurate to less than $0.1 \mathrm{kev}$, but the intensities of some of the weaker gamma rays are known to be somewhat in error (work is in progress on improved values). The intensities are given here as a qualitative guide to the possible usefulness of a particular ganma ray. Two comments are in order. The first is that the ${ }^{242} \mathrm{Pu}$ emits no gamma rays and, therefore, cannot be included directly in any gamma-ray measurement of isotopic distribution. The second is with respect to the gamma rays labeled ${ }^{241} \mathrm{Pu}\left({ }^{237} \mathrm{U}\right)$. Those are actually emitted by the ${ }^{237} \mathrm{u}$ daughter of $241_{\mathrm{Pu}}$. Inasmuch as $237_{\mathrm{U}}$ has a $6.75-\mathrm{d}$ ialf-1ife, the activities will come into equilibrium in about a month, after which the gamma rays may be used as a measure of ${ }^{241} \mathrm{Pu}$.

\subsection{General Ideas and Technical Considerations}

3.2.1 Isotopic Ratios Are Quantities Measured. In general, the total amount of each isotope in the sample cannot be measured quaneftatively, but ratios of the isotople masses can be determined. These are. of course, the same as the ratios of the isotopic fractions. In principle, threc ratios involvIng the isotopes $238,239,240,241$ Pu are sufficient to deterwine their relative lsotopic abundances. If the isotopic fraction of ${ }^{242} \mathrm{Pu}$ is neglegibly small the relative isotopics will be very close to the actual isotopic mass fractions. If the ${ }^{242} \mathrm{Pu}$ fraction can be estimated reasonably wrll, the estimated ${ }^{242}$ Pu may be included when normalizing the sum of the mass fractions to one. It must, nevertheless, be repeated as a fundamental 1 imitation (though often not a serfous one) that there is no way of directly decermining ${ }^{242} \mathrm{Pu}$ by passive gamma-ray spectroscopy.

Calibration could be accomplished in two ways, eithe: by comparison with standards of known

\section{TABLE A.1}

\section{GAMMA RAYS USEFUL IN ISOTOPIC DETERMINATIONS}

\section{Isotope Half-Life Energy (keV) Intensity $\gamma$, s/dis}

\begin{tabular}{|c|c|c|c|}
\hline${ }^{238} \mathrm{Pu}$ & $87.78 \mathrm{y}$ & $\begin{array}{l}152.8 \\
766.4\end{array}$ & $\begin{array}{l}1.01 \\
2.40\end{array}$ \\
\hline${ }^{239}{ }_{\mathrm{Pu}}$ & $24082 y$ & $\begin{array}{l}129.3 \\
144.2 \\
161.5 \\
171.3 \\
179.2 \\
189.3 \\
195.7 \\
203.5 \\
255.3 \\
297.4 \\
345.0 \\
375.0 \\
413.7 \\
646.0\end{array}$ & $\begin{array}{l}6.20 \\
2.86 \\
1.30 \\
1.09 \\
6.39 \\
7.76 \\
1.07 \\
5.60 \\
8.03 \\
5.00 \\
5.61 \\
1.58 \\
1.51 \\
1.45\end{array}$ \\
\hline${ }^{240} \mathrm{Pu}$ & $6537 y$ & $\begin{array}{l}160.35 \\
642.3 \\
687.6\end{array}$ & $\begin{array}{l}4.20 \\
1.45 \\
3.70\end{array}$ \\
\hline${ }^{24} 1_{\mathrm{Pu}}$ & $14.35 \mathrm{y}$ & $\begin{array}{l}148.6 \\
160.0\end{array}$ & $\begin{array}{l}1.90 \\
6.45\end{array}$ \\
\hline $\begin{array}{l}241_{\mathrm{Pu}} \\
\left({ }^{237} \mathrm{U}\right)\end{array}$ & $14.35 \mathrm{y}$ & $\begin{array}{l}164.6 \\
208.0 \\
267.5 \\
332.3\end{array}$ & $\begin{array}{l}4.50 \\
5.12 \\
1.77 \\
2.80\end{array}$ \\
\hline${ }^{241} \mathrm{Am}$ & $434.1 \mathrm{y}$ & $\begin{array}{l}125.3 \\
169.6 \\
662.4\end{array}$ & $\begin{array}{l}3.95 \\
1.68 \\
3.46\end{array}$ \\
\hline
\end{tabular}


Isotopic composition or by use of the funtamental data on haif-lives and goma-ray incensfeles. There is st 111 enough uncectalnty in sone of the half-life and intensity data that the first procedurc is recomended for rout ine use although the fundamental data are of extreme usefulness in predicting possibiltties and probably performance.

\subsubsection{Relative Detection Efficiency. Because both} the sample self-ottenuation and the detector efficlency vary with energy, the overall relut lve efficiency for the detection of gama rays from a particular sample using a given detector is a strong function of energy. Although the detector efficlency curve may be quite well measured, the attenuation effects of an arbitrary unknown package of "junk" are most of ten impossible to predict. As a result the overall relative efficlency curve as a function of energy is often impossible to predict for given unknown sample-detector combinations. Let it be emphasized that the discussion here is with respect to samples of arbitrary shape, size, mass, and chemical composition. In cases with well defined geometry and known chemlcal composition, the effects of sample self-attenuation can in fact be accurately and usefully predicted.

Because of the recognized but often unknown variation of relative detection effictency, it is customary and prudent to use gamma rays as close together in energy as possible in measuring isotopic ratios. The use of the 203.5-kev $\left({ }^{239} \mathrm{Pu}\right)$ and $208.0-\mathrm{keV}\left({ }^{241} \mathrm{Pu}^{237} \mathrm{U}\right)$ gamma rays in determining the ${ }^{241} \mathrm{Pu} /{ }^{239} \mathrm{Pu}$ ratio is a typical example. Most often, if the relative efficiency changes could not be directly calculated over the range 5-10 kev, they have been ignored. If good results are desired, however, the relative efficiency changes cannot be ignored for the rate of change may yary between $\pm 1 \% / \mathrm{keV}$ between 100 and $400 \mathrm{keV}$. Furthermore, the shape of the relative efficiency curve will radically vary with size, shape, and composition of the sample. External absorbers can change the shape considerably.

Fortunately it is usually possible to construct a reasonably good curve of relative detection efficlency versus energy based on the known relative Intensities of the gamma rays of ${ }^{239} \mathrm{Pu}$. Referring to Table A.l it is seen that ${ }^{239} \mathrm{Pu}$ has 13 gamma rays between 129 and 4 ff het. Satw are seath and suffer Interferences from ocher lsotopes but. neversholess. usteful information mat be extracted. The ive gama rays frow 24 Pu ma hlso be used to suplenent and improse the Information galnced from the 239 pat ganata rays. Finally it should be emptrasized thate once o curve of relative efficlency is constructed. gamma-ray pales wldely separated in encrgy nay be used in determining lsotopic rat los.

\subsubsection{Americium Corrections. As beforementioned} the gaman rays from the ${ }^{237} \mathrm{v}$ daughter of ${ }^{241} \mathrm{pu}$ are only useful in determining the ${ }^{24 !} \mathrm{Pu}$ fraction ofter equilibrlum is reached between the two isotopes. Another correction must be made before the ${ }^{237} \mathrm{v}$ gamma rays can be used with confidence, namely, for the contribution of the ${ }^{241} \mathrm{Am}$ daughter of ${ }^{241} \mathrm{Pu}$ to the gamma-ray activity. Both ${ }^{237} \mathrm{l}$ and $24 \mathrm{Am}$ populate excticed levels of the ${ }^{237} \mathrm{~Np}$ nucleus on decay and hence give rise to the same ganma rays although with different relative intensities. The half-ife and intensity relationships are such that even when ${ }^{241} \mathrm{Pu}$ and ${ }^{241} \mathrm{Am}$ are equal in mass, the ${ }^{241}$ Am concributions to the gamma rays of interest (rainly $164.6,208.0,267.5$, and $332.3 \mathrm{keV}$ ) are only a few percent. Nevertheless, if more than four years have elapsed since the ${ }^{241}$ fim was removed, ccrrections should be made. The correction for americtum can be made by first determining the intensity of the 241 Am gawa rays to determine the ${ }^{241}$ Am contributions for the gama rays of interest. There are other approaches to the correction problem. What is emphasized here is the necessity of the correction if good results are desired.

\subsubsection{Rate-Related Errors. Two types of errors may} result from high count rates, both due directly or indirectly to the loss of events from the fullenergy spectral peaks by pulse pileup. The first difficulty results directly from storage of the piled-up pulses. If the intensties of the $60-\mathrm{keV}$ 241 Am peak and the $x$-ray peaks in the 90 - to $120-\mathrm{keV}$ region are allowed to be much higher than those of some of the peaks in the 120- to $200-\mathrm{keV}$ region upon which the isotopic assay is based, the piled-up pulses can cause "bumpy" background continuuns under the weaker assay peaks increasing the error in the measured area of those peaks. The intensity of the 
low-energy gamma rays can be reduced by judicious selective filtering. Electronic pileup rejection may also be profitably employed to avold storage of pileci-up events.

The second type error arises from unequal pileup losses to the various spectral peaks. Ir cases where the main amplifier pulses are $210 \mu \mathrm{s}$ (as will be the case with most high-resolution systems) p(leup may affect a substantial fraction of events. As tndicated in Chapter 6, that frac$t$ Ion is given roughly by $f=R T$ where $R=$ gross rate of detected events and $T=$ the pulse width. If, for example, $R=5 \times 10^{3} \mathrm{~s}^{-1}$ and $\mathrm{T}=20 \times 10^{-6} \mathrm{~s}$, $i \sim 0.1$, implying that about $10 \%$ of all events will be distorted to some extent by pileup. As shown in Chapter 6, peaks of considerably different intensity will usually suffer different pileup losses. The relations given there will show what the limitations on rate must be in order to ignore the effect.

The purpose here is not to give a full discussion of how efther problem is minimized or eliminated but simply to point out a pair of problems which could have a measurable effect on isotcpic determinations.

\subsubsection{Peak Area Determinations. Accurately deter-} mining the relevant full-energy peak areas is crucial to any sort of quantitative gamma-ray measurement; the problem of isotopic determinations is no exception. If the peaks of interest are well resolved, satisfactory results may be obtained by one of the simple methods described in Chapter 4. If the peaks are not well resolved then recourse must be had to one of the good peak fitting codes. The isutopic analysis of plutonium $f a l l s$ very nearly in between cases. With a detector of the best resolution, reasonably good results are obtained by the simple methods. Nevertheless, as the americlum concentration grows, a number of the multitude of ${ }^{241}$ Am peaks come above the background continuum in awkward places, requiring great care in the selection of background windows for the plutonium peaks. Although efforts are still in progress to see just how well the simple methods can be made to work, it is clear that the best results will be obtained, espectally in difficult situations, by more sophisticated peak fitting procedures. Systems have been built consisting of a small computer processor with additional disk storage which are fully capable of doing a whole analysis including the least-squares fitting routines. Such a system would probabiy be desired and justified for doing routine isotopic assays by gamma-ray spectroscopy.

\subsubsection{Isotopic Verification. In some situations it} may be desirable to just verify that an assumed isotopic distribution is correct. In such instances an accurate measurement is of ten not required and many of the above considerations can be ignored. A single intensity ratio may give a sufficiently reliable check. The ${ }^{241} \mathrm{Pu} /{ }^{239} \mathrm{Pu}$ ratio is probably best for such checks $\left(208 \mathrm{keV} / 203.5 \mathrm{keV}\right.$ if ${ }^{237} \mathrm{U}$ in equilibrium or $148.6 \mathrm{keV} / 129.3 \mathrm{keV}$ if not in equilibrium). Relatively small chinges in the ${ }^{239} \mathrm{Pu}$ concentration will be accompanied by large changes in the ${ }^{241} \mathrm{Pu}$ concentration so this is a good check of ${ }^{239} \mathrm{Pu}$ concentration. If the scrap and waste assay system includes a multichannel analyzer and computer, one of these line ratios should be checked routinely to assure that the assumed ${ }^{239} \mathrm{Pu}$ concentration is correct.

\subsection{Determination of Isotopic Ratios}

This section will be devoted to a qualitative discussion of the possible ways of determining specific isotopic ratios, along with some comment on the advantages and disadvantages.

3.3.1 Ratio ${ }^{241} \mathrm{Pu} /{ }^{239} \mathrm{Pu}$. Over quite a wide range of isotopic fractions, the $203.5-\mathrm{keV}$ gamma ray from ${ }^{239} \mathrm{Pu}$ and the $208.0-\mathrm{keV}$ gamma ray from the ${ }^{237} \mathrm{U}$ daughter of ${ }^{241} \mathrm{Pu}$ form a convenient pair by which to deternine the ${ }^{241} \mathrm{Pu} /{ }^{239} \mathrm{Pu}$ ratio. of course, there must be assurance that the ${ }^{237} \mathrm{U}$ is in equilibrium with the parent ${ }^{241_{\mathrm{PL}}}$. Then correction should be made for the ${ }^{241}$ Am contribution to the 208-keV peak and for the difference in relative detection effictency.

An alternative pair is the $129.3-\mathrm{keV}$ gamma ray from ${ }^{239} \mathrm{Pu}$ and the $148.6-\mathrm{keV}$ gamma ray from ${ }^{241} \mathrm{Pu}$. In this case there is no worry about equilibrium or americium contribution, for the 148.6-keV photons are directly from ${ }^{241} \mathrm{Pu}$. On the other hand, because of the much larger energy difference (19.3 keV 
vs $4.5 \mathrm{keV}$ ) the correction for relative detection efficiency must be made very carefully.

Other possibilities exist but the two cited seem the most promising. It appears that the ${ }^{241} \mathrm{Pu} /{ }^{239} \mathrm{Pu}$ ratio can be determined with an accuracy of $\pm 1 \%$ (one sigma) if care is exercised. Let it be mentioned once more that here the discussion is about arbitrary "junk", not prepared samples of known geometry and composition where better accuracy may be obtained.

3.3.2 Ratio ${ }^{238}{ }_{\mathrm{Pu}}^{241} \mathrm{Pu}$. In most cases the 152.8keV gamma ray of ${ }^{238} \mathrm{Pu}$ will be the one with energy $\geq 120 \mathrm{keV}$ that must be used. Because of its proximity to the $148.6-\mathrm{keV}$ gamma ray of ${ }^{241} \mathrm{Pu}$, it is reasonable to measure that ratio. A ratio of the 144.2-keV gamma ray of ${ }^{239} \mathrm{Pu}$ to the $152.8-\mathrm{keV}$ gamma ray might be taken for a ${ }^{238} \mathrm{Pu} /{ }^{239} \mathrm{Pu}$ ratio, but usually the area of the $144.2-\mathrm{keV}$ gamma ray cannot be determined with sufficient precision. In material with 10 w ${ }^{238} \mathrm{Pu}$ isotopic fraction ( $0.01 \%$ ) the determination of the ${ }^{238} \mathrm{Pu}_{\mathrm{u}} /{ }^{241} \mathrm{Pu}$ ratio may not be better than $\sim \pm 10 \%$ because of the very bad signal-to-background ratio the peak of the ${ }^{238} \mathrm{Pu}$ wil.1 have. As the fraction of ${ }^{238} \mathrm{Pu}$ increases, the accuracy of the determined ratio will improve; so that by the time the ${ }^{238}$ Pu fraction reaches $1 \%$, the accuracy of the ${ }^{238} \mathrm{Pu} /{ }^{241} \mathrm{Pu}$ ratio may well by $\pm 1 \%$ at one sigma. As usual, care must be taken with relative efficiency corrections and the possibility of interference from weak ${ }^{241}$ Am gamma rays.

3.3.3 Ratio ${ }^{240} \mathrm{Pu} /{ }^{239} \mathrm{Pu}$. This ratio is probably the most difficult overall to measure of any that must be determined. Two approaches may be used employing gamma rays with energies $\geq 120 \mathrm{keV}$.

The first employs the $642.3-\mathrm{keV}$ gamma ray of ${ }^{240} \mathrm{Pu}$ and the $646.0 \mathrm{keV}$ gamma ray of ${ }^{239} \mathrm{Pu}$. There are also several ${ }^{241}$ Am gamma rays in the region which make it difficult to get the peak area by simple background subtraction methods if the americium level is appreciable. The main difficulty in using this pair of gamua rays is their very low intensities. Long counts will surely be required, and if there is any fission product activity in the material the whole regic'n may sink into the background.
The second possible energy region is the 160to $164-\mathrm{keV}$ region including the $160.3-\mathrm{keV}$ ganma ray of ${ }^{240} \mathrm{Pu}$. The difficulties here include the 160.0 $\mathrm{keV}$ gamma ray of ${ }^{241} \mathrm{Pu}$ which cannot be resolved. low intensities, and the possibility of pulse pileup creating irregular backgrounds under the peaks of interest. By using due care in both spectrum acquisftion and analysis, results can be obtained but perhaps a lo accuracy of $\pm 5 \%$ is the best that could be extracted from the $160-\mathrm{keV}$ region for the $240 \mathrm{Pu} /{ }^{239} \mathrm{Pu}$ ratio. If it is free of extraneous activities and the count is sufficiently long, somewhat better accuracy can be expected from the 640-keV region.

3.3.4 Ratio ${ }^{241} \mathrm{Am} /{ }^{239} \mathrm{Pu}$. As before-mentioned, if it is desired to interpret calorimetric measurements of plutonium, it is necessary to determine the ratio of 241 Am to the plutonium. Several approaches are available.

The 125.3-keV gamma ray of ${ }^{241} \mathrm{Am}$ and the 129.3keV gamma ray of ${ }^{239} \mathrm{Pu}$ have proven a useful pair. A slight difficulty, especially at low concentrations, is that there are two weak ${ }^{239} \mathrm{Pu}$ gamma rays $(125.2 \mathrm{keV}$ and $124.5 \mathrm{keV})$ which interfere with the 241 Am gamma ray and whose influence must be subtracted out. Attention must as usual be paid to relative detection efficiency corrections which may be as much as $10 \%$ over the $4-\mathrm{keV}$ span of energy. For ${ }^{241} \mathrm{Am}$ concentrations $2500 \mathrm{ppm}\left({ }^{241} \mathrm{Am} / \mathrm{Pu}\right)$, precisions of a few percent should be attainable.

If the region at $640 \mathrm{keV}$ is being used to determine the ${ }^{240} \mathrm{Pu} /{ }^{239} \mathrm{Pu}$ ratio the ${ }^{241} \mathrm{Am} /{ }^{239} \mathrm{Pu}$ ratio could also be determined by including the 662.4-keV 241 Am gamna ray, although it is likely that real peak fitting procedures would have to be applied to extract the $662.4-\mathrm{keV}$ peak area.

As a third possibility a group of gamma rays between 332.3 and $345.0 \mathrm{kev}$ can be used. The 332.3- and 335.4-keV gamma rays arise from both ${ }^{237} \mathrm{U}$ and ${ }^{241} \mathrm{Am}$ but with widely differing branching ratios. By using the nearby $345.0-\mathrm{keV}$ gamna ray from ${ }^{239} \mathrm{Pu}$ to eliminate some irritating ${ }^{239} \mathrm{Pu}$ interference, the peak areas of the 332.3- and 335.4-keV gamma rays may be accurately determined. An equation involving the measured areas and known relative intensities then yields the ${ }^{24:} \mathrm{Am} / \mathrm{f}^{241} \mathrm{Pu}$ ratio. Just how well this attack will work remains to be seen, 
but it has the advantage of using some of the more intense garma rays in the emitted spectrum.

\subsection{Preliminary Results}

Work is in progress to determine just how well the procidures and approaches outlined above will work over a broad range of situations. It is already certain that for many stiuations isotople information of suffictent accuracy can in fact be obtained on the "arbitrary" sample. The procedures outlined could, of course, be applied to any plutonium sumple, but where geometry is controlled and chemical content known better results will no doubt be achieved in many cases by using more spectalized procedures whlch take advantage of the constant geometry and knowledge of the sample.

As an example of the results obtained so far, Table 1.2 compares, for a known scrap standard, the mass spectrometric isotopic values and $241 \mathrm{Am}$ soncentration (determined by alpha counting) with the isotoplc distribution and 241 Am concentration from gamma-ray spectroscopy. As expected, the most serfous discrepancy is in the value for ${ }^{240} \mathrm{Pu}$ which is $6 \%$ in error. Although the ${ }^{238} \mathrm{Pu}$ value is $16 \%$ different, its concentration is so low that neither value has great accuracy. The americium value differs by $\sim 10 \%$ but is based en tabulated data of americfum gamna rays which are in some degree suspect. Considerably better results should be expected for the $241 \mathrm{dm}$ concentration.

In summary, Table A.2 gives an encouraging example of what might be achieved. Defining the posstble precisions and accuracies over the expected range of isotopic distributions awaits further investigations and analysis.
TABLE A. 2

\section{COMPARISON OF ISOTOPIC DISTRIBUTION BY GAMMA-RAY SPECTROSCOPY WITH ACCEPTED VALUES}

\begin{tabular}{|c|c|c|c|}
\hline Isotope & $\begin{array}{c}\text { Accepted } \\
\text { Valuea }\end{array}$ & $\begin{array}{l}\text { Gamma-Ray } \\
\text { Value }\end{array}$ & $\left(\right.$ Accepted ${ }^{-1}$ \\
\hline${ }^{238} \mathrm{Pu}$ & 0.0116 & 0.010 & 0.86 \\
\hline${ }^{239} \mathrm{Pu}$ & 94.10 & 93.75 & 0.996 \\
\hline $240 \mathrm{Pu}$ & 5.60 & 5.95 & 1.06 \\
\hline${ }^{241} \mathrm{Pu}$ & 0.271 & 0.270 & 0.996 \\
\hline $241_{\mathrm{AIII}}$ & 536 & 486 & 0.91 \\
\hline
\end{tabular}

a All values are given in wt\%, except ${ }^{241}$ Am which is in ppm.

\section{REFERENCES}

A.1 R. Gunnink, "plutoniun Isotopic Measurements by Gamma-Ray Spectrometry," Mound Laboratory report MLM 2177, Proceedings of the Symposium on the Calorimetric Assay of Plutonium, Oct.1973, pp. 45-59.

A.2 T. D. Reilly, R. B. Walton, and J. L. Parker, "The Enrichment 'Meter'--A Simple Method for Measuring Isotopic Enrichment," Los Alamos Scientific Laboratory report LA-4605-MS (1970), pp. 19-21. 


\section{DIFFERENTIAL ABSORPTION ATTENUATION CORRECTION FACTOR}

The four figures in this appendix illustrate the potential and problems with the differential absorption attenuation correction sactor. They show attenuation correction factors at $414 \mathrm{keV}$ or $186 \mathrm{keV}$ as a function of the intensity ratios $I(414) / I(129)$ or $I(186) / I(143)$. The graphs are drawn for varying matrix and high- $Z$ densities (for this discussion, $\mathrm{DM}=\mathrm{g} / \mathrm{cm}^{3}$ matrix and $\mathrm{DU}=\mathrm{g} / \mathrm{cm}^{3}$ uranium or plutonium). The matrix is assumed to have the attenuation properties of carbon; this is a good assumption for $Z \leqslant 26$, which includes all combustible materials and the metallic oxides usually found in harder residues such as ash and slag. Uranium and plutonium are assumed to have the same attenuation properties (the worst difference is $5 \%$ ). The attenuation coefficients used are given in Table B.1. The matrix and the fissile material are assumed to be a homogeneous mixture. Figures B. 1 and B.2 pertain to a small scrap can $10-\mathrm{cm}$ diam by $12-\mathrm{cm}$ high. Figures B.3 and B.4 pertain to a large waste drum $58-\mathrm{cm}$ diam by $90-\mathrm{cm}$ high (55-gal drum).

\section{Small Scrap Can}

Figure B.1 illustrates the variation of CF(414) as a function of $I(414) / I(129)$ for a small scrap can. It illustrates the following points. The iso-fissile lines slope both positive and negative in different regions. This means that the intensity ratio can either increase or decrease as the density and gross attenuation increase. The latter case is interesting and not at all obvious without studying this graph. The incensity ratio is very insensitive to changes in the matrix density, so

TABLE B.I

\section{ATTENUATION COEFFICIENTS $\left(\mathrm{CM}^{2} / \mathrm{G}_{1}\right)$}

\begin{tabular}{|c|c|c|c|c|}
\hline \multirow[b]{2}{*}{ Material } & \multicolumn{4}{|c|}{ Energy (keV) } \\
\hline & 129 & 143 & 186 & 414 \\
\hline Matrix & 0.143 & 0.138 & 0.128 & 0.0925 \\
\hline $\begin{array}{l}\text { Uranium } \\
\text { or } \\
\text { Plutonium }\end{array}$ & 3.70 & 2.87 & 1.45 & 0.25 \\
\hline
\end{tabular}

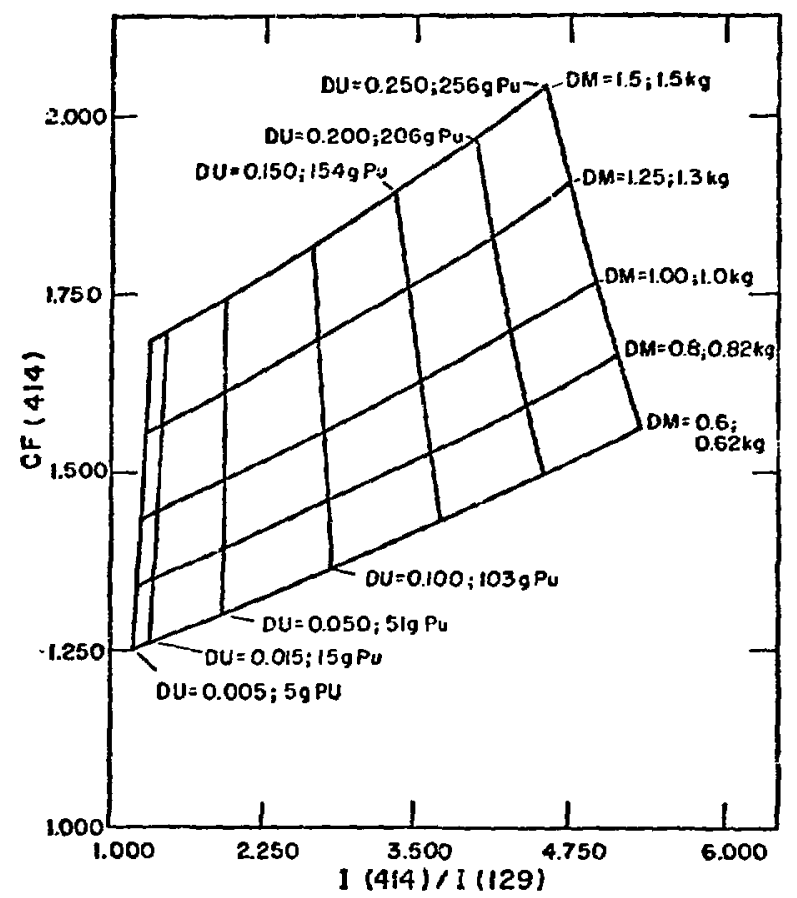

Fig. B.l Attenuation correction factor at $414 \mathrm{keV}^{\prime}$ as a function of the 414- to $129-\mathrm{keV}$ $\left({ }^{39} \mathrm{Pu}\right)$ intensity ratio. The sample container is a $10-\mathrm{cm}-\mathrm{diam}$ by 22-cm-high can.

without any further information the intensity ratio cannot give accurate information on the correction factor. Now assume the net weight is known and the cans are all filled to a roughly unfform height.

Then the matrix density $D M$ is known, and this plus the intensity ratio define a unique $C F$. It is then possible also to do an iteration to check on selfabsorbing lumps (sample uniformity). The argument is illustraten schematically below.
(1) Net weight $\rightarrow$ DM
(2) $\cdot \mathrm{DM}+[\mathrm{I}(414) / \mathrm{I}(129)] \rightarrow \mathrm{CF}(414)$
(3) $\mathrm{CF} \times \mathrm{C}(414) \rightarrow \mathrm{g} \mathrm{Pu}$
(4) $\mathrm{g} \mathrm{Pu} \rightarrow \mathrm{DU}$
(5) $\mathrm{DU}+\mathrm{DM} \rightarrow[\mathrm{I}(414) / \mathrm{I}(129)]^{\cdots}$
(6) $(\mathrm{I} / \mathrm{I})^{\circ} \approx(\mathrm{I} / \mathrm{I})^{\cdots}$

If the two values of $I(414) / I(129)$ agree reasonably well, the assumption of sample uniformity should be good and the assay accurate. 
Figure B.2 illustrates the samu sample can for a 235 measurement involving the 186 - and $143-\mathrm{keV}$ lines. For this case the intensity ratio is rather insensitive to changes in the attenuation correction factor. As CF varies from 2.0 to 4.0 , I(186)/1(143) changes only from 1.04 to 1.j8. The "lever arm" is the wrong way. In some cases it may still be possible to use this ratio, but the results would probably not be as good. For low-enriched urantum where the entichment is known and the $234 \mathrm{~m}$ pa daughter is in equilibrium with 238 , this ratio can be used with good results.

\section{Large Waste Drum}

Figure B.3 illustrates the variation of CF(414) as a function of $I(414) / I(129)$ fot a latge waste drum (208 liter or 55 gal). The following points are svident. Over the range of fissile loadings below 300 g plutonium, $C F(414)$ is independent of ifssile loading: it varies only with matrix density. The "lever arm" is not as good as in the small can, but it should work. As CF(414) varies from 1.17 to 2.50. $[(414) / I(129)$ changes only from 1.09 to 1.42 .

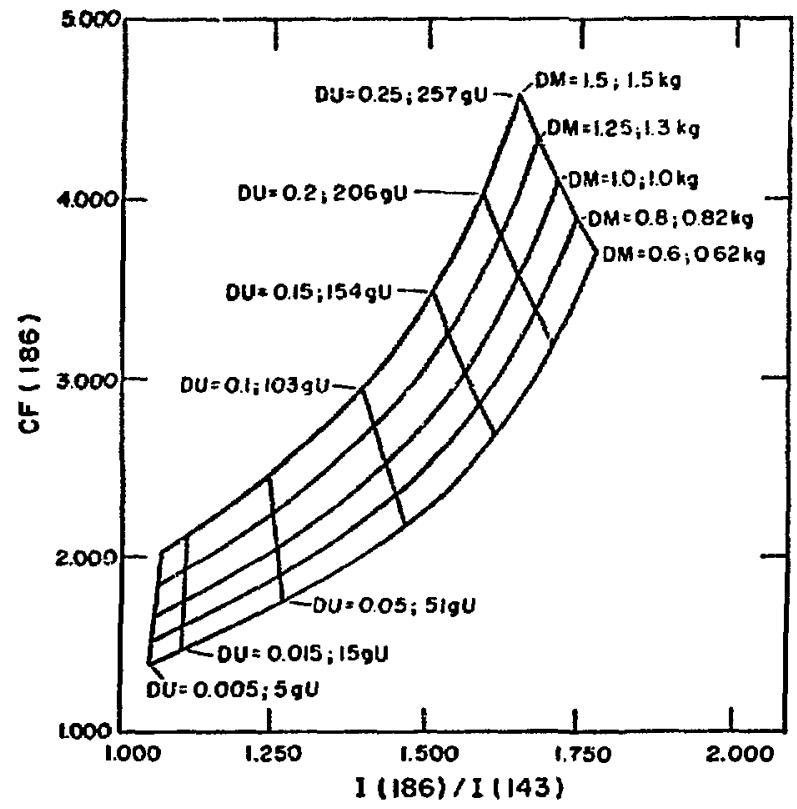

Fig. B.2. Attenuation correction factor at $186 \mathrm{keV}$ as a function of the $186-$ to $143-k e V$ $(235 \mathrm{U})$ intensity ratio. The sample container is a 10-cm-diam by 12-cm-high can.

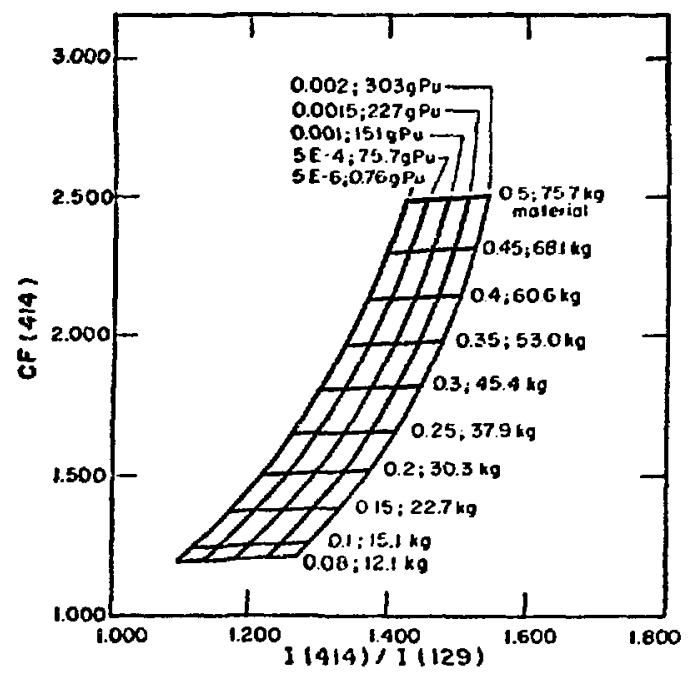

Fiq. B.3. Attenuation correction factor at $414 \mathrm{keV}$ as a function of the $I(414) / I(129)$ intensity ratio. The sample container is a 58-cm-diam by 90-cm-high drul: (55 gal).

The same comments on net weight, iteration, and uniformity check apply for this case. This graph (for $D U=0$ ) is the case diseribed by Jim Cline in ANCR-1055 (sue Ref. 5.1).

Figure B.4 shows the large waste drum for $\mathrm{CF}(186)$ ys $\mathrm{I}(186) / \mathrm{I}(143)$. This ratio will not provide any useful information because there is no "lever arm" at all. Again the 1001- to 186-keV ratio will work well for low-enriched uranium sanples which meet the necessary requirement.

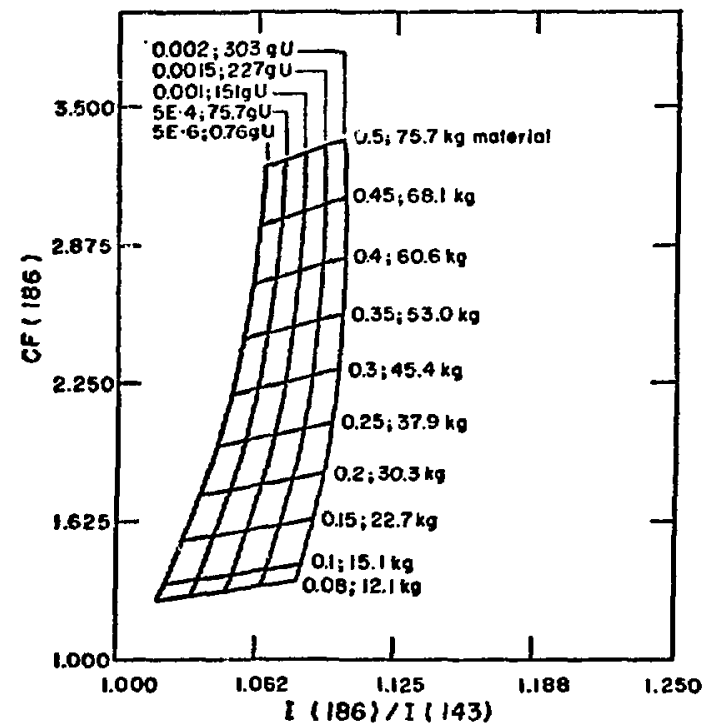

Fig. B.4. Attenuation correction factor at $186 \mathrm{keV}$ as a function of the $I(186) / I(129)$ intensity ratio. The sample container is a 58-cm-diam by 90-cm-high drum (55 gal). 


\section{APPENDIX $C$ \\ ASSAY EXPRESSIONS FOR A TRANSMISSION-CORRECTED \\ SEGMENTED SCAN GAMMA ASSAY MEASUREMENT}

The measurement is assumed to involve three gamma-ray lines: one from the isotope of interest in the sample, one from the external transmission source and one from the livetime and pileup correction source taped to the detector. The Compton background is subtracted from each peak using the procedure described in Sec. 3.2 (see Fig. C.1). The net count rate or peak area (A) is given by

$$
A=p-\frac{n_{p}}{z}\left(\frac{B_{1}}{n_{B_{1}}}+\frac{B_{2}}{n_{B_{2}}}\right) \text {, }
$$

where

$A=$ net counts due to activity of interest,

$\mathrm{P}=$ total peak region count,

$\mathrm{B}_{1}, \mathrm{~B}_{2}=$ total background window counts,

$n_{p}=$ number of channels in peak window,

${ }^{n_{1}}, n_{B_{2}}=\begin{aligned} & \text { number of channels in background } \\ & \text { windows. }\end{aligned}$

The uncertainty associated with each peak area

[Eq. (C.3)] is determined from the usual definition of standard deviation

$$
\sigma_{f}^{2}=\sum_{i}^{n}\left(\frac{\partial f}{\partial x_{i}}\right)^{2} \sigma_{x_{i}}^{2},
$$

where

$$
f=f\left(x_{1}, x_{2}, \ldots x_{i}, \ldots x_{n}\right) .
$$

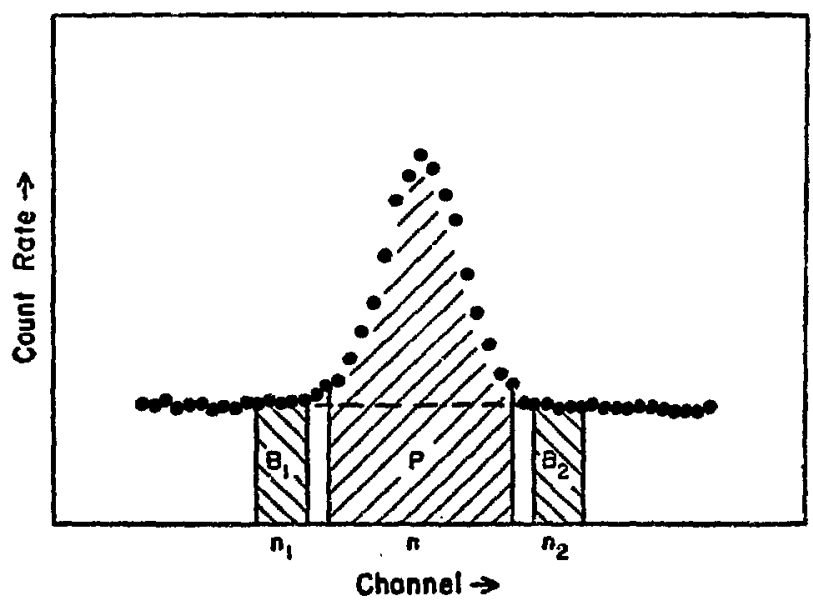

Fig. C.I. Pulse-height spectrum of single photopeak illustrating general procedure for determining photopeak area. The area of interest is above the dashed line which is determined from $B_{1}$ and $B_{2}$.

$$
\sigma_{A}^{2}=P+\left(\frac{n_{P}}{2 n_{B 1}}\right)^{2} B_{1}+\left(\frac{n_{P}}{2 n_{B_{2}}}\right)^{2} B_{2}
$$

where

$$
\begin{aligned}
& \sigma_{\mathrm{P}}^{2}=\mathrm{P}, \\
& \sigma_{\mathrm{B}_{1}}^{2}=\mathrm{B}_{1}, \\
& \sigma_{\mathrm{B}_{2}}^{2}=\mathrm{B}_{2} .
\end{aligned}
$$

Eq. (C.4) gives the expression for the corrected count from the isocope of interest in the sample. It is this number which is dilectly proportional to the material quantity of interest.

$$
\mathrm{CC}=\sum_{i} \mathrm{CC}_{i}=\sum_{i} \mathrm{C}_{i} \frac{\mathrm{LT} \mathrm{O}_{\mathrm{O}}}{\mathrm{LT}} \mathrm{CF}\left(\mathrm{T}_{i}^{\prime}\right) \cdot \mathrm{CF} \mathrm{Can}_{\mathrm{i}},
$$

where

$$
\begin{aligned}
\mathrm{CC}= & \text { total corrected count for sample, } \\
\mathrm{CC}_{i}= & \text { corrected count for } i^{\text {th }} \text { segment, } \\
\mathrm{C}_{i}= & \text { sample activity in line of interest } \\
& \text { from } i \text { th segment, } \\
\mathrm{LT}_{i}= & \text { activity from livetime source for } i^{\text {th }} \\
& \text { segment, } \\
\mathrm{LT}_{0}= & \text { initial activity from livetime source } \\
& \text { with no sample up, }
\end{aligned}
$$

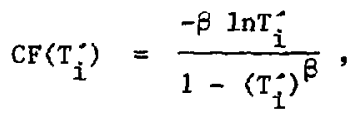

$\beta=$ product of geometric correction factor $(\sim 0.82$ for cylinder) and ratio of mass attenuation coefficients at assay energy and transmission energy,

$\mathrm{CF}_{\text {can }}=\frac{1}{\sqrt{\mathrm{T}_{\mathrm{c}}}}$,

$T_{c}=$ transmission of empty can at assay energy,

$\mathrm{T}_{i}^{\prime}=\frac{\mathrm{T}_{i}}{\mathrm{~T}_{0}} \cdot \frac{\mathrm{LT}}{\mathrm{LT}} \cdot \frac{1}{\mathrm{~T}_{\mathrm{i}}}$,

$T_{0}=$ initial transmission activity with no sample up.

An approximate expression for the uncertainty in the corrected count $\left(\mathrm{CC}_{i}\right)$ is giver in Eq. (C.5). This expression is derived under the following 
assumptions. A more complete expression is

$$
\begin{aligned}
& \sigma_{T_{0}}=\sigma_{L_{0}}=\sigma_{T_{C}}=0, \\
& \frac{\partial T_{i}^{\prime}}{\partial \mathrm{LT}_{i}}=0 \text {, i.e. } \sigma\left(T_{i}^{\prime}\right)=\sigma\left(T_{i}\right),
\end{aligned}
$$

given in Ref. 7.2. The extra terms given in this reference will usually be insignificant.

$$
\begin{aligned}
& \sigma_{C C_{i}}^{2}=\left[\frac{L T_{0}}{L T_{i}} \cdot C F_{i}\left(T_{i}^{-}\right) \cdot \frac{1}{\sqrt{T_{c}}}\right]^{2} \sigma^{2} A\left(C_{i}\right) \\
& +\left[C_{i} \cdot \frac{L_{0}}{L T_{i}^{2}} \cdot C F_{i}\left(T_{i}^{\prime}\right) \cdot \frac{1}{\sqrt{T_{c}}}\right]^{2} \sigma^{2} A\left(L_{i}\right) \\
& +\left[\left(\frac{A^{2} \ln T_{i}^{\prime}\left(T_{i}^{\prime}\right)^{A-1}+\frac{\Lambda}{T_{i}^{-}}\left[1-\left(T_{i}\right)^{A}\right]}{\left[1-\left(T_{i}\right) A\right]^{2}}\right)\right. \\
& \left.\cdot \mathrm{c}_{i} \cdot \frac{\mathrm{LT}_{\mathrm{o}}}{\mathrm{LT}_{\mathrm{i}}} \cdot \frac{\mathrm{I}}{\sqrt{\mathrm{T}_{\mathrm{c}}}}\right]^{2} \sigma^{2}\left(\mathrm{~T}_{\mathrm{i}}\right)
\end{aligned}
$$
interfaced to the assay system. 